San Jose State University

SJSU ScholarWorks

Master's Theses

Master's Theses and Graduate Research

1995

\title{
The effect of albedo modification on residential roof and indoor temperatures
}

Mehrdad Banihashemi

San Jose State University

Follow this and additional works at: https://scholarworks.sjsu.edu/etd_theses

\section{Recommended Citation}

Banihashemi, Mehrdad, "The effect of albedo modification on residential roof and indoor temperatures" (1995). Master's Theses. 1117.

DOI: https://doi.org/10.31979/etd.422a-m7az

https://scholarworks.sjsu.edu/etd_theses/1117

This Thesis is brought to you for free and open access by the Master's Theses and Graduate Research at SJSU ScholarWorks. It has been accepted for inclusion in Master's Theses by an authorized administrator of SJSU ScholarWorks. For more information, please contact scholarworks@sjsu.edu. 


\section{INFORMATION TO USERS}

This mamuscript has been reproduced from the microfilm master. UMI films the text directly from the original or copy submitted. Thus, some thesis and dissertation copies are in typewriter face, while others may be from any type of computer printer.

The quality of this reproduction is dependent upon the quality of the copy submitted. Broken or indistinct print, colored or poor quality illustrations and photographs, print bleedthrough, substandard margins, and improper alignment can adversely affect reproduction.

In the unlikely event that the author did not send UMI a complete mamuscript and there are missing pages, these will be noted. Also, if unauthorized copyright material had to be removed, a note will indicate the deletion.

Oversize materials (e.g., maps, drawings, charts) are reproduced by sectioning the original, beginning at the upper left-hand corner and contimuing from left to right in equal sections with small overlaps. Each original is also photographed in one exposure and is incinded in reduced form at the back of the book.

Photographs included in the original mamuscript have been reproduced xerographically in this copy. Higher quality $6^{\prime \prime} \times 9^{n}$ black and white photographic prints are available for any photographs or illustrations appearing in this copy for an additional charge. Contact UMI directly to order.

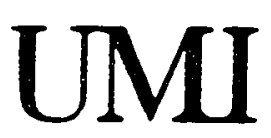

A Bell \& Howell information Company 



\title{
THE EFFECT OF ALBEDO MODIFICATION ON RESIDENTIAL ROOF AND INDOOR TEMPERATURES
}

\author{
A Thesis \\ Presented to \\ The Faculty of the Department of Geography \\ and Environmental Studies \\ San Jose State University \\ In Partial Fulfillment \\ of the Requirements for the Degree \\ Master of Science
}

by

Mehrdad Banihashemi

December 1995 
UMI Number: 1377208

Copyright 1995 by

Banihashemi, Mehrdad

All rights reserved.

UMI Microform 1377208

Copyright 1996, by JMI Company. All rights reserved.

This microform edition is protected against unauthorized copying under Title 17, United States Cocle.

\section{UMI}

300 North Zeeb Road

Ann Arbor, MI 48103 
(C) 1995

Mehrdad Banihashemi

ALL RIGHTS RESERVED 
APPROVED FOR THE DEPARTMENT OF GEOGRAPHY AND ENVIRONMENTAL STUDIES

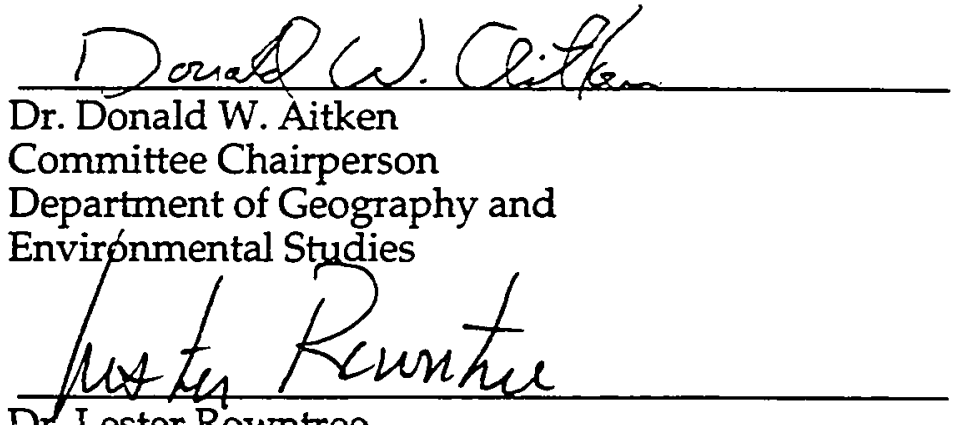

Dr. Lester Rowntree

Department of Geography and

Environmental Studies

$$
\text { Hoider Tshe 11-1-95 }
$$

Dr. Haider Taha

Lawrence Berkeley National Laboratory

APPROVED FOR THE UNIVERSITY

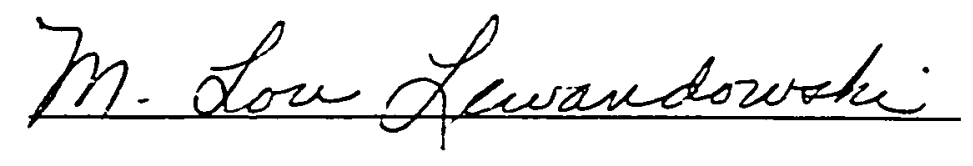




\section{ABSTRACT \\ THE EFFECT OF ALBEDO MODIFICATION ON RESIDENTIAL ROOF AND INDOOR TEMPERATURES \\ by Mehrdad Banihashemi}

It is well known that the formation of urban heat islands in most major cities has an adverse impact on energy consumption for cooling residential buildings. This in turn has placed a greater peak load demand on power plants in response to peak cooling requirements.

This thesis reviews the formation as well as causations of urban heat islands, and analyzes the trend of urban warming for the past few decades. The mitigation strategies that have proven to be successful in alleviating this adverse impact on residential buildings are reviewed.

This thesis then documents the impact of using white surfaces on the rooftop of a residential building in San Jose, California. The roof was covered with a white cloth to increase albedo by $40 \%$. As a result of this modification, the roof surface temperature dropped by almost $32 \%$. Indoor temperatures immediately below the roof dropped by $2-4^{\circ} \mathrm{F}$. The implications of rooftop albedo modification, as suggested by this sample measurement, are discussed. 


\section{TABLE OF CONTENTS}

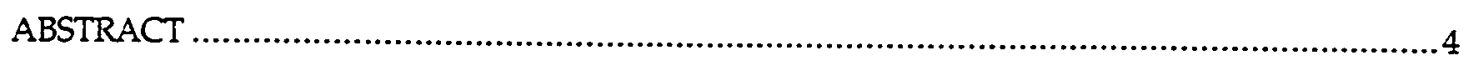

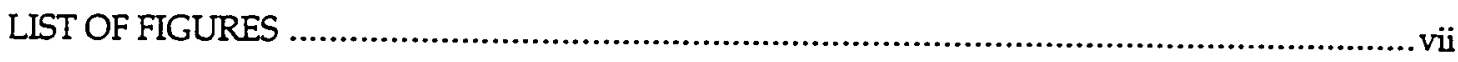

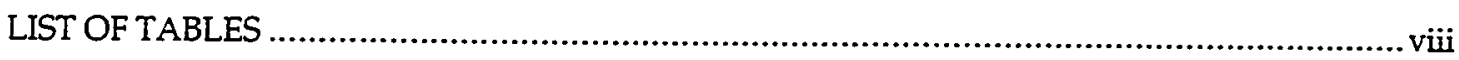

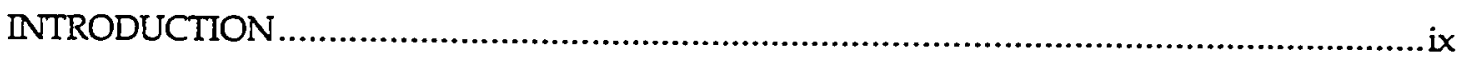

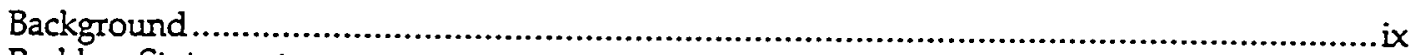

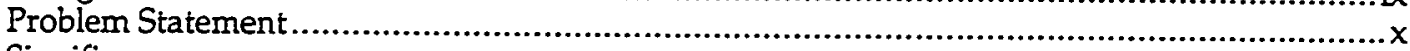

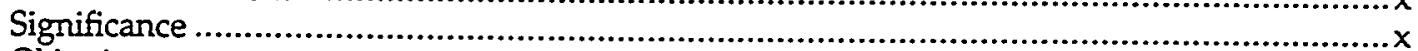

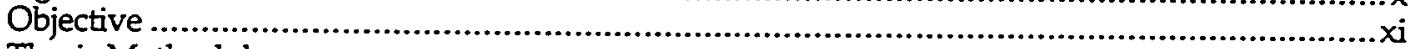

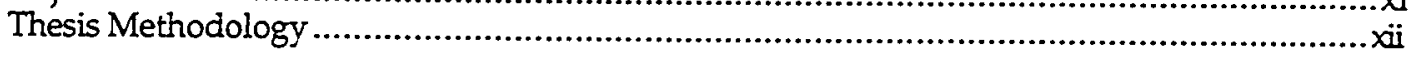

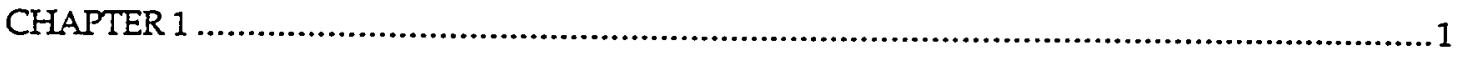

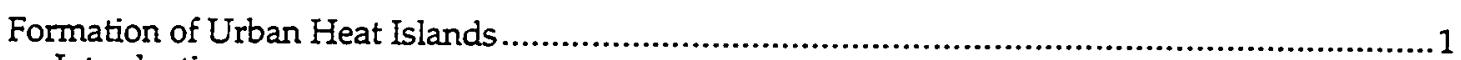

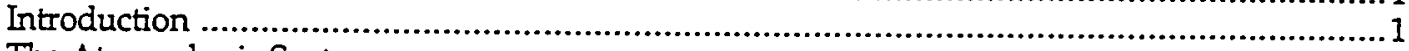

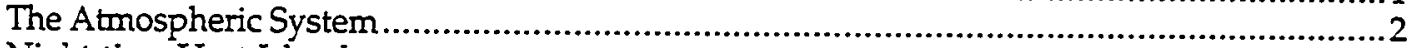

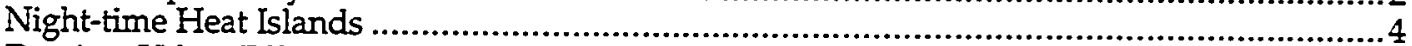

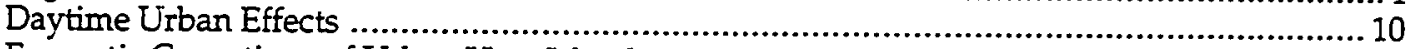

Energetic Causations of Urban Heat Islands................................................................... 12

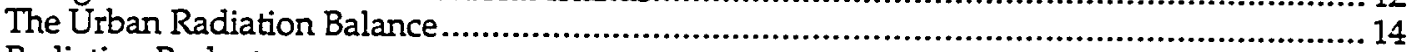

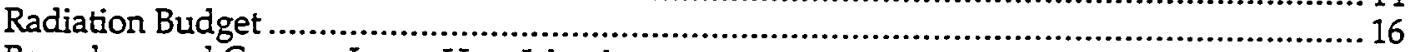

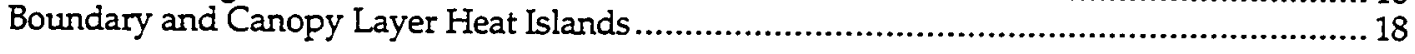

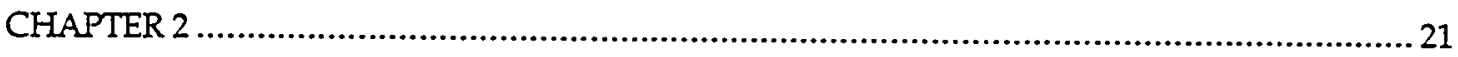

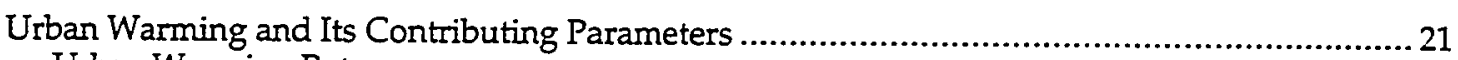

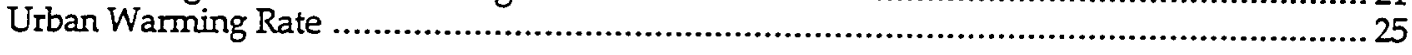

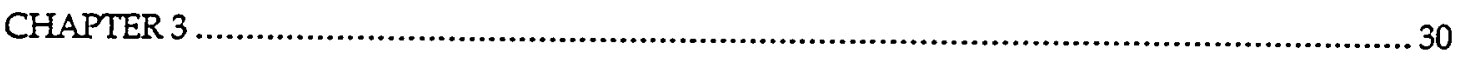

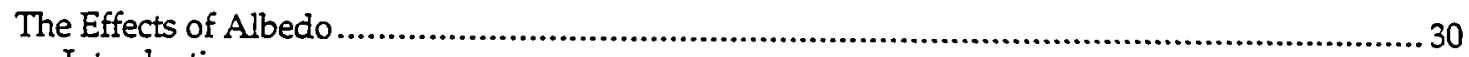

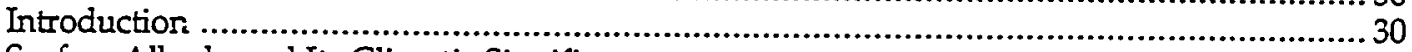

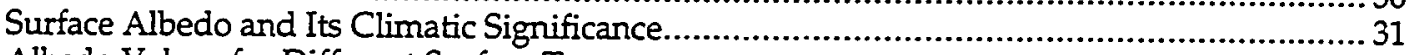

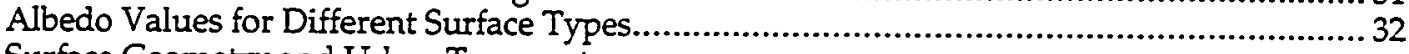

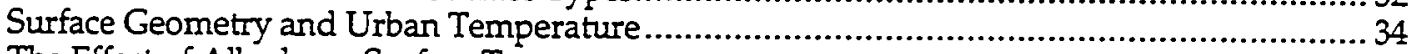

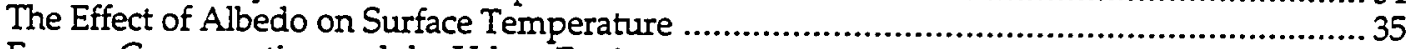

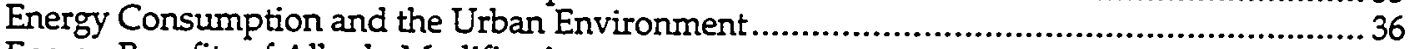

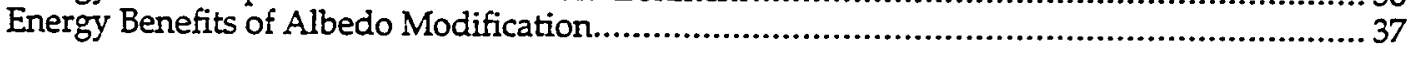

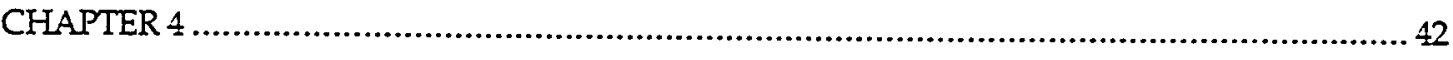

The Effect of Albedo Modification on Residential Roof Surface and Indoor Air Temperature..... 42

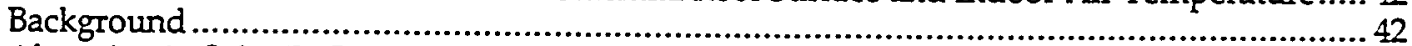

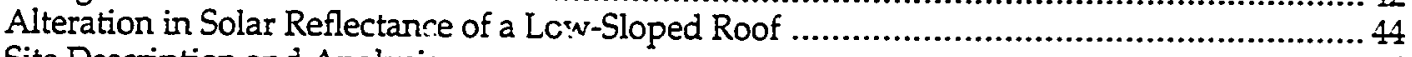

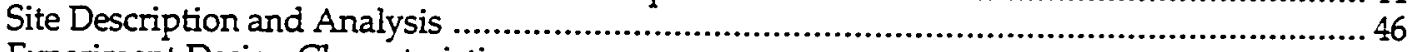

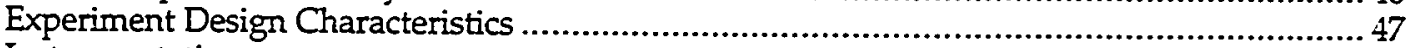

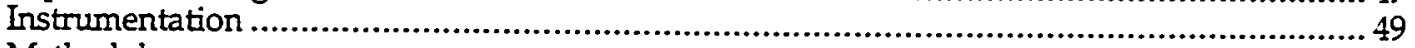

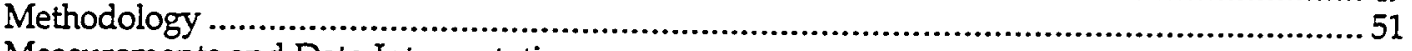

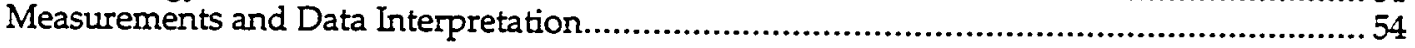


Limitations.

Conclusions

LIST OF REFERENCES .......................

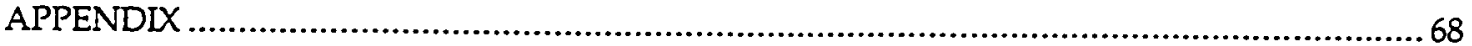




\section{LIST OF FIGURES}

Figure 1 Comparative Monthly Temperature Average ........................................ 5

Figure 2 Mean Hourly Urban-based Temperature Rates ........................................

Figure 3 Air Temperature Profile ……..............................................................10

Figure 4 Cross Section of City and Urban-Rural Temperature Difference .........12

Figure 5 Schematic Representation of Urban Atmosphere ..................................13

Figure 6 Relation Between Heat Island Intensity and Population .......................22

Figure 7 Change of Urban Temperature with City Growth .................................24

Figure 8 Effect of Solar Radiation on Dark and Light-Colored Surfaces ............36

Figure 9 Temperatures Before and After Reflective Roof Coating ........................44

Figure 10 Diagram of the House .........................................................................47

Figure 11 White Cloth on the Roof ......................................................................48

Figure 12 Close-up of White Cloth on the Roof ..................................................49

Figure 13 Hand-held Infra-Red Thermometer .....................................................50

Figure 14 Pyranometer for Albedo Measurement ................................................51

Figure 15 Effect of Outside Temperature on Room 1 .........................................59

Figure 16 Effect of Outside Temperature on Room 2 .........................................60

Figure 17 Comparison Between Temperature Trends ..........................................61

Figure 18 Effect of Ambient Air Temperature ...................................................62 
LIST OF TABLES

Table 1 Suggested Causes of Urban Heat Islands 19

Table 2 Rates of Urban Warming of Ten U.S. Cities .23

Table 3 Linear Temperature Trends for Urban Sites in Southwestern U.S. ......26

Table 4 Summary of Reported Annual Urban Warming Rates Worldwide .....28

Table 5 Albedo of Some Natural Surfaces .............................................................33

Table 6 Albedo Values of Some Urban Materials and Areas .................................34

Table 7 Estimates of Urban Fabric for Sacramento, California................................39

Table 8 Air-conditioning Use Savings from a White Surface ................................41

Table 9 Hourly Measured Data ..............................................................................53 


\section{INTRODUCTION}

\section{Background}

Most urbanization activities are safe, comfortable, economically and functionally efficient. But a few of these activities result in inadvertent environmental and atmospheric alterations. In cities where buildings are concentrated, these activities may result in significant local climatic changes.

Urbanization typically results in a significant increase in local temperature. Most studies have shown that cities are becoming warmer than their suburban areas (Karl et al., 1988). Some analyses also show that since the 1940's this trend has been significant in some cities of the United States (Akbari et al., 1990); e.g., downtown Los Angeles is now $5^{\circ} \mathrm{F}$ warmer than it was in 1940.

The urban heat island is a result of inadvertent climatic changes caused by man-made modification of urban surfaces. Paved surfaces, roofs, and walls store some of the solar heat received in the daytime and give it off after sunset to the urban air. The urban heat island is best developed during evening and night hours, and results from a delayed cooling of the city compared with that of suburban areas (Barring et al., 1985). This phenomenon has been verified to exist not only in mid-latitude cities but also in tropical areas (Tyson et al., 1972), in polar regions (Benson et al., 1975), and in quite small settlements or groups of buildings (Kopec, 1970).

In addition, it has been well documented that other factors, such as a city's polluted air, anthropogenic heating and dry surfaces have contributed to the 
temperature difference between cities and rural areas. This phenomenon is intensified by a lack of evaporation in the cities. In a land with little or no vegetation, rapid runoff after precipitation leaves no water for evaporation.

\section{Problem Statement}

Besides a number of meteorological and socio-economic impacts, urban heat islands have raised the amount of cooling needs in cities. Any moderate increase in temperature results in considerable changes in electricity demand: every $1^{\circ} \mathrm{F}$ rise in urban air temperature corresponds to $1-2 \%$ increase in peak power demand (Akbari et al., 1989). As already mentioned, the overall effect of urban heat islands has been a steady rise in the urban temperatures in most U.S. cities. Given that this trend is not alleviating, and that the effect of urban temperature rise is an increase in peak cooling loads, the long-term effect of urban heat islands on energy use is a matter of importance.

\section{Significance}

In addition to possible adverse climatological consequences of urban heat islands, the effect of temperature increase on space conditioning in hot and temperate climates is also a matter of significance. While urban heat islands could reduce the need for heating in certain cold climates (Thurow, 1983), they usually contribute to a significant increase in suminer cooling loads in most hot and temperate climatic conditions (Taha et al., 1988). Indeed, the additional energy needed for air-conditioning in summer outweighs the contribution of heat islands to possible savings in the cold season. Due to this increase, the 
California Energy Commission (CEC) estimates significant changes in California's summer cooling loads by the year 2010 (California Energy Commission, 1989).

\section{Objective}

The aim of this thesis is: 1) to review the formation and causations of urban heat islands and urban warming; 2) to explore the effects of white rooftops as an urban heat island mitigation method and its impact on residential indoor temperature; and 3) to review the most recent studies on the reduction of airconditioning usage resulting from the above method.

One of the most essential mitigation meihods-using high albedo (high reflectance) materials-as an energy conservation measure for controlling summer urban heat islands will be discussed. Because different building types vary in structure, loads, and energy performance (Huang et al., 1990), the focus of this project is or residential buildings. It is important to keep in mind that energy savings resulting from albedo modification in residential buildings located in hot, humid, and arid climates are different from those in temperate climates.

In a moderate climate like San Jose, California, residential cooling loads comprise only a small fraction of total electrical demand. However, in this circumstance, white surfaces on the rooftops may still result in significant reduction in air-conditioning usage during the summer, therefore leading to potentially important savings in peak electrical demand. 
Thesis Methodology

This study consists of two sections. The first part will examine the main causes of the urban heat island phenomenon. On a larger scale, the trend of urban warming in the past few decades will also be examined. To place the present study in the context of the above issue, the geographical situation of San Jose, California and its climatological conditions will be presented.

The second part of this thesis concentrates on analyzing the energy conservation potential of high albedo materials on rooftops of residential buildings. An experiment to evaluate the above effect was conducted on an actual building. The roof of a residential building was covered by a high albedo material (white cloth) and temperature measurements were taken at several outdoor and indoor locations for a period of two weeks before and after the albedo was modified. 


\title{
CHAPTER 1
}

\section{Formation of Urban Heat Islands}

\author{
Introduction
}

The growth of the economy and the process of industrialization and urbanization in the past forty years have caused many environmental problems such as thermal pollution and heat islands. The literature of the past hundred years has documented a series of studies of urban effects based on empirical evidence from various cities. This effort has resulted in the recognition of the heat island phenomenon and its linkage to other factors (e.g., urban warming).

Beside the heat added by combustion processes and anthropogenic heat, the reduction of wind speed inside an urbanized area reduces the exchange of air with the outside and affects evaporative processes. The impervious surfaces of a town, the thermal properties of street and building materials and surface geometry of built-up areas contribute to further increasing urban temperatures.

Generally speaking, the urbanization process converts a natural landscape into a human settlement and replaces the natural surface materials with those used in construction which create a new set of surface configurations, radiative properties, and thermal qualities. This dramatic and irreversible land-use change alters the pre-urban energy balances, and ultimately modifies the state of all climatological parameters. 
The Atmospheric System

There are various factors that contribute to the formation of urban heat islands. Typically, urban areas have some impervious surfaces which lead to rapid runoff of precipitation and consequently to a reduction of evaporation. Also, daytime heat is stored in the stone, concrete, and asphalt of the city and is released later at night. The result, an increase in temperature, is what has been called "urban heat islands". As opposed to this urban scenario, vegetated rural areas usually reflect more incoming solar radiation and channel the heat absorbed into latent fluxes (evaporation) and thus less is stored compared to the street level in the city. A brief discussion is needed in order to understand the formation of the heat island phenomenon on a seasonal basis. One must keep in mind that some factors are more influential in summer, whereas others more so in winter.

On a summer day, in an urban environment, solar heat is absorbed by building and paving materials that have large heat storage capacity. As mentioned earlier, lack of vegetation, green cover, and evaporation in the city combined with heat stored in buildings allows the surface temperature of streets and buildings to soar. In addition, the buildings can also break up the cooling winds that would otherwise contribute to the cooling process (Givoni et al., 1972). Heat from heavy usage of air conditioning, machinery, and mobile sources (cars, etc.) are also ultimately released to the urban air, creating a heat feedback loop that only makes the problem worse.

On a winter day, the solar radiation at street level is less intense, but can still warm up streets and other paved surfaces. The street level air is also slightly 
warmed by the anthropogenic heat released from transportation. During the daytime the atmosphere is comparatively unstable, and the urban warmth is dissipated before street-level temperature can be affected (Landsberg, 1956). This gives significance to artificial heat sources in the city which play a larger part in determining urban warming, cooling rates and heat island intensity in winter.

By nightfall, however, the furnaces begin to work hard against the cooler temperatures, and the increasing stability of the atmosphere allows their heat to accumulate more readily in the urban environment. In addition, the smoke, water vapor and carbon dioxide escaping from the chimneys spread out in a blanket above roof-level that augments heat radiation downward to the city (Duckworth et al., 1954).

Indeed, the problems posed by air pollution are important in the formation of urban heat islands. The pollutants of greatest concern are those released as waste products from the combustion process via chimneys and automobiles exhausts. Chimney effluent consists largely of nitrogen oxides, carbon dioxide, and water vapor. In addition there may be substantial quantities of coarse ash, fine dust, and finer smoke. Plumes of chimney pollution are dispersed according to the atmospheric stability at various elevations. Dispersion upward is almost completely blocked by an inversion layer, especially if the chimney is low relative to the inversion layer (Duckworth et al., 1954). Under these circumstances, this phenomenon reduces the normal diurnal temperature swing (night cooling) of urban areas, and thus, temperatures remain relatively high in the city throughout the night, from street level to the rooftops. 
Generally speaking, the intensity of heat islands depends on weather conditions, seasonal variability, and individual city characters. It is generally weaker in daytime than in nighttime. This is because the formation of heat islands is mainly caused by stronger surface cooling at the outside of the cities. The pattern of the heat island of each city is also dominated by microscale features related to land use and building density. Thus, this necessitates the study of the urban climate of each city with its own unique characteristics.

\section{Night-time Heat Islands}

The heat island is known to exhibit its greatest magnitude during nights with light winds and clear skies (Landsberg, 1970). While global short wave radiation dominates in the daytime and the net radiation flux is downward, at night upward longwave radiative fluxes are dominant. Lower nocturnal temperatures mean that the terrestrial radiation is less than in the daytime, but it still remains greater than the downward atmospheric radiation. Therefore, at night the net radiation flux is upwards, cooling the ground.

At night, building and paved surfaces begin to cool down and give off heat that they absorbed during dayime. In a city, building materials have a higher thermal conductivity than the ground, so that the heat is conducted to the building surfaces and warms the air. This process continues throughout the night; the elevated temperatures of the buildings and street surfaces keep the air from cooling down as much as it would otherwise. Therefore, the following day begins at a higher temperature than otherwise (Lee, 1975). 
The effect of an urban area on its temperature at night is one of the most important factors in the formation of urban heat islands. It has been argued that during midday in summer, the city may be a fraction of a degree cooler than its surroundings. This is because of the reduced sunlight due to the geometric limitation of the amount of sky visible from the ground between obstructing buildings (sky view factor).

In their documentation of the comparative monthly average temperature for each hour of the day for Vienna, Austria, Steinhauser et al. (1957) noted that the city continues to hold its temperature level in the late afternoon, whereas temperatures have already begun to drop in the suburbs (See Figure 1).

Therefore, the city may reach its maximum daily temperature a couple of hours after the suburbs, causing the minimum temperatures also to be reached later in the city.

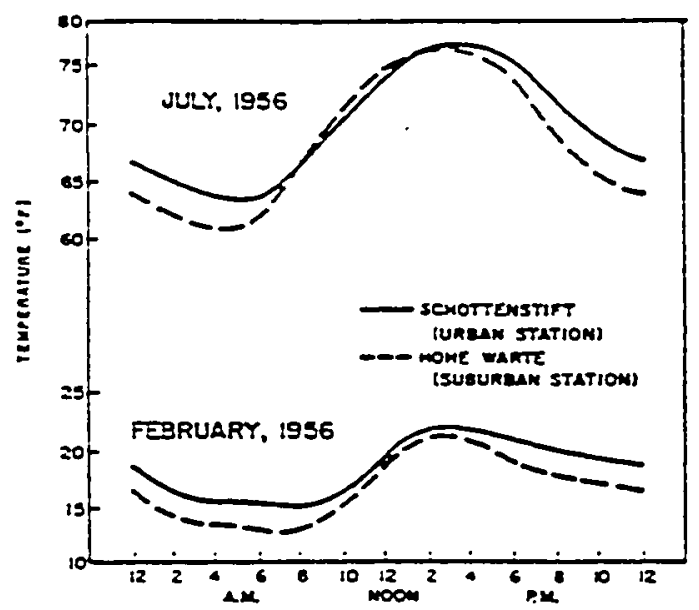

Figure 1. Comparative Monthly Average Temperature in Vienna, Austria. Source: Steinhauser et al. (1957). 
The analysis of the above study shows similar results for both winter and summer heat islands: 1) daily maxima and minima of temperature are reached slightly later in the city than in the suburbs; 2 ) the daily temperature range is less in the city.

Using urban-rural cooling rates on selected nights, Maxwell (1974) investigated the roles of urban and rural surfaces in the growth and decay of urban heat islands in two Canadian cities. Analysis of that study demonstrated that around sunset rural cooling was much more intense than in the urban area where cooling remained relatively slight and almost constant. As a result the heat island grew rapidly after sunset in rural areas, characteristically reaching its maximum at night.

Chandler (1965) demonstrated that heat island intensity is greatest during summer, mainly because of the greater amount of direct solar radiation absorbed by the building fabric during the day and subsequently released at night. Therefore, contrasts in warming and cooling rates should be greater during summer than winter. Figure 2 shows the average hourly summer data for Montreal, Quebec and Vancouver, British Columbia.

It is shown in Figure 2 that with calm and clear conditions the change from daytime warming to nocturnal cooling starts a couple of hours prior to sunset in both urban and rural areas (Chandler, 1965). At the same time the rural cooling rate begins to increase and shows its strongest effect at about sunset, whereas the urban rate is evidently steady and constant. In order to explain the difference, Maxwell (1974) remarks that rural cooling rates may be expected to be more sensitive to wind and cloud condition than those of urban areas. 

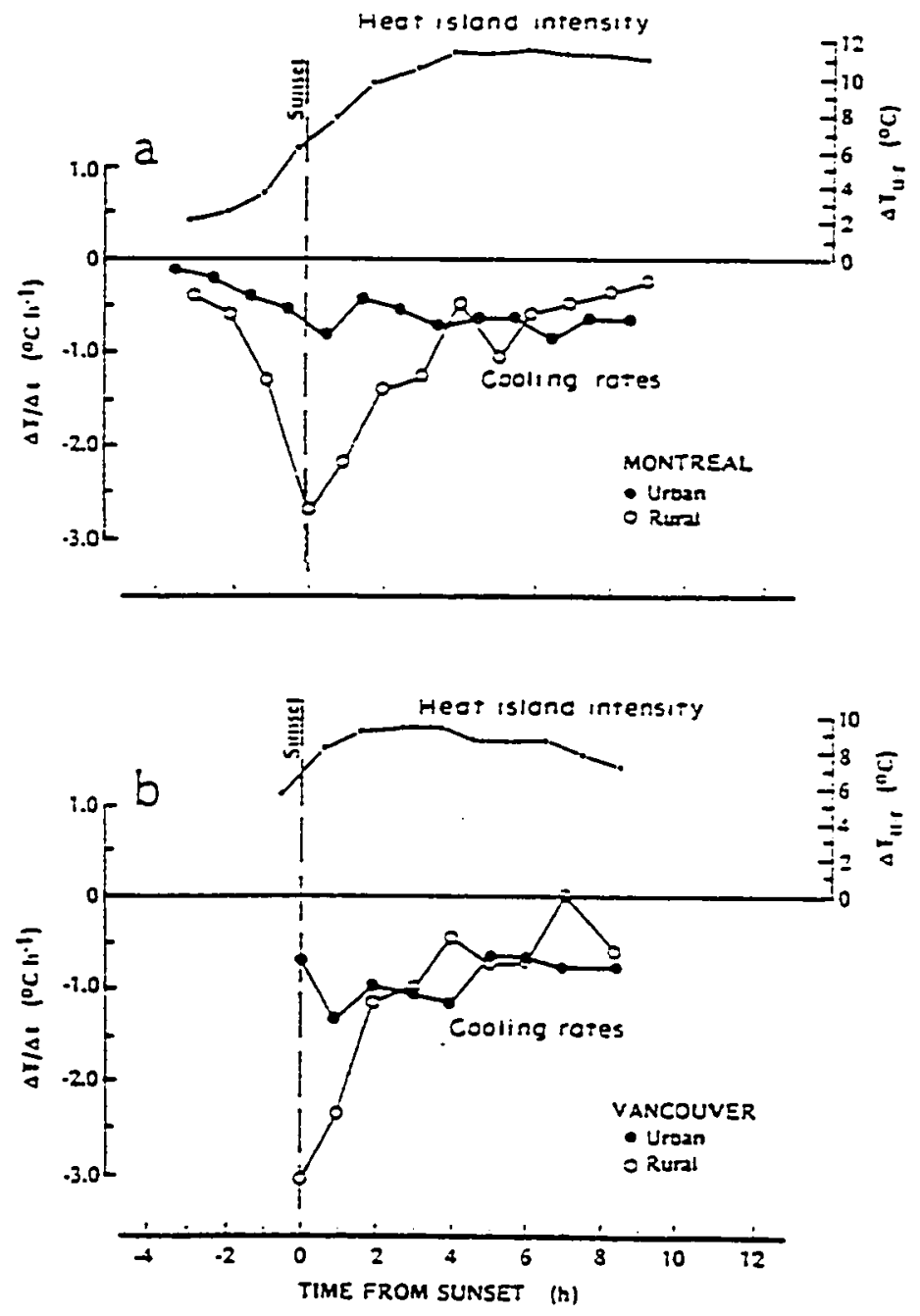

Figure 2. Mean hourly urban-based temperature rates and heat island intensity based on date from summer nights in: (a) Montreal; (b) Vancouver. Source: Maxwell et al. (1974).

This has also been confirmed by Stanford Aerosol Laboratory (1953a), which argues that at street level in a city, not much sky is visible and the buildings diminish the effects of wind. Consequently, the urban cooling 
processes will not depend so much on sky condition, and the heat transfer from the surface will be unaffected by wind speed. Thus, one may infer that nocturnal cooling in the city is much less dependent on meteorological conditions than it is in the country, with more sky visibility and open space in the country.

Martien et al. (1989), too, state that the urban cooling rate depends less on the nature of the sky and air flow, and more on the radiative environment which is dominated by the surrounding man-made structures with only a relatively small opening to the sky. Therefore, on calm, clear nights the principal heat loss from both rural and urban surfaces will be net long-wave radiation to an open and cold night sky, except that in an urban area this heat loss is restricted by the diminished sky view factor (The Stanford Aerosol Laboratory, 1953c).

In general, the universality of the effects of the urban heat islands suggests a search for a relationship between this phenomenon and other meteorological parameters. Some of these parameters would affect the heat transfer processes and would include such meteorological factors as cloud cover, humidity, wind speed and pollution. Sundborg (1951) and Chandler (1965) have both used this explanation in their studies on the intensity of the heat island effects in Uppsala, Sweden, and London, England, respectively.

The Stanford Aerosol Laboratory (1953b) presented a series of reports suggesting that there was a relation between atmospheric "lapse rate" $(\Gamma)$ and the urban-rural temperature difference. Lapse rate is the numerical rate of change of temperature with altitude and the report considered that to be an important meteorological factor in the study of the effects of heat islands. When the air rises, the reducing pressure causes it to expand and cool. Such cooling through 
expansion and the fact that elevated air is further away from its heat source at the ground, produce a temperature decrease, or a positive lapse rate. A negative lapse rate indicates increasing temperature with altitude, a situation which occurs usually at night and is known as an "inversion" (Oke, 1978). However, by day temperature ordinarily decreases with height.

The role of an inversion is further complicated. It inhibits the upward dispersion of smoke and other pollutants in the city. As Sundborg (1951) describes, an inversion may be intensified by the pollution layer whose upper surface cools by radiation to the sky, just as in the country the ground cools itself by radiation. This, in turn, promotes the further increase of pollution concentration in the city, until arrival of morning when the sun's heat can finally produce convective currents and ground warming that destroy the inversion. Sundberg also remarked that valleys, which are common locations for cities, happen to be the worst places for formation and persistence of temperature inversions. The reasons are the pooling of cold air from surrounding hills, shading from the sun which reduces convection, and shelter from winds which would otherwise destroy inversions. Thus, high pressure systems with light winds and inversion conditions lasting for several days may lead to progressive deterioration of conditions with prolonged accumulation of heat at surface levels. The example of the air temperature profile is demonstrated in figure 3.

Thus, one can infer that, 1) formation of temperature inversions at night is more dramatic in outskirts of the city, 2) the cooling at night is smaller inside the built-up areas with relatively uniform building height than on the outskirts, and 
3) the urban-rural temperature contrast is maximum during the night, and hence reflected most in the daily minimum temperatures.

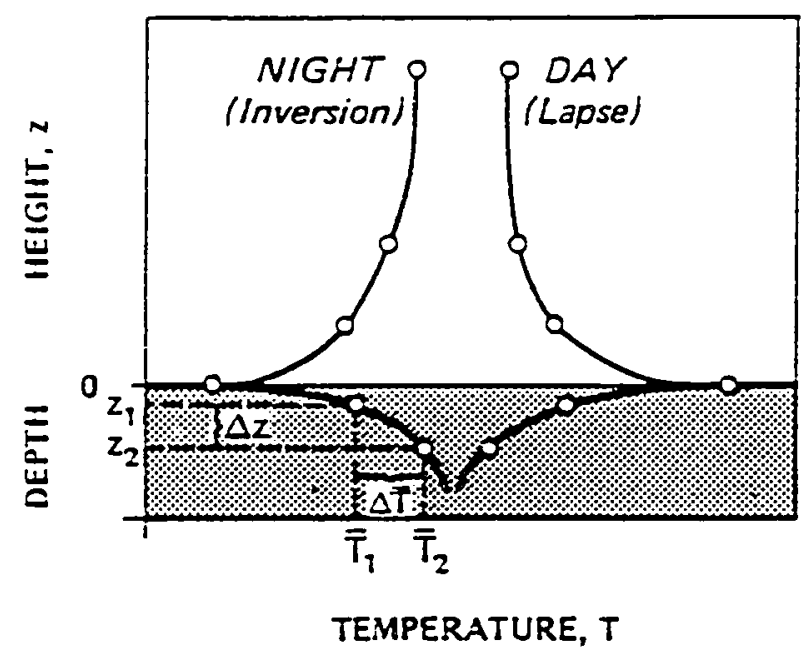

Figure 3. The air temperature profile in the lower portion of the surface layer. Source: Oke (1978).

\section{Daytime Urban Effects}

Usually, the warmest parts of the city in the day-time are those with densely packed buildings of medium height. The area of tall buildings is not as warm due to the wind effect and shading. Residential areas and those with vegetative cover are normally cooler (Givoni, 1989). To explain the day-time effects of heat islands, it is important to describe the effects of insolation which is absent during the right.

Solar radiation impinges upon a variety of configurations when it reaches the ground surface of an urban area. Kratzer (1956) considers three types of 
configurations in typical urbanized area: 1) flat surfaces or areas of widely separated, low buildings; 2) medium-size buildings of equal height and spacing; and 3) tall buildings whose height is great compared to their spacing. For the flat surfaces, some fraction of the incoming solar radiation is reflected back to space and is lost. For the medium-size building case, much of the reflected insolation strikes another building or the street and is absorbed. The same process occurs in the case of tall buildings, but most of the absorption takes place at the higher levels and the amount of radiation reaching street level is small (Kratzer, 1956). A typical large U.S. city has a distribution of buildings consisting of a central core of tall buildings surrounded by densely packed buildings of moderate height.

Figure 4 depicts the spatial and temporal features of urban and rural air temperatures. The "cliff" is noticed especially on the urban-rural boundary and follows the outline of the built-up area for much of the city perimeter, giving rise to an urban heat island under clear sky and light winds, mostly at night. As illustrated in this figure, most of the rest of the urban area is within a "plateau" characterized by a slacker horizontal temperature gradient, but is interrupted by warm or cool spots associated with areas of high or low building density, vegetative area, and sky view factor. For instance, a park might be relatively cooler whereas a commercial area, an apartment complex, a shopping center or the central city area might be relatively warmer. Finally the city core district exhibits a central "peak," the warmest point of which is usually the urban maximum temperature at night.

Street-level daytime temperatures increase as we go away from the central core with its shielded streets and into the buildings of medium height with 
increased absorption near ground level. As we continue further away from the central area, temperatures again drop as we proceed to the residential area where the buildings are more widely spaced with consequently smaller absorption of insolation. Furthermore, as the amounts of vegetation increase in residential and rural areas, there is more cooling by evapotranspiration from the vegetation.

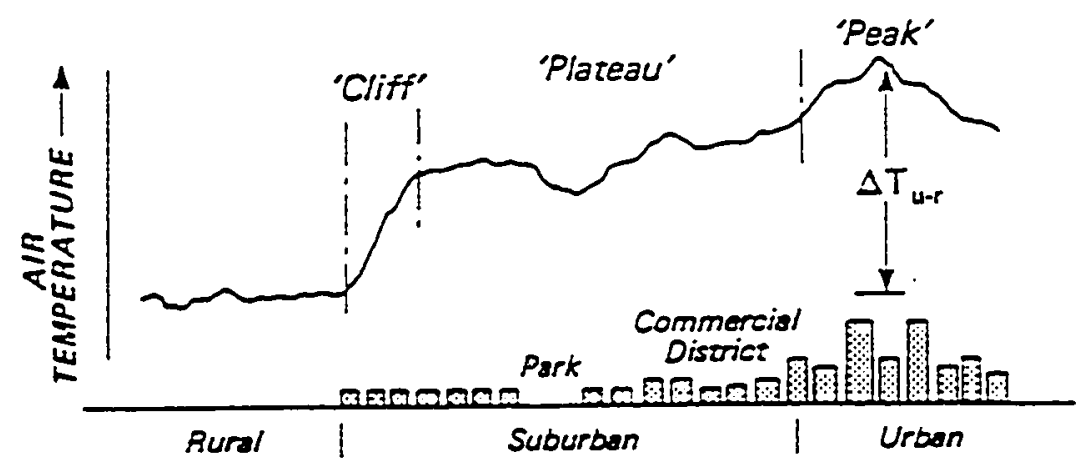

Figure 4. The Cross Section of a Typical City and Urban-Rural Temperature Difference. Source: Oke (1978).

\section{Energetic Causations of Urban Heat Islands}

The inherent characteristics of the city-atmosphere system are complex. The atmospheric state in the lowest layer contains exchanges of energy and mass involving significant anthropogenic as well as natural forces. In each city certain elements, such as geographical location, city size, weather and climate must be taken into account when studying heat islands.

Clarke (1969) has summarized the major factors which may cause the urban heat island: 
1. a change in surface characteristics (e.g. concrete replacing soil) which changes the thermal properties of the surface and the amount of possible evaporation;

2. buildings and other structures which change the wind field characteristics;

3. additional heat sources from combustion; and

4. changes in the radiation budget due to atmospheric pollutants.

When air flows from the countryside to an urban area, it encounters a changing set of boundary conditions (See Figure 5). Oke (1981) has discussed the importance of canyon geometry on the formation of urban heat islands, giving significance to the idea that the materials, geometry and surface properties of the structures around a given place may modify the local climate. He demonstrated the existence of two different layers:

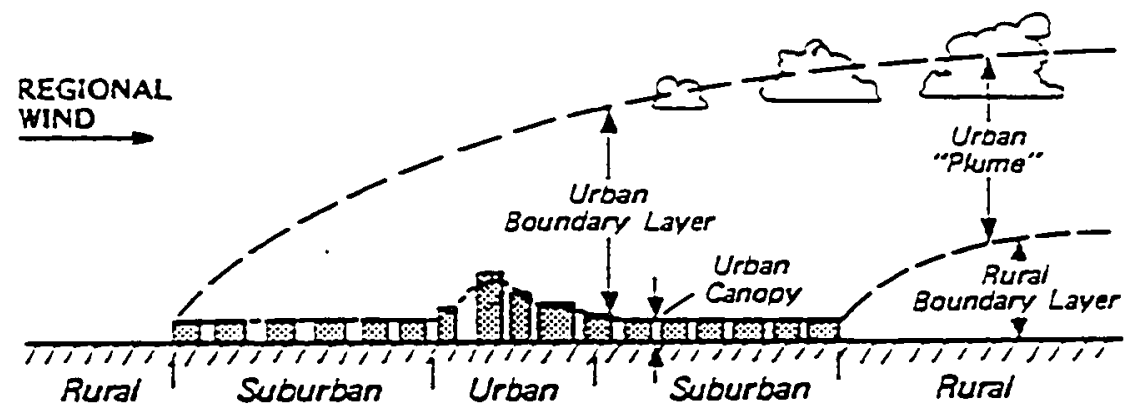

Figure 5. Schematic Representation of the Urban Atmosphere Illustrating a Two Layer Classification of Urban Modification. Source: Oke (1981). 
1. the "urban boundary layer" which is a local to meso-scale phenomenon whose characteristics are governed by the nature of the general urban surface. Because of the size of the city, the distinct properties of its air extend higher than the roof level and the phenomenon can be seen from a distance in the form of a layer of turbid air over the city's boundaries

2. the urban canopy layer which is below roof level and is produced by micro-scale processes

There are also a number of complex influences of the surface geometry on the urban atmosphere to be considered, such as reducing the loss of sensible and latent heat, increasing the trapped short wave radiation in the city canyons (streets), and decreasing the loss of long wave radiation energy (heat) due to the obstruction of the night sky in the canyons. In order to further investigate the causations of heat island, thus, it is essential to 1) understand the concept of urban radiation balance, 2) distinguish between boundary and canopy heat islands.

\section{The Urban Radiation Balance}

One of the most important factors in formation of heat islands is the change in the radiation balance. The overall energy available in a climatic system on a planetary scale originally comes from the distribution of solar radiation impinging on the earth's surface and re-radiating back to the atmosphere. It has been pointed out that the urban heat island is a universal effect due to an altered radiation budget in the urban locale, but is modulated by other variables 
including the size of the urban development, topography, surface characteristic, and meteorological conditions (Landsberg, 1981).

The albedo changes from the field and forest to asphalt and stone is not very large but the conductivity and heat capacity dramatically change. In short periodic heat transaction such as the diumal variation, the dense building materials, which are also good heat conductors, store considerably more energy than tree leaves and other natural surface types (Thornthwaite, 1956).

Consequently, they act as reservoirs of the radiatively received heat. In contrast, soil and vegetation covered areas have a large storage capacity for water which evaporates gradually, and therefore, increases the latent portion of the energy fluxes (Lorenz,1966). These results are compatible with the conclusion that:

The change in the heat balance is considerably radical. Here, by changing a rural area to an urban one, we convert an essentially spongy surface of low heat conductivity into an impermeable layer with high capacity for absorbing and conducting heat. Also, the albedo is usually lowered. This is, of course, equivalent to a heat gain-one which is amplified by radiative heat gain resulting from the lowering of albedo. (Landsberg, 1970)

It is difficult to control released or stored heat on urban surfaces through the heat balance of solar energy and artificial heat. Hence, thermal pollution may be of primary importance in both the development of heat islands, and further urban warming.

The earth surface heat balance generally consists of two elements: 1) natural heat which refers to the heat balance of solar energy on the earth's surface; 2) artificial heat released by human activity. 


\section{Radiation Budget}

Typically, all surfaces on earth gain heat from short wave solar radiation and lose it in the form of outgoing long wave radiation. The solar gain takes place only during the daytime; however, the heat loss by outgoing long wave radiation continues day and night. Akbari et al. (1986) have documented the formation of urban heat island and discussed the surface energy balance equation:

$$
A+R_{S}+R_{L}=A+R n=L E+H+G
$$

where,

$A$ is the anthropogenic heat,

$R_{S}$ is the net shortwave radiation (direct and diffuse) at the surface, $R_{L}$ is the net longwave radiation at the surface, $R_{n}$ is the net shortwave and longwave radiation at the surface, $L E$ is the latent heat flux from the surface, $H$ is the sensible heat flux, and $G$ is the ground heat flux.

The longwave radiation budget consists of incoming and outgoing radiation at the surface. The net radiation $R_{n}$ at the surface is channeled into three fluxes: latent heat flux $L E$, sensible heat flux $H$, and ground heat flux $G$.

Although the urban heat island is a result of the interaction of all the above factors, the importance of each factor and its contribution to the undesirable urban heat is seasonal and region dependent. For example, in a green rural area, fifty percent of $R_{n}$ is channeled to $L E$ and the other half is divided equally between $H$ and $G$ (Akbari et al., 1989). The outgoing radiation is 
a variable dependent upon the surface temperature; the lower the vegetation cover, the higher the surface temperature, will be. The incoming short wave radiation of a city has been detected to be five percent more than that of a rural area (Landsberg, 1981).

The long wave heat loss is one of the major cooling factors of any area. Also, it is important to note that the magnitude of the long wave radiation heat loss from the ground level in a city and in a suburban area may be different. As a result, the net balance between the solar heat gain and the long wave heat loss is different in an urban area as compared with an open country. This is one of the major factors which causes different climatic conditions in those two areas.

Givoni (1989) explains that the incoming solar radiation impinges primarily on the rooftops of buildings. Another significant part of it hits the vertical surfaces and walls. A small fraction of this radiation reaches the ground surfaces. Some of these buildings are taller and block the sky. This, consequently, will reduce the amount of long wave radiation from the roofs and walls of the lower building, thus reducing the total amount of heat loss from within the urban canyon. Evidently, the reduction of the sky view factor for long wave radiant heat loss is the pivotal part of Givoni's argument as he concludes:

The radiation falling on the vertical walls is partly reflected, mostly towaids other walls of nearby buildings. In an urban area, a great part of these bounced-off rays hit walls of the adjacent buildings. In this way, the process begins of radiation bouncing back and forth a number of times between the walls of different buildings. At the end of this process, in a densely built urban area, only a small part of the solar radiation impinging on walls is reflected upwards to the sky, while most of it is absorbed in the walls of the buildings regardless of the color of the walls, to be released back in the evenings and night hours. (Givoni, 1989) 
Data provided by Oke (1981) suggested that the sky-view factor in the city is the dominant mechanism that produces urban heat islands during nights with calm, cloudless sky, when anthropogenic heat is negligible. As previously emphasized, the heat island intensity at night is the highesi. This would mean that the result of the reduced heat loss from the urban canyon (below the roof's level) is reflected in the slower cooling rate of the urban area as compared with an open country; therefore, the denser the built-up area is, the slower the rate of night time cooling might be.

\section{Boundary and Canopy Layer Heat Islands}

At this stage it is possible to draw a general conclusion that the urban heat island is the result of urban/rural energy balance differences. In addition, it is critical to distinguish between the micro-scale energy exchange mechanisms in the Urban Canopy Layer and meso-scale ones in the Urban Boundary Layer. Even though the roof level has been considered the approximate boundary between the two layers, the influence of canopy heat exchange extends into the boundary layer. Thus, any understanding of the boundary layer may be partially dependent upon the vertical heat fluxes emitted from the canopy layer (Yap et al., 1974).

The urban canopy has many contrasting surfaces (walls, floors, and roofs). This, in turn, complicates the canyon geometry, surface area, and multiple radiative reflection between the surfaces. It also influences the loss of long wave radiation to the sky. A great part of this whole system is made of relatively dry surfaces, such as street canyons and roadways between two adjacent buildings. To this is added the anthropogenic heat source as an important component of 
local energy balance and reduced evapotranspiration due to lack of vegetation in the canopy.

Table 1.-Suggested Causes of Urban Heat Islands in Two Distinct Layers. Adapted from: Oke (1981).

A. Canopy Layer

1. Increased absorption of short wave radiation

2. Increased absorption of long wave radiation from the sky

3. Decreased long wave radiation loss

4. Anthropogenic heat source

5. Increased sensible heat storage

6. Decreased evapotranspiration

7. Decreased total turbulent heat transport

B. Boundary Layer

1. Increased absorption of short wave radiation

2. Anthropogenic heat source

3. Increased sensible heat input-entrainment from below

4. Increased sensible heat input-entrainment from above

The development of a heat island in the urban boundary layer has certain similar characteristics with that of canopy layer (See Table 1). At this scale, the surface of the canopy corresponds to the level of the boundary layer. Therefore, the heat exchange between the city and its overlying air includes those from individual canopies, such as roofs, canyon tops, and roads. Here, the anthropogenic heat flux enters the boundary layer through chimneys and roofs. Also, the city (canopy) has a significant impact on the short and long wave components of the radiation budget of iis overlying atmosphere (boundary layer) 
due to the presence of radiatively active pollutants in the city air and to changes in the surface radiative properties (Atwater, 1971). 


\section{CHAPTER 2}

\section{Urban Warming and Its Contributing Parameters}

The amount of heat energy accumulated above the city might originate from artificial heat production in cities. In this regard, meteorological stations have played a major role in the detection of climatic change and especially increased urban temperatures between 1940s and 1980. In one study Kukla et al. (1986) recorded an average rate of $0.12^{\circ} \mathrm{C}$ of increased urban warming per decade. The result of their study is similar to many others including Mitchel (1953) and Landsberg (1981).

Most of those stations were located in an urban area subject to heat islands, and computation of temperature increases were compared to those of the suburban area. Although most studies concentrated on temperature trends of the past forty years and almost all showed tremendous temperature increase in the city, the compilation of land surface air temperatures proved the early 1980s to be the warmest in one hundred thirty years (Jones et al., 1986).

The purpose of all these studies was to develop a variety of methoc's to detect the effects of urbanization--mainly temperature increase--during specific time periods, especially between 1900 and 1980s. Different parameters were chosen to represent urbanization factors, such as population, or the difference in the thermal properties between urban and rural surfaces (Karl et al., 1988).

The inclusion of a population factor in the field of urban warming and urbanization has long been an indispensable part of most studies. Such 
relationships have been shown to exist. Indeed, beside the population factor, the city diameter, accumulation of anthropogenic heat, and building materials are correlated with city size. These factors have been considered in studying the effects of city size and population growth on heat island intensity in both European and North American cities (See Figure 6).

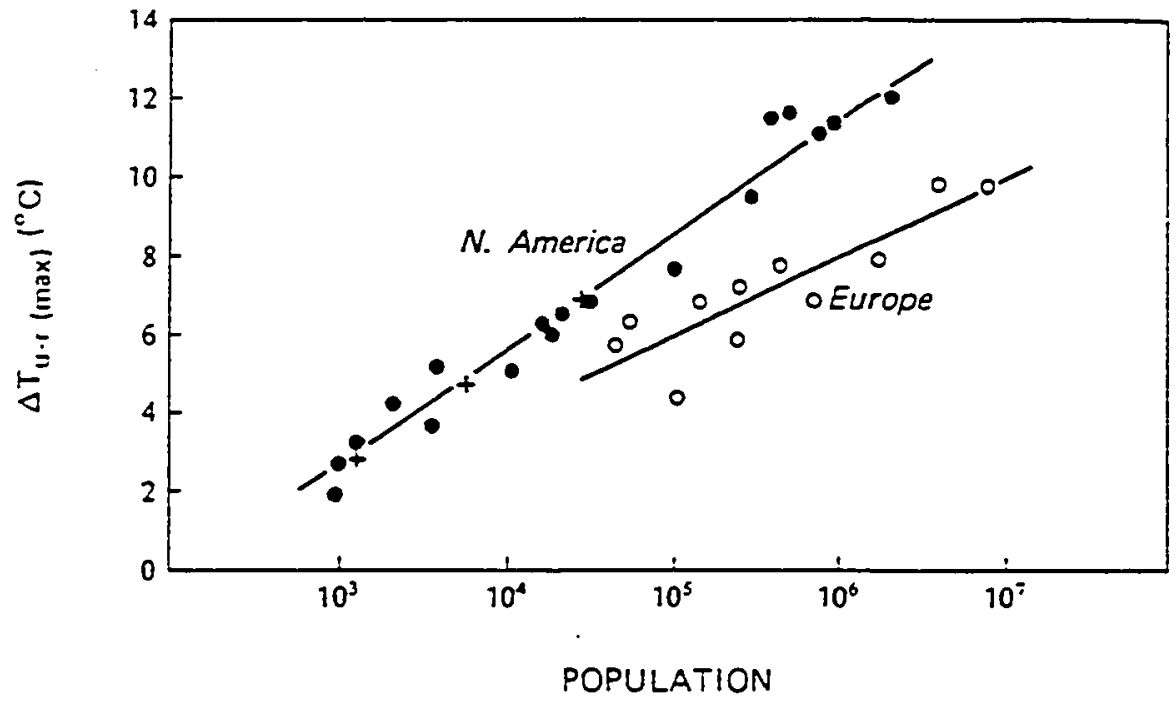

Figure 6. Relation Between Heat Island Intensity $\left(\Delta \mathrm{T}_{\mathrm{U-}-\mathrm{r}}\right)$ and Population for European and North American Settlements. Source: Lansberg (1979).

Mitchell (1961) showed a gradual increase in the intensity of urban warming parallel with city growth in size and population. He ranked the cities in order of growth rate, measured by the change of square root of population of 
each city. Using the above method, Mitchell compared the rates of urban warming for ten U.S. cities since the 19th Century for each season (See Table 2).

Table 2. Rates of Urban Warming of Ten U.S. Cities, by Seasons.

\begin{tabular}{|c|c|c|c|c|c|c|}
\hline \multirow[b]{2}{*}{ City } & \multirow[b]{2}{*}{ Period } & \multirow{2}{*}{$\begin{array}{l}\text { Root } \\
\text { Populatior:/ } \\
\text { year } \\
\text { Growth rate }\end{array}$} & \multicolumn{4}{|c|}{$\begin{array}{l}\text { Urban warming rate } \\
\text { (degree }{ }^{\circ} \mathrm{F} \text { per } 100 \text { years) }\end{array}$} \\
\hline & & & Winter & Spring & Summer & Autumn \\
\hline Cleveland & $1895-1941$ & 12.9 & 1.8 & 3.8 & 5.1 & 2.7 \\
\hline Boston & $1895-1933$ & 10.5 & $\overline{2.9}$ & 3.2 & 4.7 & 3.7 \\
\hline Washington & 1893-1954 & 9.9 & * & 1.5 & 4.3 & 27 \\
\hline Tampa & 1893-1954 & 6.6 & 4.8 & 26 & 29 & 3.4 \\
\hline Baltimore & 1894-1954 & 6 & * & 2 & 3 & 27 \\
\hline Charlotte & $1897-1951$ & 5.1 & * & * & 1.7 & * \\
\hline Rochester & $1914-1940$ & 4.5 & * & $\overline{7}$ & * & * \\
\hline Nashville & $1897-1948$ & 3 & 7 & * & * & * \\
\hline Lincoln & $1895-1954$ & 2.4 & ¥ & * & 22 & * \\
\hline Marquette & $1899-1954$ & 0.6 & * & * & * & * \\
\hline
\end{tabular}

* Not significantly different from zero. Adapted from Mitchell (1961).

The table shows that the highest rates of urban warming are associated with the most rapidly growing cities. It also shows that the relation is close in summer, but not so close in winter or for the rest of the year as a whole (e.g. Cleveland, Ohio with an urban warming rate of $5.1^{\circ} \mathrm{F}$ per hundred years in summer, but 1.8 and $2.7^{\circ} \mathrm{F}$ per hundred years for winter and autumn respectively). The annual and summer mean temperatures are presented in graphical form to show the relation between the urban warming trend and the city growth (See Figure 7). 
Another study by Moffitt (1972) detected the effects of urbanization on mean temperatures at several stations, and suggested that a comparison between observations be made at the same site in different eras. In this observation the mean temperatures at two different sites, one in an urbanized region and the other one at the nearest rural area, were compared.

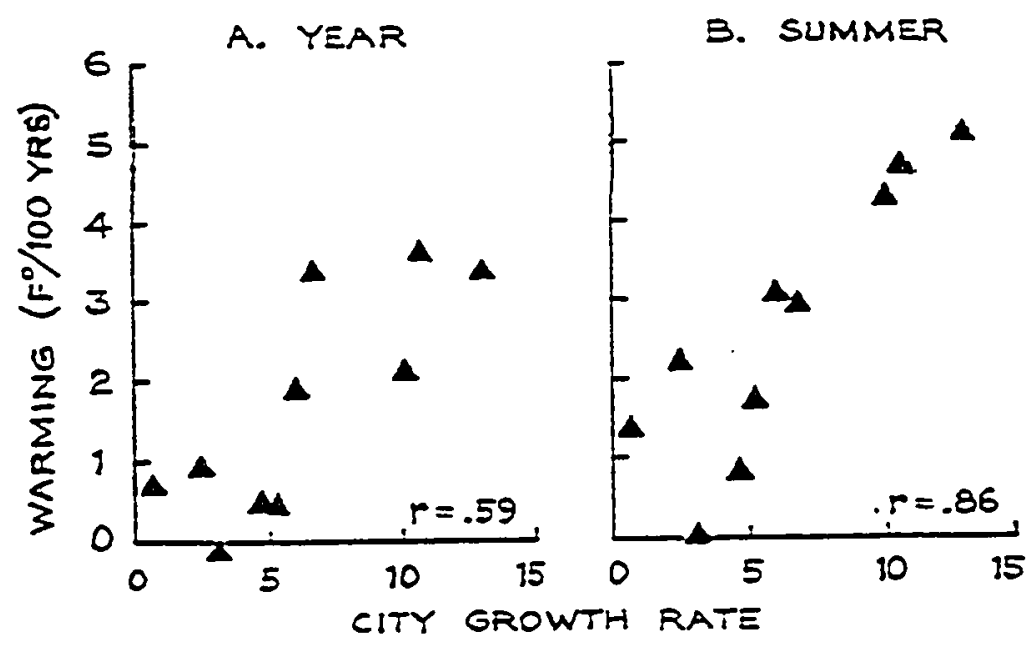

Figure 7. Change of Urban Temperature With City Growth. Source: Mitchell (1961)

The results showed that in the urban areas, roads and buildings readily absorb solar radiation whereas in the open countryside much incoming radiation is used in the evaporation of moisture by growing plants, and thus, a fairly high proportion is channeled into latent heat. 


\section{Urban Warming Rate}

The variability of surface temperature and urban warming over the recent past few decades has received much attention with a heightened interest in climatic changes due to natural and man-induced causes. Considering the large scale pattern of surface temperature change, a number of studies have researched the temporal and spatial variation of that change over a large geographical spectrum from the Northern Hemisphere (Van Loon et al., 1977), to certain cities of the Southwestern United States over the 1941-1980 period (Cayan et al., 1984).

The rate of urban warming may be explained by looking at the temperature changes at rapidly growing urban sites during the past four decades compared to those at non-urban sites. Most studies have documented a large scale trend of urban warming over a historical temperature record. Dronia (1967) esiimated an urban temperature rise over a 90-year period (1871-1960) of about $.008^{\circ} \mathrm{C}$ per year as a worldwide average. On the west coast of the United States this rise at urban sites was about .007 to $.021^{\circ} \mathrm{C}$ per year, and considerably smaller trends, for the most part, at non-urban locations over various periods of record during the late 1800's through 1963 (Roden, 1966).

In their study of the urban surface temperature, Cayan et al. (1984) computed the linear trends for all surface stations in the southwestern United States during the period of available data from 1933-1980. These trends, along with the mean temperature, and means for January and July, were measured (See Table 3). The study clearly showed that the trends divide themselves into two classes: 1) significant warming for urban stations, and 2) considerably less warming, or even slight cooling for the non-urban sites. Particularly strong 
warming trends were detected at Tucson UA (University of Arizona), Phoenix, San Diego, Los Angeles and Bakersfield. In contrast, much smaller positive or even negative trends were found at Tucson AP (Airport), Santa Maria, Red Bluff, and Scripps Pier.

Table 3. Linear Temperature Trends for Urban Sites in the Southwestern United States

\begin{tabular}{|c|c|c|c|c|c|}
\hline Station & Month & $\begin{array}{c}\text { Number } \\
\text { of Years }\end{array}$ & $\begin{array}{c}\text { Mean } \\
\text { Temp. }{ }^{\circ} \mathrm{C}\end{array}$ & $\begin{array}{c}\text { Linear Trend } \\
\text { ( }{ }^{\circ} \text { Cer Year) }\end{array}$ & $\begin{array}{c}\text { Total Warming }{ }^{\circ} \mathrm{C} \\
\text { (Number of Years } \mathrm{X} \\
\text { Linear Trend) }\end{array}$ \\
\hline Bakersfield & Jan & 48 & 8.6 & 0.037 & 1.76 \\
& Jul & 48 & 29 & 0.016 & 0.74 \\
\hline Las Vegas & Jan & 44 & 6.7 & 0.024 & 1.06 \\
& Jul & 44 & 32 & 0.041 & 1.78 \\
\hline Los Angeles & Jan & 48 & 13.8 & 0.014 & 0.67 \\
& Jul & 48 & 22.6 & 0.047 & 2.26 \\
\hline Phoenix & Jar & 48 & 10.9 & 0.029 & 1.41 \\
& Jul & 48 & 33.3 & 0.031 & 1.47 \\
\hline Red Bluff & Jan & 48 & 7.4 & 0.009 & 0.42 \\
& Jul & 48 & 27.8 & 0.01 & 0.49 \\
\hline Sacramento & Jan & 40 & 7.3 & 0.005 & 0.21 \\
& Jul & 40 & 24 & 0.023 & 1.65 \\
\hline San Diego & Jan & 48 & 13.4 & 0.034 & 1.84 \\
& Jul & 48 & 20.9 & 0.038 & -0.09 \\
\hline Santa Maria & Jan & 48 & 7.3 & 0.002 & 0.24 \\
& Jul & 48 & 24 & 0 & -1.32 \\
\hline Scripps Pier & Jan & 48 & 14 & 0.005 & 0.17 \\
& Jul & 48 & 20 & -0.028 & -0.17 \\
\hline Tucson AP & Jan & 40 & 10.5 & 0.004 & 2.44 \\
& Jul & 40 & 28.9 & -0.004 & 1.27 \\
\hline Tucscn UA & Jan & 48 & 10.7 & 0.051 & \\
& Jul & 48 & 31 & 0.027 & \\
\hline & & & & & \\
\hline
\end{tabular}

Adapted from: Cayan et al. (1984). 
One important point was to explain that the strong trends were found at those stations located in urban settings, whereas less intensive trends occurred in non-urban areas. Considering the average temperature over the urban stations, Cayan et al. (1984) remarked that the difference of the maximum temperatures for January and July were +0.44 and $+0.56^{\circ} \mathrm{C}$, significantly lower than the minimums, which were +2.24 and $1.52^{\circ} \mathrm{C}$.

In order to understand the magnitude of urban warming and its effect on different environmental aspects, the distinction between urban and rural areas may have to be based on not only the level of urbanization in the city but also on population size in both regions. For this purpose, Kukla et al. (1986) compared the trends of 34 urban/rural station pairs in the United States and Canada during the period of 1940-1980 (See Table 4). These urban/rural comparisons usually may be only approximations of urban modification. Therefore, in selecting station pairs, it was important to diminish or eliminate extraneous effects of topography, such as water bodies of the city sites, compared to the rural ones.

Most non-urban stations had less than 11000 inhabitants in 1980 with less than a 30\% increase in population over the 40 -year interval, whereas all urban stations showed tremendous population growth and ranged from 150,000 to almost $4,000,000$. The urban stations showed a warming with respect to the countryside throughout the years with an average annual difference of the trend of $0.11^{\circ} \mathrm{C}$ per decade.

Dronia (1967) compared data for 67 urban sites with population over 100,000 and 67 rural areas with population under 10,000 worldwide. During the period 1891-1960 the global urban warming shows an average trend of $0.12^{\circ} \mathrm{C}$ 
per decade. A similar approach, using the effect of population growth on urban warming trends, has been employed for South America (Prohaska, 1954), and Japan (Arakawa, 1937). The results of local studies agree with those found for different parts of the world over the past century. Despite dissimilar climatological conditions and different topographical situations, most urbanized areas across the world have shown a consistent warming trend over the past hundred years. It now seems reasonable to suggest that cities with a greater number of inhabitants may exhibit more extreme signs of urbanization in their core areas and therefore greater thermal modification.

Table 4. Summary of Reported Annual Urban Warming Rates Worldwide.

\begin{tabular}{|c|c|c|c|c|}
\hline $\begin{array}{c}\text { Rate } \\
\left({ }^{\circ} \mathrm{C} / \text { decade }\right)\end{array}$ & $\begin{array}{c}\text { No. of } \\
\text { Cities }\end{array}$ & Interval & Region & Remarks \\
\hline 0.11 & 34 & $1941-1980$ & U.S./Canada & Urban/Rural Pairs \\
\hline 0.12 & 9 & $1941-1980$ & U.S. & " \\
\hline 0.14 & 9 & $1941-1980$ & U.S. & Urban/divisions \\
\hline 0.3 & 7 & $1933-1980$ & SW U.S. & Cities vs rural cites \\
\hline 0.42 & 2 & $1940-1980$ & SW U.S. & \\
\hline 0.3 & 3 & $1946-1980$ & SW U.S. & \\
\hline 0.14 & 31 & $1917-1983$ & California & Cities vs 31 rural cites \\
\hline 0.11 & 31 & $1941-1960$ & California & \\
\hline 0.31 & 31 & $1960-1983$ & California & \\
\hline 0.15 & 3 & $1871-1890$ & Europe & Largest cities/rural cites \\
\hline 0.14 & 17 & $1891-1920$ & World & Cities vs selected rural cites \\
\hline 0.01 & 61 & $1921-1940$ & World & \\
\hline 0.13 & 45 & $1941-1960$ & World & \\
\hline 0.09 & 3 & $1886-1935$ & Japan & 3 Large cities vs rural cites \\
\hline 0.33 & 1 & $1920-1950$ & Argentina & Buenos Aires vs Countryside \\
\hline
\end{tabular}

Adapted from Kukla et al. (1986). 
In general, the geographical location of a city imposes a wide range of possible effects especially related to the presence of water bodies, topographic features, and the nature of soils, vegetation and land use in the region. The combinations possible are almost as great as the number of cities. Although the great majority of studies refer to the unique form of the urban warming in one particular city, however, as shown earlier, almost all sought the relation between the urban warming rate (mean temperature trend over specific time period) and city size (as measured by population). In other words, these works have been directed at evaluating the effects of a city's growth over time on its warming rate. The study showed warming in summer, cooling in spring and fall and little noticeable change in winter, with maximum linear trend of about $0.03^{\circ} \mathrm{C}$ per year. 


\section{CHAPTER 3}

\section{The Effects of Albedo}

\section{Introduction}

In general, albedo is defined as the fraction of solar energy reflected back to space by the earth-atmosphere system. The urban heat island is believed to be the result of anomalies in several meteorological and surface parameters in an urban area. The contribution of some of these parameters have been discussed in previous chapters. In this section, the increased absorption of solar radiation by the urban surfaces will be taken into account. The urban surface is complex in quality and geometrical structure, thus, albedo will be difficult to determine. However, the effects of surface irregularity of an urban structure on the absorption of incident solar radiation is important. This occurs when multiple reflections of solar radiation between urban complex surfaces decreases the apparent albedo of an urban area.

In attempting to address the significance of albedo in the development of heat islands, this section will discuss the albedo values for different surface types, and differentiate the reflectivity of white surfaces as opposed to that of dark surfaces. 


\section{Surface Albedo and Its Climatic Significance}

Because the amount of solar radiation absorbed at the surface is the principal energy source driving the climate, a change in surface albedo is an important component of energy balance in the climate system. Whether the changes are significant depends on how rapidly and by how much the physical characteristics of the surface are altered. One example which was mentioned in previous chapters is the inadvertent and artificial massing of heat-retaining, nonevaporative stone and concrete in urban areas. If less water evaporates from some surface, it will be relatively hotter than a highly evaporative one. As another example, if green and vegetated areas are converted into buildings with darker surfaces and roof-tops, the result is a new landscape with lower albedo. These alterations in the albedo and heat balance affect climate because they affect the absorption of solar energy. In general, atmospheric heating decreases if the albedo goes up.

The surface albedo is a measure of the reflectivity of a surface to solar radiation, and is defined as the ratio of the reflected solar energy to the incident solar energy at that surface. Thus, albedo $(\alpha)$ is:

$$
\alpha=\mathrm{K} \uparrow / \mathrm{K} \downarrow
$$

where $K \downarrow$ is the solar radiant energy received by a surface, or an area composed of a mosaic of surfaces and $\mathrm{K} \uparrow$ is the radiation in the solar spectrum reflected back. In this formula, $1-\alpha$ is the fraction of short wave radiation absorbed by the surface which is regulated by the solar input $K \downarrow$.

A study by Martien et ai. (1989) differentiated between reflectivity and surface albedo in terms of wavelength dependence. Reflectivity is specified to a 
particular wavelength of radiation, whereas albedo is independent of wavelength. In that regard, Taha et al. (1988) explain that:

Usually at a narrow wavelength band, albedo is the ratio of reflected to incident radiation at a particular surface or combination of surfaces, over all the wavelengths of solar radiation. In addition reflectivity is directional, whereas albedo is an effective reflectivity obtained from the integration over the hemisphere of all possible directional reflectivities resulting from geometrical and component variations of the surfaces, materials and constructions. Therefore, the term surface albedo means the time, angle, and spectrum average of the reflectivities at a particular surface or combination of surfaces. (Taha et al., 1988)

The value of albedo reveals the absorptivity of a given surface and becomes an important factor in determining the heat flux of a surface and its temperature. In other words, from a radiative standpoint, a high albedo would suggest low surface temperature, and a reduced long-wave output. Any change in surface albedo alters the radiation balance and causes a warming or a cooling of the immediate surrounding (Kukla et al., 1979).

\section{Albedo Values for Different Surface Types}

If an albedo of 1.0 corresponds to a surface that completely reflects the total solar radiation received upon it, an albedo of 0.0 refers to one that totally absorbs the incident solar radiation. Because the fraction of the incident solar energy which is not reflected at the earth's surface represents the absorbed solar energy available for differential heating of the lower atmosphere, the study of the surface albedo has crucial importance in understanding the atmospheric heat budget.

The albedo value has a wide range. For example, the albedo of the glaciers in Antarctica is 0.9, while the albedo of sea ice is 0.6-0.7. The albedo of the ocean 
is 0.07 , and land has maximum values in grasslands and deserts, where it varies from 0.20 to 0.28 (Katayama, 1972). Another important finding of that research was the development of a relationship between temperature fluctuation and surface albedo. That study by Katayama (1972) showed that the global surface air temperature sensitivity reaches $0.3^{\circ} \mathrm{C}$ per one percent albedo change.

Tables 5 and 6 represent albedo values for various natural surfaces and urban materials and areas, respectively. As shown, snow and ice have the highest albedo because they reject a large portion of $K \downarrow$ which is a primary importance of their low energy status. The introduction of even a thin snow cover over the landscape has dramatic effects. Oke (1978) recorded an increase in albedo from approximately 0.25 to 0.80 in a matter of a few hours over a natural landscape. The difference between fresh and dirty snow indicates that as a snow pack ages, albedo decreases. The resulting decrease of surface albedo from up to 0.80 of fresh snow was detected by Kondratyev (1969).

Table 5. Albedo of Some Natural Surfaces

\begin{tabular}{ll}
\hline Type of Surface & Albedo \\
\hline Snow and Ice & \\
Fresh, dry snow & $0.80-0.95$ \\
Clean, moist snow & $0.60-0.70$ \\
Dirty snow & $0.40-0.50$ \\
Sea ice & $0.30-0.40$ \\
Bare Soil & \\
Dark soil & $0.05-0.15$ \\
Moist, gray soils & $0.10-0.20$ \\
Dry, light, sandy soils & $0.35-0.45$ \\
Fields, meadows, tundras & \\
Cotton fields & $0.20-0.25$ \\
Meadows & $0.15-0.25$ \\
Tundra & $0.15-0.20$ \\
\hline
\end{tabular}

Adapted from: Budyko (1982). 
Table 6. Albedo Values of Some Urban Materials and Areas

\begin{tabular}{ll}
\hline Type of Surface & Albedo \\
\hline Asphalt & $0.05-0.20$ \\
Walls & $0.10-0.35$ \\
Concrete & $0.20-0.40$ \\
Brick & $0.20-0.35$ \\
Stone & \\
Roofs & $0.08-0.18$ \\
Tar and Gravel & $0.10-0.35$ \\
Tile & 0.10 \\
Slate & \\
Windows & $0.09-0.52$ \\
Clear Glass & \\
Paints & $0.50-0.90$ \\
White, Whitewash & $0.20-0.35$ \\
Red, Brown, Green & $0.20-0.15$ \\
Black & $0.10-0.27$ \\
Urban Areas & 0.15 \\
$\quad$ Range & \\
Average & \\
\hline
\end{tabular}

Adapted from: Oke (1978).

\section{Surface Geometry and Urban Temperature}

Beside several contributing factors in the production of urban heat islands surface geometry may also result in temperature increase. Albedo also depends on surface geometry and irregularity. The subject was researched by Aida (1982) who constructed several models of an urban structure, with its buildings and canyons using concrete blocks. When the models were compared with a flat surface made of the same materials, they showed more absorption than the flat surface because of multiple reflection within the canyons. The result is that the intensity of heat islands seems to relate to the density of buildings. Temperatures 
tend to be higher where buildings are closer together and streets are narrower. This temperature increase may take place up to a point beyond which this correlation will not hold.

The Effect of Albedo on Surface Temperature

Although the close relation of high albedo to cooling energy benefits is of primary importance in today's urban planning, as will be discussed later, it is important to briefly explore the potential surface temperature decrease as a result of albedo alteration. A high albedo surface usually, but not always, corresponds to a light color or white surface which tends to reflect most of the incident solar radiation upon it, and consequently stays cooler. If albedos of 0.70 or 0.80 represent the range of light colors and whitewash surfaces, the values between 0.10 and 0.20 are typical of dark surfaces.

Conner (1985) studied the effect of high albedo materials on surface temperature and compared it with a dark surface with low albedo (Figure 8). A difference of almost $10^{\circ} \mathrm{C}$ was detected between the two surfaces. A more dramatic difference was shown when on sunny days the surface temperatures of conventional roofing materials (gravel, and bituminous roofs) rose to about 40 degree ${ }^{\circ} \mathrm{C}$ warmer than air temperature, while the surface temperature of the high-albedo materials were only about $5^{\circ} \mathrm{C}$ warmer than air (Taha et al., 1991).

Because the greatest amounts of solar radiation are available during the long days of summer, generally a clear day with high incoming solar radiation may be the best candidate to test and compare the effect of different albedos on surface temperature. A study by Givoni (1976) was performed to document the effect of different colors on wall surface temperatures. It was shown that a gray- 
colored south facing wall can reach an exterior surface temperature as much as $32^{\circ} \mathrm{C}$ higher than the maximum ambient temperature, whereas for white-colored walls, it is about $1^{\circ} \mathrm{C}$. Berg et al. (1978) also showed that on a day when the ambient temperature was $65^{\circ} \mathrm{F}$, the average surface temperature for a black pavement was $88^{\circ} \mathrm{F}$, whereas the average temperature for the white section reached only $67^{\circ} \mathrm{F}$.

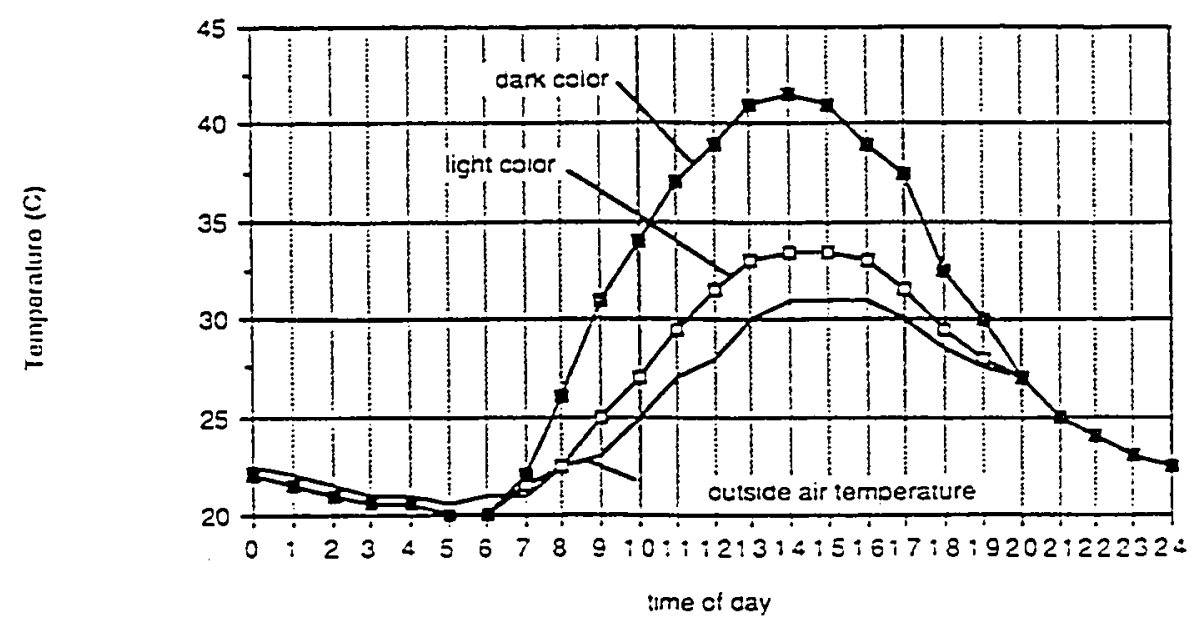

Figure 8. The Effect of Solar Radiation on Dark and Light-colored Surfaces. Source: Conner (1985).

\section{Energy Consumption and the Urban Environment}

Before discussing the effect of albedo increase on energy use, it is important to explore how energy is used in an urbanized area and how it is affected by climatological parameters. Indeed, the decline of environmental quality in urban areas is closely related to energy use. However, energy use and continuing urbanization appear to be an increasing trend in most modern 
societies. Therefore, the role of cautious urban planning to avoid further environmental deterioration and energy waste is of primary importance.

Climate is a major factor in residential, commercial, and industrial energy use for space heating, ventilation, and cooling. In the U.S., $7 \%$ of electricity use goes to space heating $-4.3 \%$ for residential buildings and $2.6 \%$ for commercial structures. Space cooling's share of U.S. electrical use is $9.3 \%-5.6 \%$ for commercial and 3.7\% for residential buildings (Gregerson et al., 1993). Space cooling and heating have the strongest seasonal dependence.

Categorically, the climate's effect on certain forms of energy use is in part controllable through design of structures, and the choice of building materials. The form of the actual relationships which expresses the dependence of energy use on climate is thus determined by a range of controllable factors associated with urban development, and building practices. Reduction of energy demand is therefore aimed at manipulation of such controllable factors as home insulation and albedo modification (Steinhart et al., 1974). Table 6 showed that the albedo value for most urban materials is considerably low, and is further decreased as a result of urban geometry and street canyons. In the next section, albedo will be discussed as a controllable factor to modify the energy balance of the urban environment.

\section{Energy Benefits of Albedo Modification}

Taha et al. (1988) have quantified the effects of albedo on energy use as local or direct and global or indirect effects. The direct effects come from the modification in reflective characteristics of a single building, whereas indirect effects result from large scale urban albedo modification. The most common 
practice to increase the albedo of a building is to use a surface with high reflectivity on the rooftop. The fact is that some roofs reflect the solar radiation more than others and hence do not get as hot.

Roof solar reflectance affects daytime roof surface temperature and consequently impacts building cooling requirements. In terms of energy use, increasing the surface albedo reduces the solar absorptivity and hence the surface temperature of the building exterior. Consequently, the conductive heat gain through the building decreases, which, in turn, may reduce the cooling loads. This is particularly true in residential buildings, where cooling loads are dominated by heat gain through the building envelope, especially to the roof.

In the U.S. residential sector, space heating consumes about $14 \%$ of the total, as Gregerson et al. (1993) describes. Space cooling consumes only $12 \%$ but is done mostly through electricity and is thus more expensive than gas heating. However, air conditioning is responsible for the summer peak power demand. In various case studies in hot climates, albedo modification has produced direct savings in air-conditioning use. In Sacramento, California, Taha et al. (1988) decreased the albedo of the rooftop of a house by 0.18 by using a darker surface and detected an increase in cooling loads of that building by $6.7 \%$. Later, the albedo was increased twice by 0.13 and 0.60 and cooling loads dropped by 2.7 and $18.9 \%$, respectively.

The role of roof reflectance increase becomes even more significant when the different components of the urban surface are well understood. For Sacramento, California, Myrup et al. (1972) estimated the fabric of the urban environment. His study indicates the potential of energy savings resulting from residential roof modification, as a large percentage of the urban surface is 
comprised by this type of surface (See Table 7). Indeed, this potential is larger for hotter and drier cities, because the fraction of vegetated areas is less. In Los Angeles, California, only 27 percent of the whole city is covered by green area (Brown et al., 1986).

Table 7. Estimates of Urban Fabric for Sacramento, California.

\begin{tabular}{|l|c|c|c|}
\hline \multicolumn{1}{|c|}{ Area } & $\begin{array}{c}\text { Residential } \\
(46 \% \text { Of Total) } \\
\%\end{array}$ & $\begin{array}{c}\text { Commercial \& } \\
\text { Industrial }(25 \% \\
\text { of Total) } \%\end{array}$ & $\begin{array}{c}\text { Total } \\
\%\end{array}$ \\
\hline Rooftop & 23 & 43 & 22 \\
\hline Impervious Street & 22 & 15 & 17 \\
\hline $\begin{array}{l}\text { Impervious Other } \\
\text { (parking lots, etc.) }\end{array}$ & 22 & 42 & 22 \\
\hline Green & 33 & 0 & 39 \\
\hline Total & 100 & 100 & 100 \\
\hline
\end{tabular}

Adapted from: Myrup et al. (1972).

It is possible to utilize the above findings to estimate energy savings resulting from albedo increase of a single house on a more general basis. In order to do so, one needs to evaluate the savings from individual houses in different climates and extrapolate the results to urban or national levels. In this regard, the warming trend in most major U.S. cities which has been assumed as an additional factor in increased cooling loads needs to be taken into account.

In general, the amount of cooling energy savings depends upon two categories: 1) geographical location (e.g., latitude and climate), and 2) thermal integrity of the building. Taha et al. (1991) noted the latitude dependence of those savings and remarked that in low-latitude cities roofs are more important factors 
in terms of heat gain. Thus, roof modification is the primary method to achieve cooling loads savings. Their study emphasized that the roof is the primary source of receiving solar radiation during cooling hours in most central and southern Californian cities located between latitudes 32 and 42 . The higher the latitude is, the more significant the role of walls and other vertical surfaces will be.

Likewise, roof insulation may play a significant role in achieving direct savirigs through albedo increase of rooftops. A study by Reagan et al. (1979) in Tucson, Arizona, focused on a comparison of energy savings of insulated and uninsulated houses. At first, the roof colors of a high insulation house and a low insulation identical house were lightened. The results fell into two categories: 1) the heat gain through the roof of both houses was cut down by almost fifty percent, from 25 Mega Joules (MJ) to $13 \mathrm{MJ}$ for high insulation house and $59 \mathrm{MJ}$ to $29 \mathrm{MJ}$ for low insulation house; 2) the energy use dropped by $6.4 \%$ in low insulation house, whereas the reduction in the high insulation one was $4.8 \%$. The building materials used for this study were similar to those used in other parts of the U.S.

The subject of insulation became even more important when researchers performed simple calculations for insulated and uninsulated houses in different climates in the U.S. and explored larger cooling savings in uninsulated residences as opposed to insulated ones (Conner, 1985). Also, albedo turned out to be crucial in hot climates in alleviating the heat island effects and its detrimental cooling costs. This particular case, therefore, showed that a low insulation house may be the best case for albedo modification.

Although in most cases the experiments irivolved a combination of roof reflectivity application and insulation, a deeper observation of different 
insulation levels is beneficial. The reason for this is that each level of insulation may yield a different amount of savings. Backenstow (1987) used two black and white surfaces for the rooftop of a residential building representing different albedo values, and calculated air-conditioning savings for a variety of insulation levels (See Table 8). The study also estimated approximately 635 million square feet of black or gray-black roofing versus 130 million square feet of white roofing in the U.S. in 1987.

Table 8. Air-conditioning Use Savings from a White Surface with Different Insulation Level

\begin{tabular}{|c|c|c|c|}
\hline $\begin{array}{l}\text { Insulation } \\
\text { Level }\end{array}$ & $\begin{array}{l}\text { Black Surface Energy } \\
\text { Costs (\$/day) }\end{array}$ & $\begin{array}{l}\text { White Surface Energy } \\
\text { Costs (\$/day) }\end{array}$ & $\begin{array}{l}\text { Savings } \\
\text { (\$/day) }\end{array}$ \\
\hline R-1 & 40.8 & 18 & 22.8 \\
\hline R-5 & 8.16 & 3.6 & 4.56 \\
\hline R-10 & 4.08 & 1.8 & 2.28 \\
\hline R-15 & 2.72 & 1.2 & 1.52 \\
\hline R-20 & 2.04 & 0.9 & 1.14 \\
\hline R-30 & 1.36 & 0.6 & 0.76 \\
\hline
\end{tabular}

Adapted from: Backenstow (1987).

The above study marked an average percent reduction in energy costs of almost $50 \%$ each time the insulation level was increased. This means that the conclusion of that study is compatible with that of Reagan (1979) indicating that changes in roof reflectivity with different insulation levels have similar savings. 


\title{
CHAPTER 4
}

\section{The Effect of Albedo Modification on Residential Roof Surface and Indoor Air Temperature}

\author{
Background
}

The primary focus of energy conservation in residential buildings is normally on the materials and physical structures of these buildings. It has been well documented that by altering certain physical properties of some residences, specific energy savings associated with those changes can be achieved. There is a great deal of research and documentation on how to reduce residential airconditioning use in hot climates simply by increasing the roof solar reflectance. In the studies of heat island mitigation measures, there is always a reference to changing the color of residential rooftops in order to achieve cooling loads savings.

Historically, this method began its path in mid 1980s (Akbari et al., 1986) to the most recent years (Parker et al., 1994) to prove that white color roofs, if properly utilized, can offer the possibility of reducing the energy used in space cooling. As mentioned in previous chapters, the application of this particular measure is the most effective in uninsulated houses in hot climates. However, the effectiveness of this strategy may be enhanced in low or even well-insulated houses in conjunction with other techniques, such as retrofitting and recoating the rooftops and whitening the south facing walls.

There is a tremendous variation in the characteristics of residences which has emerged as the primary difficulty in evaluating the benefits of the above 
strategy. There have been some speculations or even observations that increasing the albedo of the residential houses in mild or cold climates may result in some savings in space cooling cost, but can increase the cost of space heating (Conner, 1985). Generally speaking, a white roof is preferred during daytime when cooling is needed (in a hot climate) and a black roof is favored when building heating is of primary significance. Under this circumstance, roof modification must accompany a reasonable cost effective analysis of savings in summer cooling loads and potential increase in winter heating costs. Therefore, general principles of such observations affirm that individual projects must take into account local climatological parameters. Besides, many other factors including roof maintenance costs, roof longevity, dirt accumulation, and material cost are of primary importance before any retrofit is performed.

Albedo modification principles which reduce cooling requirements for residential buildings have been performed primarily in hot climates and several detailed designs have recently been developed (Taha et al., 1991). These studies have focused on modification level which determines the amount of albedo to be increased and the usage of different surface properties for the rooftops. The reason for this is to determine the most appropriate design for different climatic regions so that the cooling loads savings could be maximized. Most of these projects have been done on two identical houses simultaneously. There are, however, other cases that used the same residence before and after alteration in two different time periods.

Figure 9 shows the effects of reflective roofs on residential interior temperature in one of the most recent studies (Parker et al., 1994). In this particular study, one house with an uninsulated attic was the subject of reflective 
roof modification and showed significant reduction of air-conditioning use, roof surface temperature, and interior air temperature. The first period indicating the unaltered roof was in July, whereas all items were measured once again after the alteration.

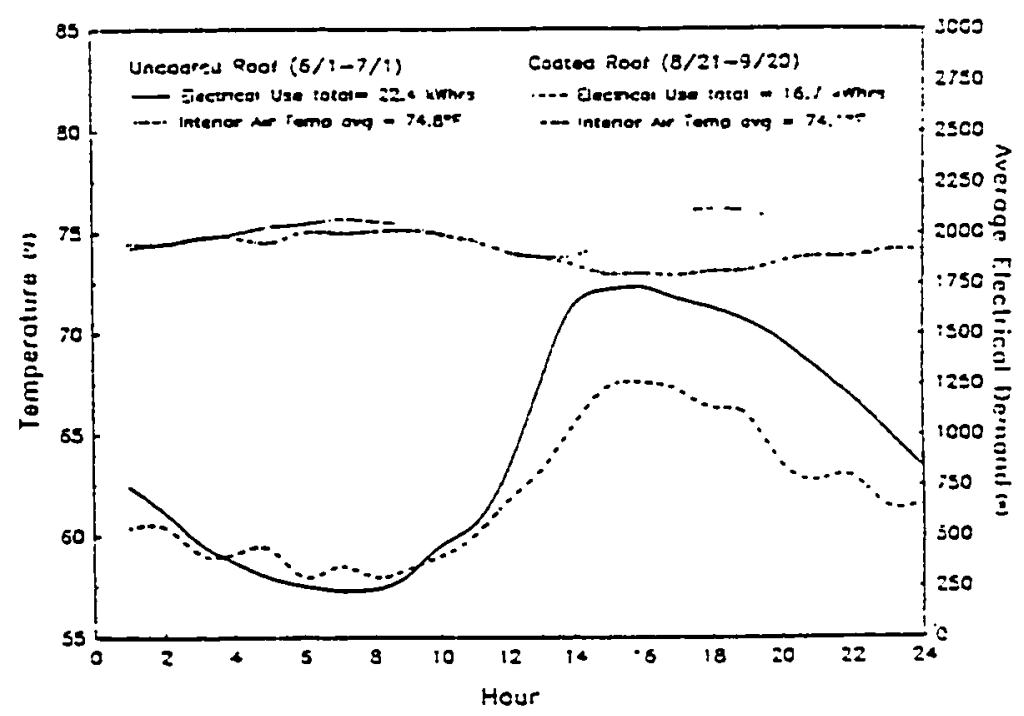

Figure 9. Temperatures Before and After Reflective Roof Coating. Source: Parker et al. (1994).

Alteration in Solar Reflectance of a Low-Sloped Roof

For the purpose of this study, an experiment was performed that focused on potential reduction of interior temperature of a residence in San Jose, California. This project was done in an actual environment and had two goals: 1) to measure the surface temperature of the rooftop before and after modification, 
2) to explore and observe the potential reduction of the interior temperature of the house as a result of that change. Bearing in mind that hot climates have proved to be the best candidates for such strategy and have shown the greatest interior temperature effects along with the most significant savings in space cooling, the results for a moderate climate with mild summers in San Jose, California may be less significant. Taha et al. (1988) in their study of heat island effects on residential cooling loads have cautioned that:

The exterior surfaces' colors are really important only in single-load dominated climates (i.e. heating only, or cooling only). In mild climates, or climates with both heating and cooling extremes, the effect of exterior color is further complicated, and its effectiveness as a conservation strategy becomes less obvious. (Taha et al., 1988)

Therefore, the study performed for this thesis did not intend to provide answers with scientific precision. Nevertheless, because it was performed in an actual environment and a number of meteorological factors were measured on hourly basis during the daytime, the results could presumably be utilized for prototypical houses in the same climatological conditions.

This study included the following factors to make a reasonable comparison between the condition of the house before and after the modification: roof surface color and texture, sky condition, and roof insulation. The roof color and texture is discussed because light reflecting from a rough surface has a higher chance of striking the surface a second time, hence, being absorbed. If all other factors were equal, a rough surface would be of a lower solar reflectance and consequently warmer than a smooth surface. This will be an obvious observation in this study when the rough and dark-colored shingles of the rooftop are covered with smooth and white cloth. 
Basically, the roof is not a very massive component in a residence. It cannot store too much heat; in case of sudden climatic changes, such as rain or strong wind, its surface temperature reduces. Thus, it was important to ensure that the project was performed under almost similar sky conditions before and after roof alteration. Even though, a roof with insulation carries less heat into the building than an uninsulated roof, and that may cause it to have a higher surface temperature, the surface temperature itself is a function of the net energy exchange between the roof surface and both the interior and exterior environment. This situation was, of course, constant for the purpose of this project.

\section{Site Description and Analysis}

In order to establish the potential reduction of the interior temperature of a residential house resulting from albedo modification of the rooftop, this project has resuited in an analysis of a specific house. The house is located on the south side of San Jose, California. It is of typical modern construction with about three inches of fiberglass in the ceiling, the floor and the walls yielding an average $R$ value of 19. The residence is about 42 feet long and 35 feet wide. There is one main entrance door on the south side. There are two sliding glass doors on the north side opening to the backyard. There are also four aluminum windows, two of them on the north side, one on the east side, and one one the south side. The roof is of conventional dark cedar shingles with a mild slope on north and south sides. 


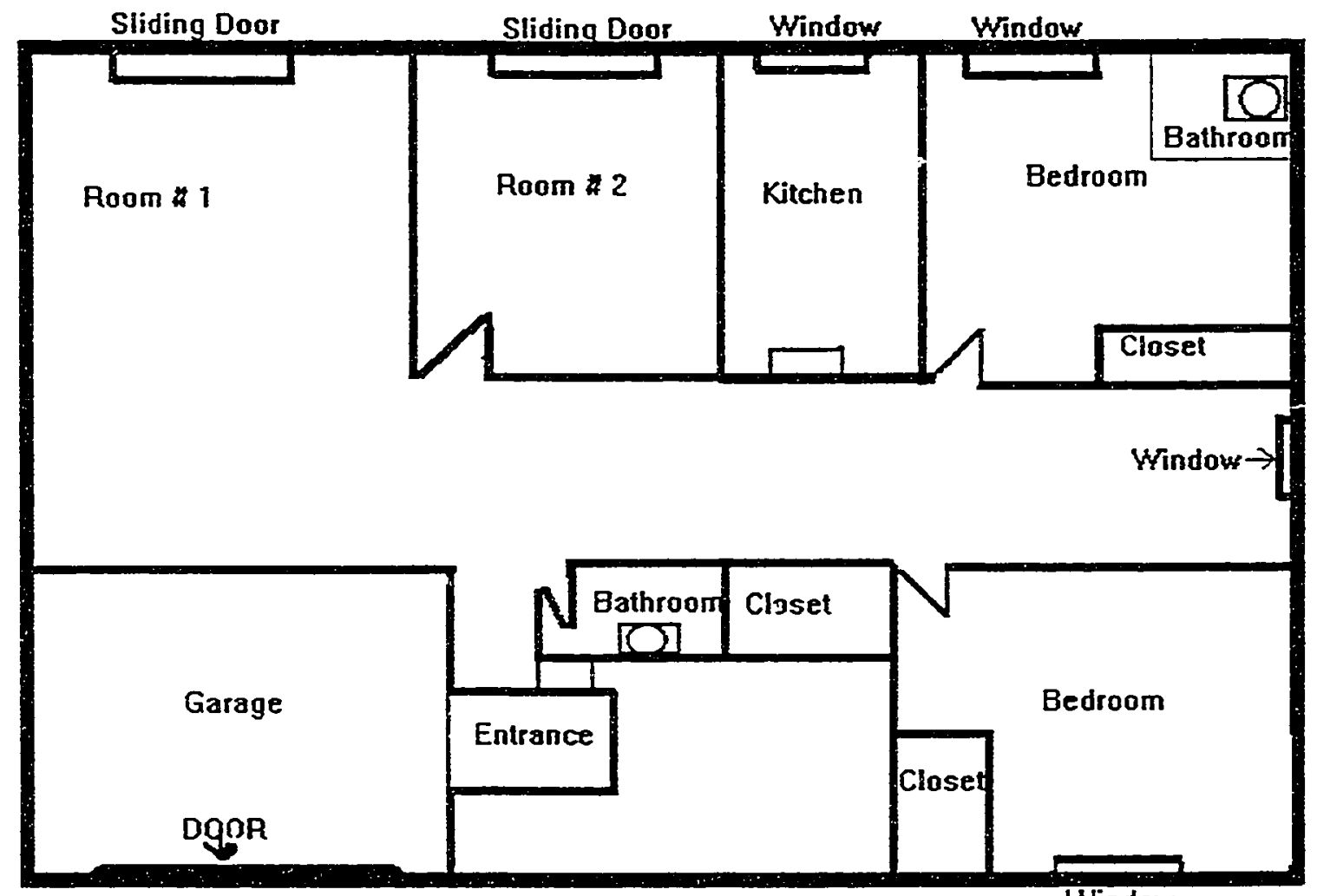

Window

Figure 10. Diagram of the House

\section{Experiment Design Characteristics}

The main focus of this investigation was to observe the effects of albedo change on roof surface temperature and indoor temperatures in a residential building. The roof was the only building component to be modified. In order to increase the reflectivity of the rooftop, the dark cedar shingles were fully covered by a layer of white cloth. The cloth later was taped to the edges of the roof and tucked under the end edges of all sides. Then it was secured to the shingles by 
thumb tacks. This allowed less air exchange underneath the cloth layer, which would otherwise affect the surface temperature fluctuation. The cloth coverage was performed after the first series of observations (before albedo change) had been made (See Figures 11 and 12).

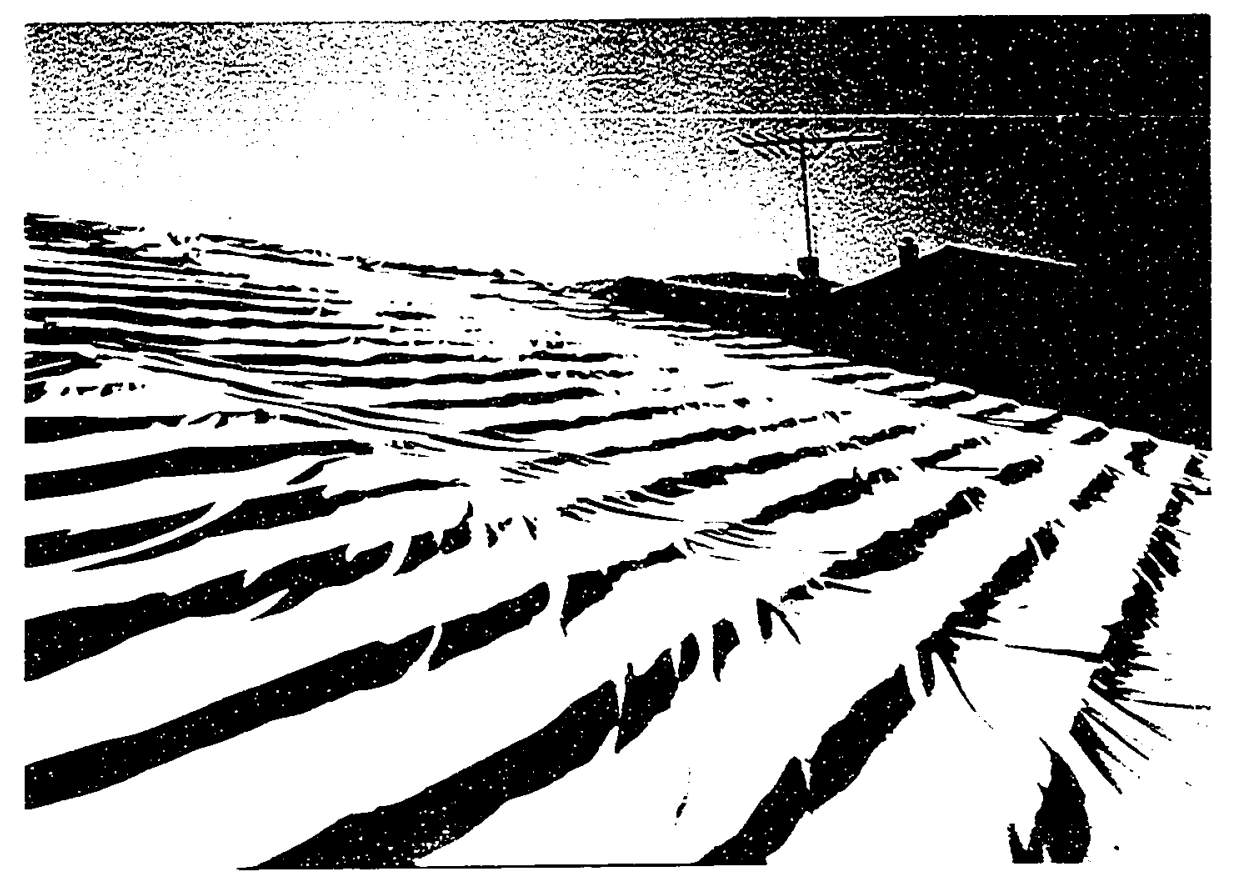

Figure 11. White Cloth on the Roof 


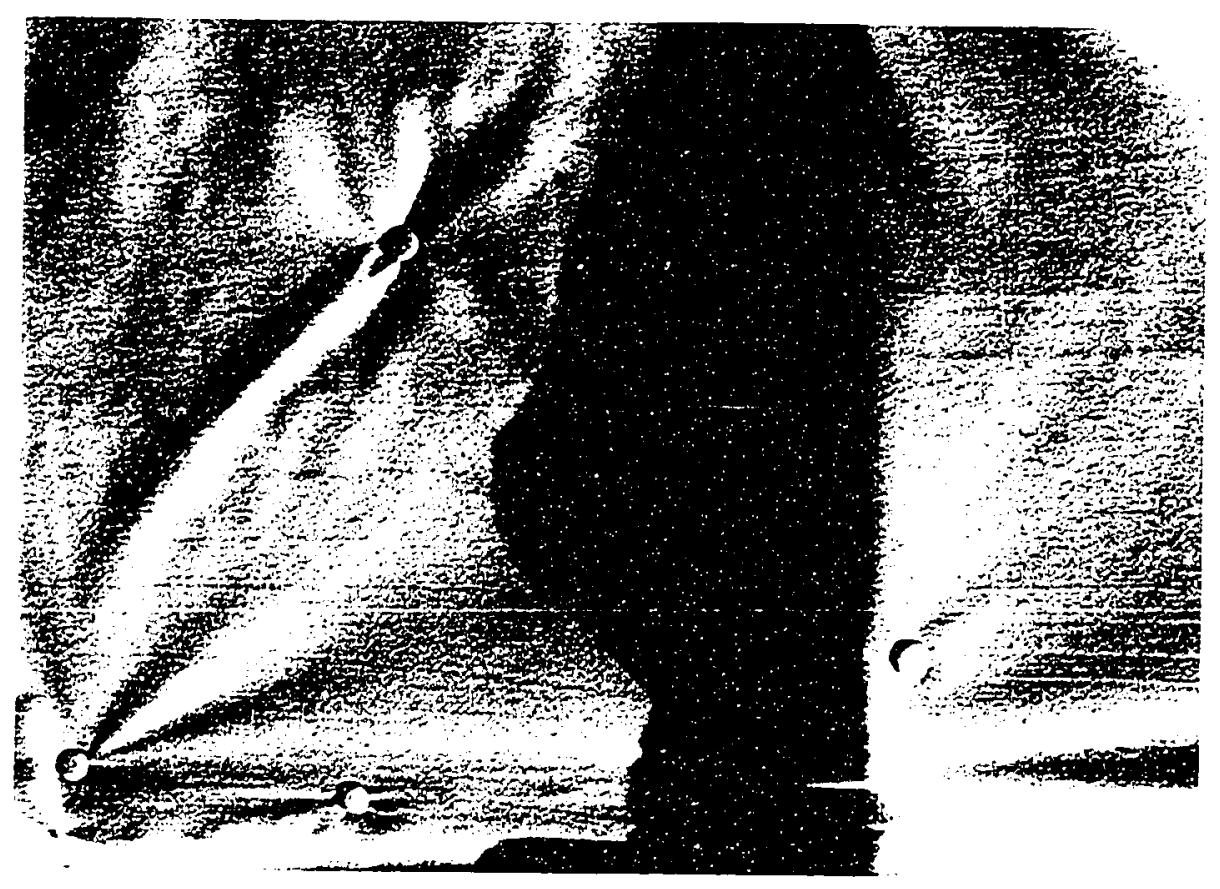

Figure 12. Close-up of White Cloth on the Roof

Instrumentation

The measurement of two different sets of temperatures (surface and ambient temperature) required two different kinds of instruments. In order to measure the surface temperature, a non-contact infra-red thermometer, (Thermonitor model LT-100) was used (See Figure 13). The hand-held LT-100 has an accuracy of $1^{\circ} \mathrm{F} / 1^{\circ} \mathrm{C}$ and measures a broad temperature range from $-20^{\circ} \mathrm{F}$ to $+2000^{\circ} \mathrm{F}$. The LT-100 is a radiometric instrument to measure surface temperature by collecting infra-red (heat) radiation from a remote object and focusing it onto an infra-red detector which converts the radiation to an electrical signal. It also has an emissivity compensation control which corrects the indicated reading for the measured object's emissivity. For dark cedar shingles, this variable was set at 95. 


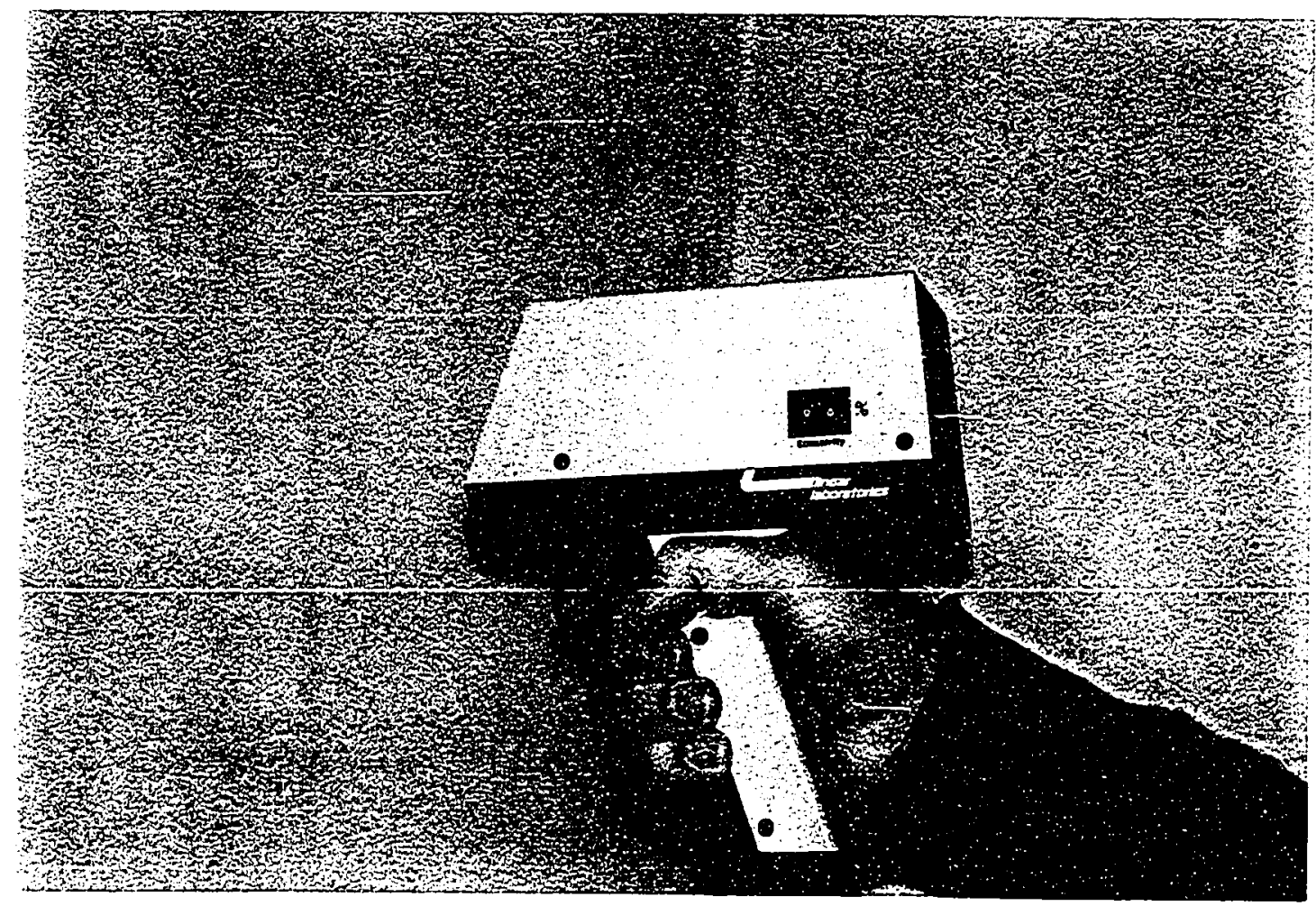

Figure 13. Hand-held Infra-Red Thermometer

For the measurement of ambient air temperature and interior temperature of the rooms, a sling psychrometer was used. Albedo of cedar shingles and white cloth were measured with a pyranometer. The instrument that would normally be used with greater precision for this measurement is an Eppley Pyranometer. This instrument was not available at the time of this investigation. Nonetheless, this paper briefly describes the structure and operation of Eppley Precision Spectral Pyranometer used by Taha et al. (1991) to measure the surface albedo. This pyranometer yields an output of $9.98 \mu \mathrm{V}$ per $\mathrm{W} \mathrm{m}^{-2}$ and has response time of one second. The Eppley pyranometer can minimize the effect of convection on reading resulting from tilting at different angles by the virtue of its double-dome design. 
The pyranometer was attached to a special stand in order to measure the surface albedo. Later, the above researchers minimized the effect of the stand by hanging the inverted pyranometer with a wire from the end of a tube (See Figure 14).

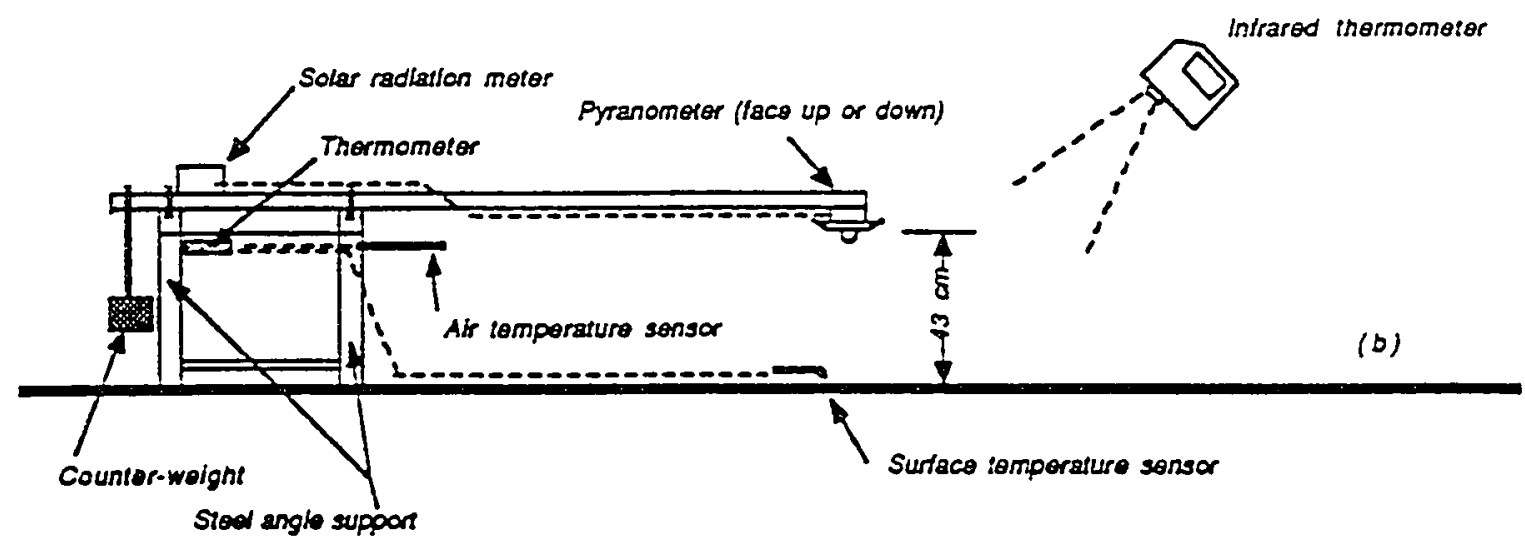

Figure 14. Pyranometer for Albedo Measurement. Source: Taha et al. (1991).

\section{Methodology}

This project has explored two subjects: the first was to potentially reduce the roof surface temperature and the interior temperature of two rooms of a residence as a result of increasing roof surface reflectivity, and the second involved establishing a relation between surface albedo, surface temperature, and indoor temperature.

This experiment consisted of two separate monitoring periods. One took place before the roof was modified and the other afterwards. In order to compare the results of the measured data before and after modification, it was necessary 
to monitor temperature variations (surface and ambient) over a large number of days so that normalization is possible. Each period took eight days and there was one day in between to do the roof surface modification.

Exterior data included the following:

- Drybulb temperature

- Wetbulb temperature

- Roof surface temperature

- Relative humidity

- Solar radiation

- Winà speed

Exterior ambient temperature was measured adjacent to the building. Relative humidity, solar radiation, and wind speed were taken from the local weather station at San Jose State University, about one mile from the test location. The indoor data included:

- Drybulb temperature \#1

- Drybulb temperature \#2

- Wetbulb temperature

Hourly measured data for one day are shown in Table 9.

Indoor temperature conditions were carefully measured on the same spot to ensure that no other factor, such as any interior heat loads, would bias the temperature readings. Also, during the course of this experiment, the house was vacant and no internal activity took place during the daytime. The reason for this is that due to wide variations in activities affecting the interior temperature pattern, the larger internal heat loads associated with the large number of lights, appliances, and people present in the residence had to be eliminated. 


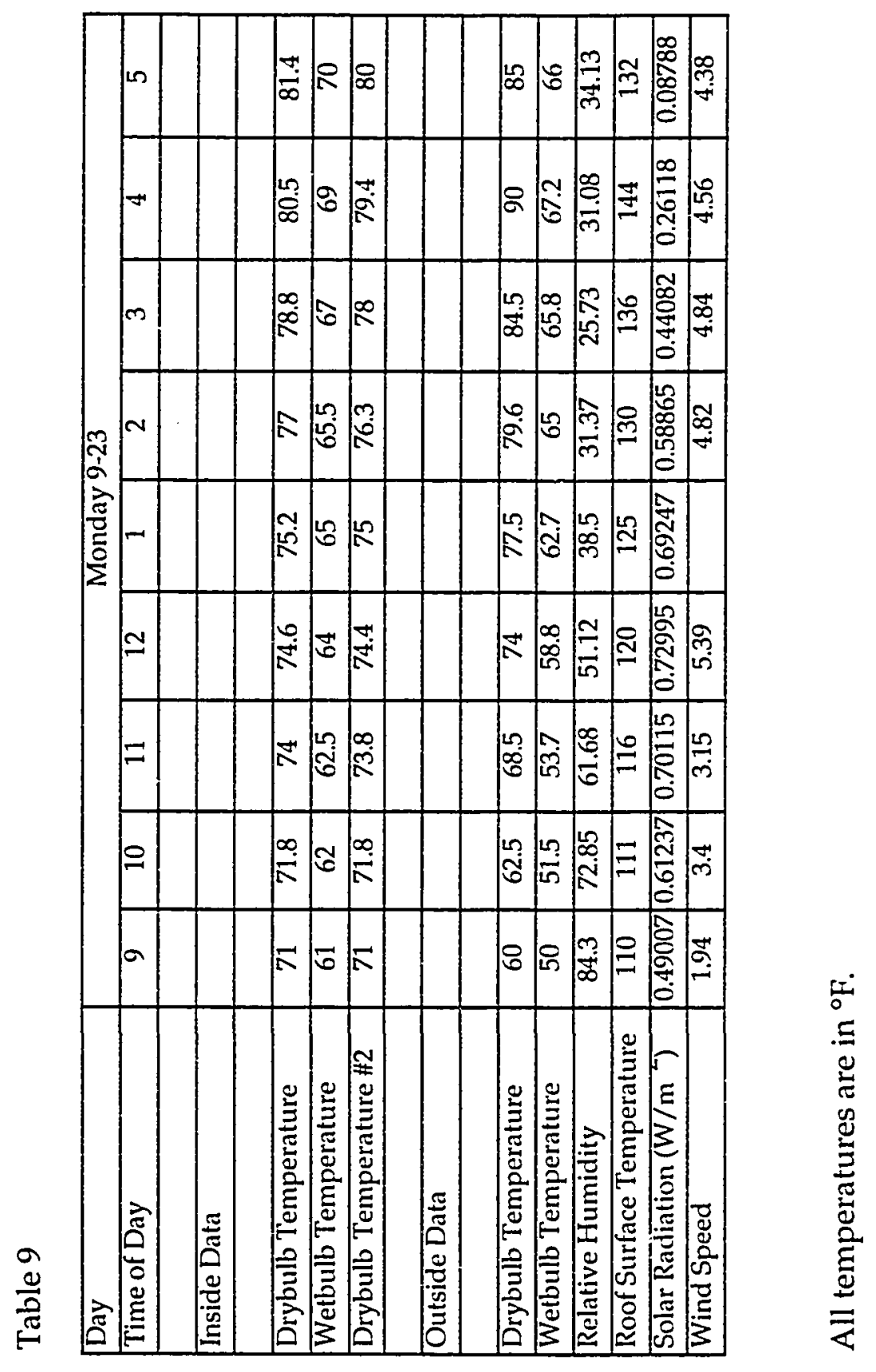


Drybulb temperatures for two rooms were measured. The reason for this was to observe a potential difference between the interior temperature of the two rooms due to relative position: room number 1, the wall of which was exposed to the afternoon sun, presumably receiving more heat transfer through that wall (See Figure 10), and room number 2, with an opening to room number 1. All data were measured on an hourly basis beginning at 9 in the morning and ending at 5 in the afternoon. Data were collected and tabulated using Excel 5.0 to form a spreadsheet for each day. Later, a variety of graphical representations were made to display the results. In particular, one form of this representation, regression analysis, was widely employed to show the differences of a variety of measured data before and after modification. Regression analysis is used to fit a line through a set of observations. It shows how an independent value like outside air temperature affects one or more dependent variables like interior temperature or surface temperature.

\section{Measurements and Data Interpretation}

Essentially two types of temperatures were measured: 1) ambient air temperature which included interior and exterior drybulb and wetbulb temperature, and 2) roof surface temperature. The main objective of interior temperature measurement was to detect any change due to albedo change. This correlation has to be considered cautiously as there are various elements preventing the investigation from reaching a precise conclusion. Basically there are no two similar days. Even if the maximum ambient temperatures of two days are identical, there are still other variables, such as cloud cover, humidity, and 
wind that can impact the effect of outside temperature on the energy and heat exchange of the inside.

The results of this experiment indicate that the interior temperature of room \#1 obviously but not dramatically dropped. During warm summer days it rose up to $81^{\circ} \mathrm{F}$, whereas after modification it clearly did not rise above 77 or on some days $78^{\circ} \mathrm{F}$ (See Figure 15). As was the case in room \#1, the adjacent room also stayed cooler during daytime periods in which the roof was covered after modification (See Figure 16). These two figures show similar temperature trends in both rooms, but a comparison between the two trends in Figure 17 displays a slight difference between the two cooling trends.

As shown in Figure 10, room \#1 is located on the west side of the building and is exposed to the afternoon heat which causes the temperature in this room to rise higher than room $\# 2$. Because there is not any door or wall between the two rooms, the heat transfer eventually affects the temperature augmentation trend in room $\# 2$. Thus, one can assume that if room $\# 2$ were separated from room \#1 by a wall or a door, it would stay even cooler. Still by comparing the figures $17 \mathrm{a}$ and $17 \mathrm{~b}$, one can draw the conclusion that after the roof surface change, the daytime warming trend in room $\# 2$ is less dramatic than that of room $\# 1$.

The most dramatic results came from the roof surface as a result of albedo increase. Under peak solar radiation in the early afternoon on warm days when the ambient air temperature rose to about $95^{\circ} \mathrm{F}$, the dark shingles temperature was measured at $145^{\circ} \mathrm{F}$, whereas the new surface (white cloth) was as low as $95^{\circ} \mathrm{F}$ (See Figure 18). In another figure the surface temperatures before and after albedo change were plotted in the same chart on hourly basis to show that 
during the daily course of the experiment (from 9 a.m. to 5 p.m.) white cloth stayed about $50^{\circ} \mathrm{F}$ cooler than dark shingles consistently. The above conclusion can be applied to all other days by comparing the values before and after surface change in the Appendix. It has to be noted that this discussion would be valid if all other climatological factors, except outside temperature, were to be excluded.

\section{Limitations}

An analysis of the use of high albedo material on the rooftop of one residence may include potential limitations. The major constraint which arises in the data comparison before and after modification in such an experiment is that no two days have the same weather conditions. Consequently, any comparison of measured data between those periods has to be considered very carefully.

As the roof was covered with white cloth, the main attention was paid to increasing the reflectivity of the roof. However, as mentioned earlier, the cloth was secured to the cedar shingles by thumb tacks that left some space below the cloth surface. Therefore, a potential air flow beneath this layer may bias the temperature readings and affect the results.

In this experiment there was no possibility to detect the effect of the west wall on the interior temperature of room \#1 and consequently room \#2. The west side wall of this room was exposed to the afternoon heat, and thus, may have been a major cause of internal warming. The heat transfer through this wall to the building can offset the effect of roof modification on the interior temperature. This is due to the fact that in mild climate the roof surface reflectivity may not play a very significant role in reducing the interior temperature and 
consequently cooling loads, as opposed to hot climates where albedo increase has proven to be of significant effect.

\section{Conclusions}

Analysis of heat island formation has demonstrated the dynamic aspect of urban heat islands and urban warming. As a result of inadvertent environmental and atmospheric modifications, temperatures of the cities have significantly increased. This study has shown the relevance of urbanization and industrialization to urban temperature increase over the past century. In this regard, a few factors that mainly contributed to the thermal features of urban canyon, e.g., sky view factor, surface temperature, and surface albedo were characterized. It was also shown that surface geometry and its regional distribution within the city area play a fundamental role in generating the urban heat island. The major factors that create urban warming were then correlated with an increase in peak power demand and cooling loads, primarily in residential buildings. In order to alleviate the detrimental effects of heat islands on residential cooling loads, roof albedo modification was shown as the most effective strategy in hot climates.

This study suggests that potential indoor temperature reduction can be realized by increasing the albedo of residential rooftops. The albedo increase in San Jose, California was employed in two respects: the first was to detect any reduction in a residence's interior temperature, while the second purpose was to reduce the surface temperature of the rooftop. A primary aspect of the results confirmed that a dramatic reduction of about $32 \%$ in roof surface temperature was achieved as a result of roof albedo increase by $40 \%$. This consistent reduction 
of almost $45^{\circ} \mathrm{F}$ or was possible solely by using a white cloth without any additional property. The analysis of the effect of this strategy on the indoor temperatures of two rooms, however, showed that this effect initially may be dependent on other factors, such as roof insulation and climate. It was noted that an uninsulated or low insulated house in a hot climate may be the best candidate for albedo change. Nevertheless, the interior temperatures of both rooms dropped by an average of 3 to $4^{\circ} \mathrm{F}$.

The latest roofing technologies have improved the role of the above strategy in the field of urban design and architecture. In an actual roofing project, the external surfaces can be coated by light color. In case of a new roof, using light-colored concrete tiles and other roofing materials will enhance the longevity of the rooftop and reduce the cost of cooling loads. At an urban scale further steps should be taken to measure the percentage of the total urban fabric represented by roof for a specific city. This, in turn, will provide additional information on the amount of surface albedo increase and cooling load savings. The study of urban heat island and energy performance in residential building indicate that albedo modification can potentially be used as an energy conservation strategy. 


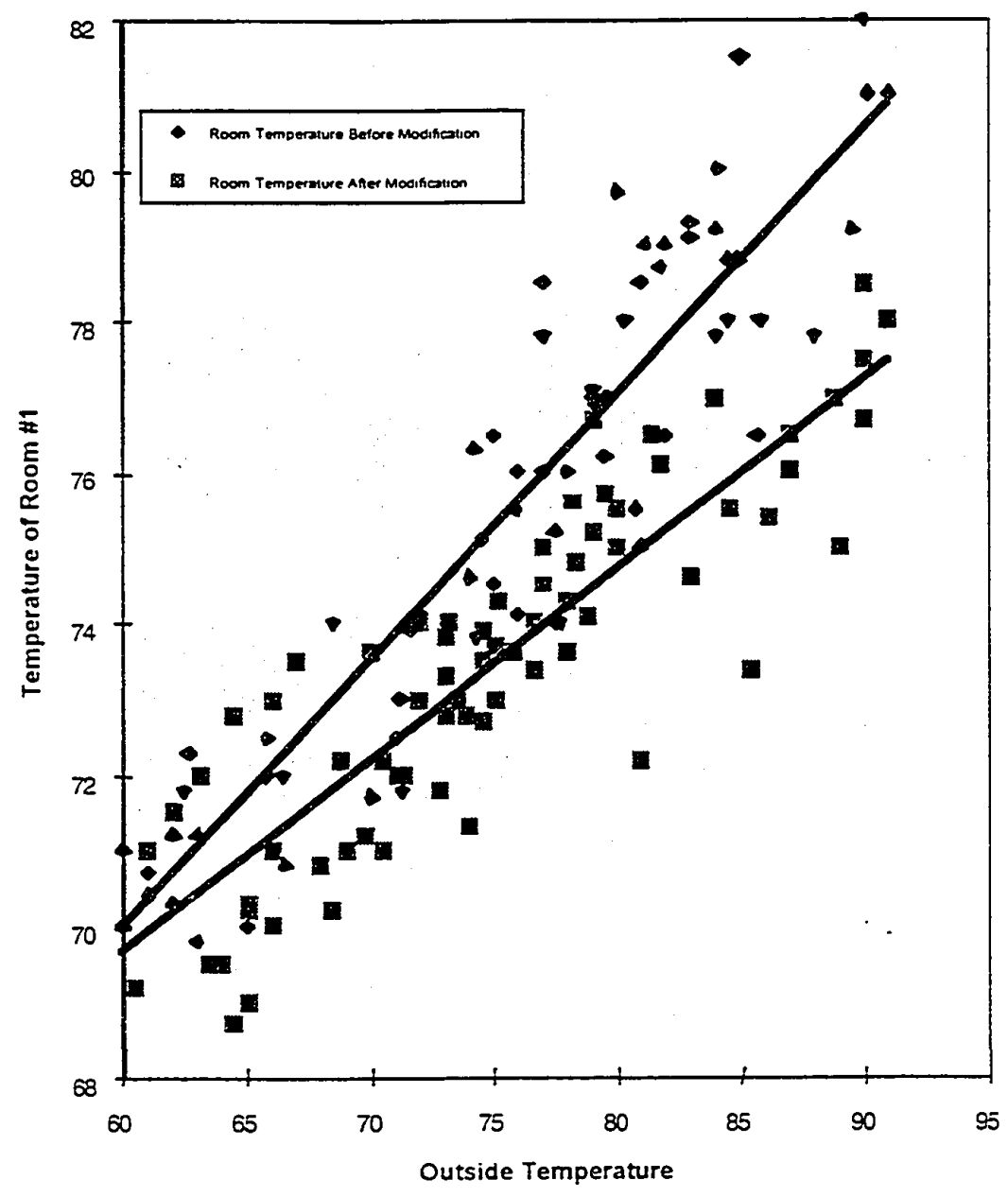

Figure 15. The Effect of Outside Temperature on the Temperature of Room \#1 


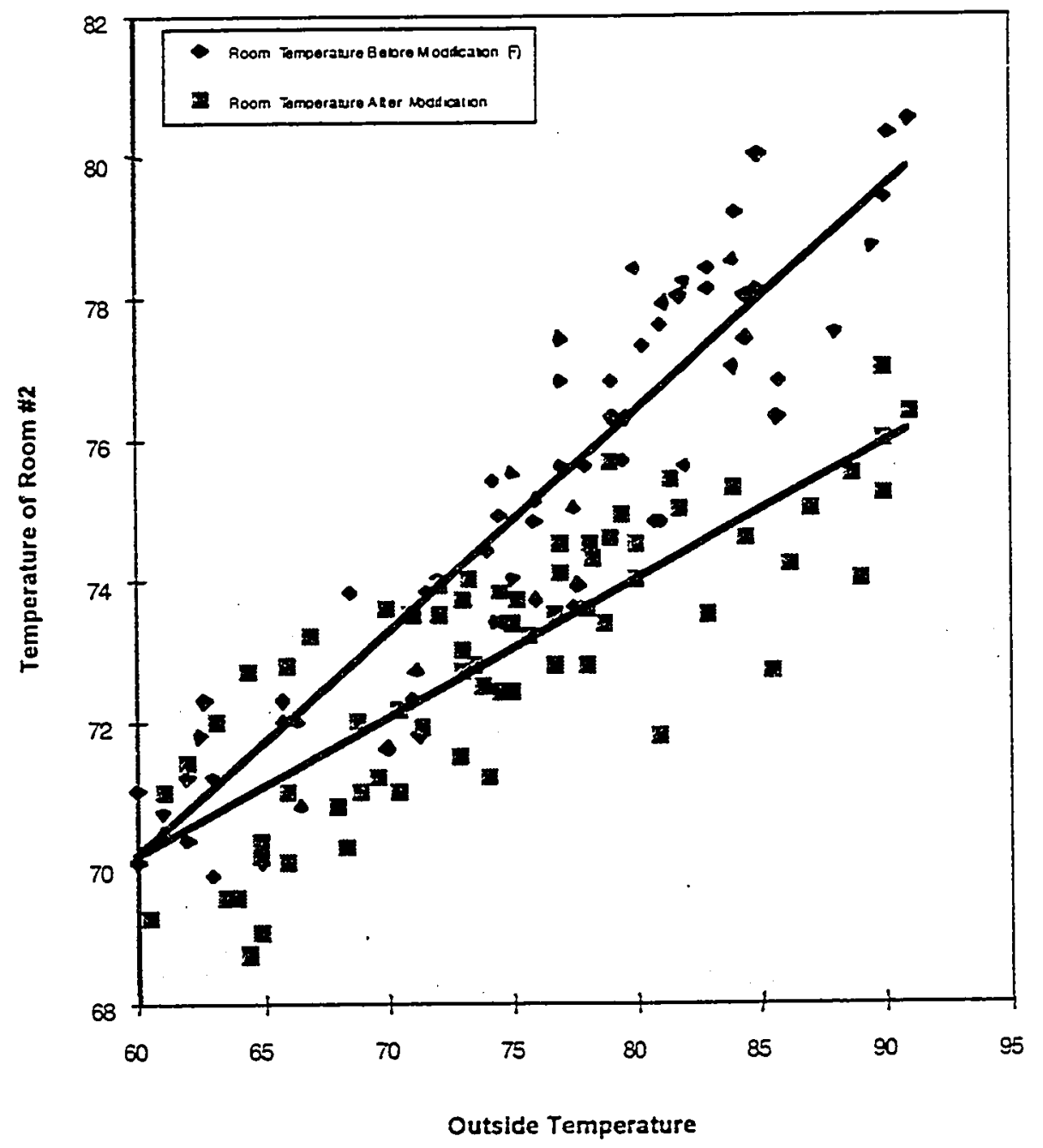

Figure 16. The Effect of Outside Temperature on the Interior Temperature of Room \#2 

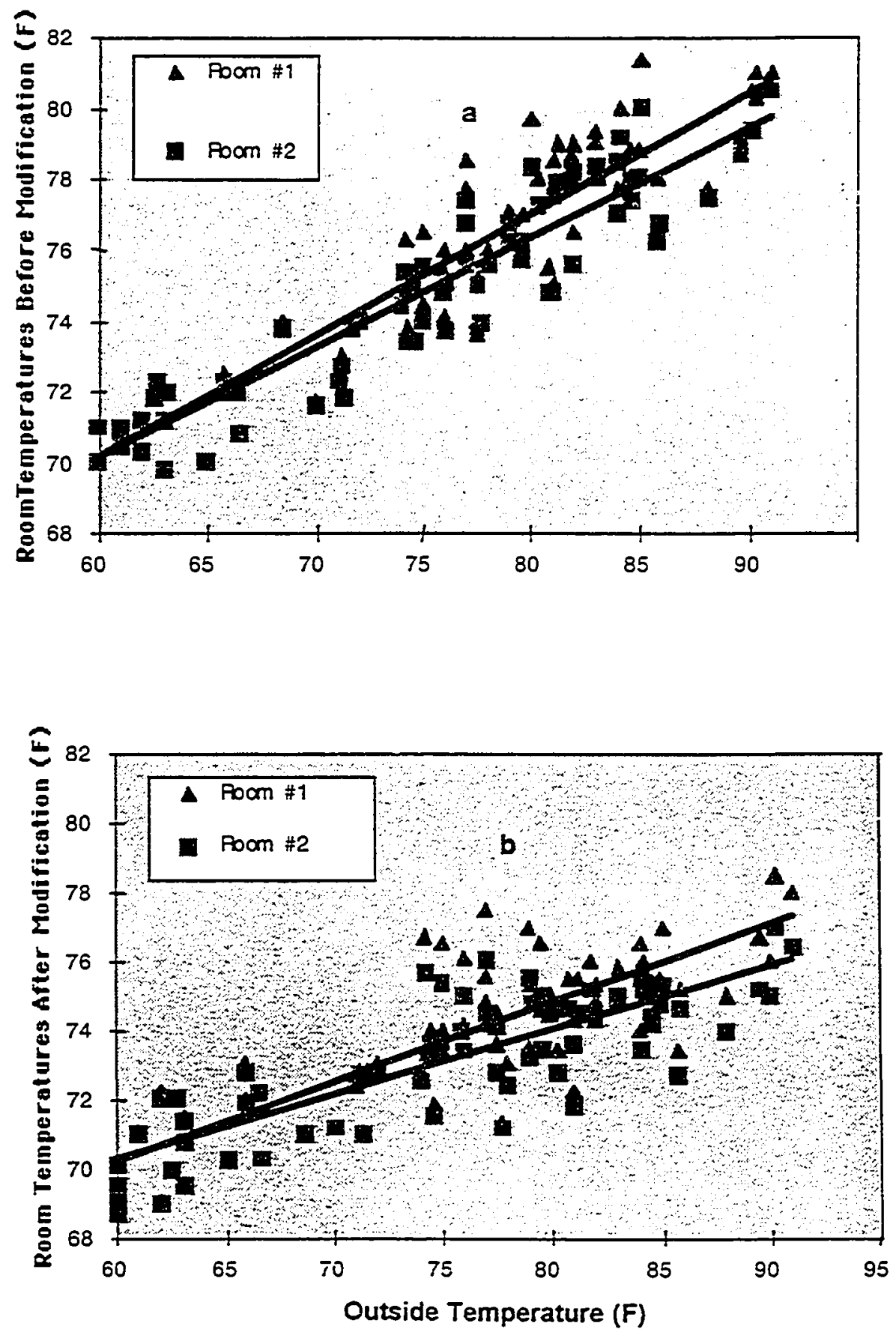

Figure 17. A Comparison Between the Temperature Trends of Two Rooms Before (a) and After (b)Modification. 


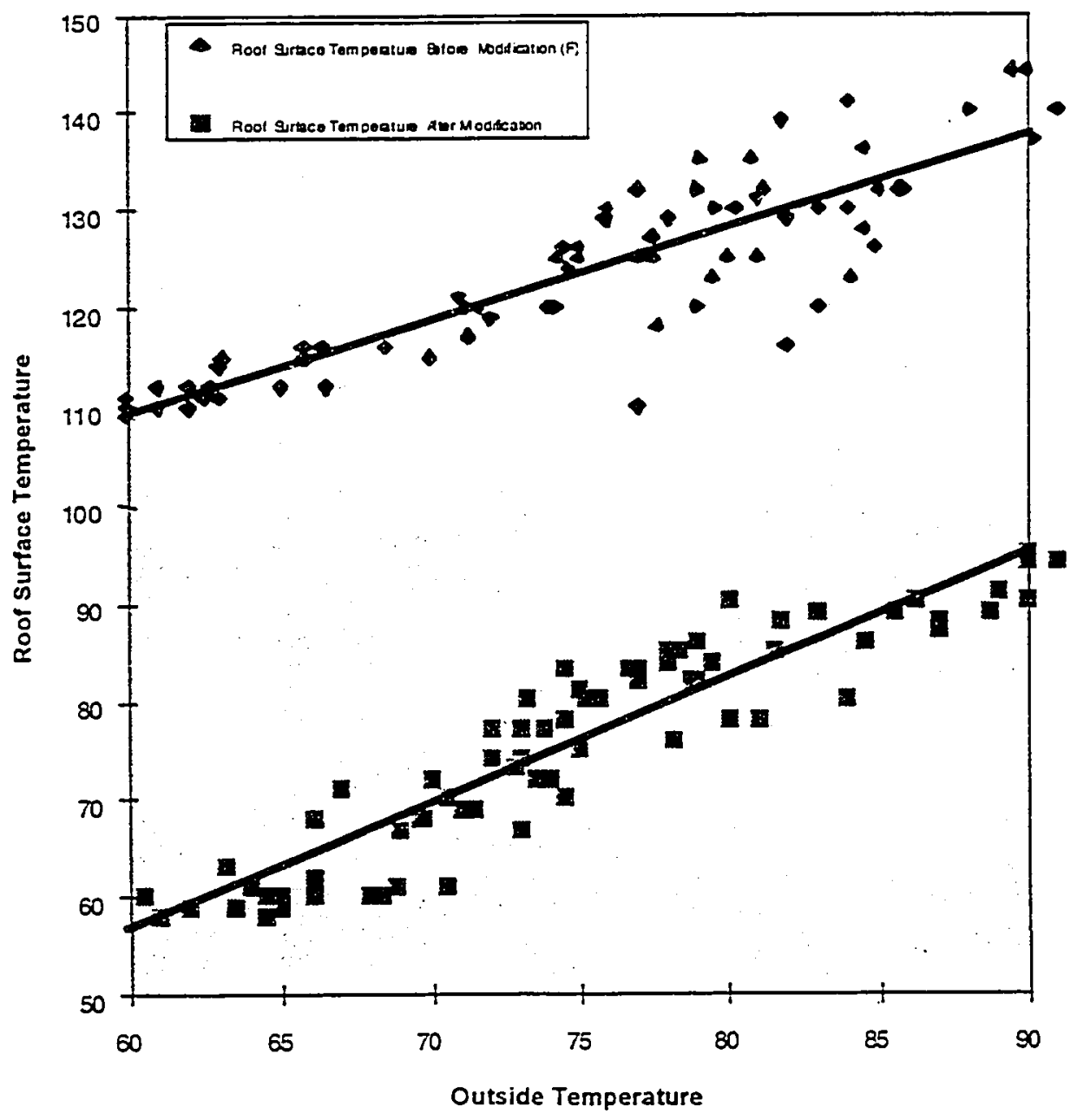

Figure 18. The Effect of Ambient Air Temperature on the Surface Temperature 


\section{LIST OF REFERENCES}

Aida, M. and K. Gotoh. 1982. Urban albedo as a function of the urban structure: A two dimensional numerical simulation. Boundary Layer Meteorology, 23, $415-424$.

Akbari, H., H. Taha, J. Huang, and A. Rosenfeld. 1986. Undoing uncomfortable summer heat islands can save gigawatts of peak power. Proceedings of the ACEEE Conference 2, 7-22, Santa Cruz, California.

Akbari, H., A. Rosenfeld, and H. Taha. 1989. Summer heat islands, urban trees, and white surfaces. Presented at the 4th AFA Urban Forestry Conference, St. Louis, Missouri, October, 16-18.

1989. Cooling urban heat islands. Proceedings of Fourth Urban Forestry Conference, St. Louis, Missouri, October, 15-19.

Arakawa, H. 1937. Increasing air temperature in large developing cities.. Geophysics 50, 3-6.

Atwater, M.A. 1971. The radiation budget for polluted layers of the urban environment. Journal of Applied Meteorology, 14, 205-214.

Backenstow, D.E. 1987. Comparison of white versus black surfaces for energy conservation. Proceedings of the 8th Conference on Roofing Technology, Applied Technology for Improving Roof Performance, April 16-17, Gaithersburg, Maryland, 27-31.

Barring L., J. O. Matisson, and S. Lindquist. 1985. Canyon geometry, street temperatures and urban heat island in Malmo, Sweden. Journal of Climotology, 5, 433-444.

Benson, C.S., and S.A. Bowling. 1975. The sub-arctic urban heat island as studied at Fairbanks, Alaska. In climate of the arctic (Weller, G., and C. S. Bowling, eds.), Geophysics Institute, University of Alaska, Fairbanks, Alaska, 309-311.

Berg, R, and W. Ouinn. 1978. Use of light-colored surface to reduce seasonal thaw penetration beneath embankments on permafrost. Proceedings of the Second International Symposium on Cold Regions Engineering, University of Alaska, 86-99.

Brown, D.E., and A.M. Winer. 1986. Estimating urban vegetation cover in Los Angeles. Photogrammetric Engineering and Remote Sensing, 52, 1, 177-123. 
Budyko, M.I. 1982. The Earth's Climate: Past and Future. Academic Press, New York.

California Energy Commission. 1989. California energy demand: 1989-2009, Vol. 1: Revised Electricity Demand Forecast, 300-89-019, Sacramento, CA.

Cayan, D. R., and A. V. Douglas. 1984. Urban influences on surface temperatures in the Southwestern United States during recent decades. Journal of Climate and Applied Meteorology 23, 1520-1530.

Chandler, T. J. 1965. The Climate of London. Hutchinson \& Co. Ltd, London.

Conner, C. 1985. The Effect of Exterior Surface Absorptivity and Emmisivity on Energy Use in Residential Buildings. Unpublished report, mentioned in Taha et al. (1988).

Dronia, H. 1967. Urban influences on worldwide temperature trends. Meteorology 74, 1-98.

Duckworth, F. S., and J. S. Sandberg. 1954. The effect of cities upon horizontal and vertical temperature gradients. Bulletin American Meteorological Society $35,5,198-207$.

Givoni, B. 1976. Man, Climate, and Architecture. Applied Science, London.

1989. Urban design in different climates. World Climate Program Applications. World Meteorological Organization, Vol., 346, Geneva.

Givoni, G., and M. Paciuk. 1972. Effect of High-rise Buildings on Air flow Around Them. Building Research Station Technion, Haifa, Israel.

Gregerson, J., B.L. Stickney, D. Houghton, J. Newcomb, K.L. George, M. Shepard, A. Wilson. 1993. Space Heating Technology Atlas. E Source, Inc., Boulder, CO.

Huang, J., H. Akbari, and H. Taha. 1990. The wind-shielding and shading effects of trees on residential heating and cooling requirements. Proceedings of American Society of Heating, Refrigeration, and Air-Conditioning Engineers, Atlanta, Georgia, February.

Jones, P. D, S. C. B. Raper, R.S. Bradley, H. F. Diaz, P. M. Kelly, and T. M. Wigley. 1986. Northern Hemisphere surface air temperature variations, 1851-1984. Journal of Climate and Applied Meteorology 25, 161-172.

Karl, T.R., H.F. Diaz, and G. Kukla. 1988. Urbanization: itsdetection and effects in the United States climate record. Journal of Climate 1, 1099-1123. 
Katayama, A. 1972. Simplified scheme for computing radiative transfer in the troposphere. UCLA, Technical Report No. 6, 77.

Kondratyev, K. Ya. 1969. Radiation in the Atmosphere. Academic Press, New York, p. 417.

Kopec, R.J. 1970. Further observations of the heat island in a small city. Bulletin of American Meteorological Society, 51, 602-606.

Kukla, G., and H. J. Kukla. 1974. Increased Surface Albedo in the Northern Hemisphere. Science 183, 709-714.

Kukla, G., J. Gavin, and T.R. Karl. 1986. Urban warming. Journal of Climate and Applied Meteorology 25, 1265-1270.

Kratzer, P.A. 1956. Das Stadtklima. Vieweg und Sohn, Braunschweig. Research translation by U.S. Air Force Cambridge Research Laboratories. Available through Federal Clearinghouse for Scientific and Technical Information, $\mathrm{AD} 248776$.

Landsberg, H. E. 1956. The climate of towns. In: Man's Role in Changing the Face of the Earth. (W. L. Thomas. Jr., editor), University of Chicago Press, 584-606.

1970. Man-made climatic changes. Science, 170, 1266-1274.

1970. Micrometeorological temperature differentiation through urbanization. In: Urban Climates. World Meteorological Organization, Technical Notes, 108, 129-136. 4, 53-82.

1979. Atmospheric changes in a growing community. Urban Ecology

1981. The Urban Climate. Academic Press, New York.

Lee, D. O. 1975. Rural atmospheric stability and the intensity of London's heat island. Weather 30, 102-109.

Lorenz, D. 1966. The effect of long-wave reflectivity of natural surfaces on surface temperature measurements using radiometers. Joumal Applied Meteorology 5, 421-430.

Martien, P., H. Akbari, and A. Rosenfeld. 1989. Light-colored surfaces to reduce summertime urban temperatures: benefits, costs, and implementation issues. Presented at the 9th Miami International Congress on Energy and Environment, 11-13, December, Miami Beach, Florida. 
Maxwell, G. B., and T. R. Oke. 1975. Urban heat island dynamics in Montreal and . Atmospheric Environment 9, 191-200.

Mitchell, J. M., Jr. 1953. On the causes of instrumentally observation of secular temperature trends. Journal of Meteorology 10, 244-261.

1961. The temperature of cities. Weatherwise 14, 224-258.

Moffitt, B. J. 1972. The effects of urbanization on mean temperatures at Kew Observatory. Weather 27, 121-129.

Myrup, L.O., and D.L. Morgan. 1972. Numerical model of the urban atmosphere. Department of Agricultural Engineering and Department of Water Science and Engineering, Contributions in Atmospheric Science No. 4, UC Davis, California.

Oke, T.R. 1978. Boundary Layer Climates. London and New York: Methuen. 1981. Canyon geometry and the nocturnal urban heat island: Comparison of scale model and field observation. Journal of Climatology 1 , 237-253.

Parker, D., and S. Barkaszi. 1994. Saving energy with reflective roof coatings. Home Energy, 11, 3, 15-20.

Prohaska, F. 1954. Bemerkungen zum saekularen gang der temperatur im sudpolargebiet. Arch. Meteor. Geophysics Bioclim. B5, 327-330.

Reagan, J.A., and D.M. Acklam. 1979. Solar reflectivity of common building materials and its influence on the roof heat gain of typical southwestern U.S.A. residences. Energy and Building 2, 237-248.

Roden, G. I. 1966. A modern statistical analysis and documentation of historical temperature records in California, Oregon and Washington, 1821-1964. Journal of Applied Meteorology 5, 3-24.

Schneider, .S. H., and R. Londer. 1984. The Coevolution of Climate and Life. San Francisco: Sierra Club Books.

Stanford University Aerosol Laboratory and the Ralph M. Parsons Co. 1953a. Behavior of aerosol clouds within cities. Joint Quarterly Report, No. 3, January-March 1952, Contracts DA-18-064-CML-2282, DDC No. AD31711. AD31508. 
.1953c. ibid., Joint Quarterly Report, No. 6, October-December 1953, DDC No. AD31711.

Steinhart, C.E., and J.S. Steinhart. 1974. Energy: Sources, Use, and Role in Human Affairs. Duxbury, Belmont, California, P. 362.

Steinhauser, F., O. Eckel, and F. Sauberer. 1957. The climate of bioclimate Vienna (Part 2). Osterreich Gesellschaft Fur Meteorologie, Vienna.

Sundborg, A. 1951. Climatological studies in Uppsala, with special regard to the temperature conditions in the urban area. Geographic, No. 22. Universitet Geografiska Institutionen, Uppsala, Sweden.

Taha, H., H. Akbari, A. Rosenfeld, and J. Huang. 1988. Residential cooling loads and the urban heat islands: the effects of albedo. Energy and Environment $23,4,271-283$.

Taha, H., David Sailor, and Hashem Akbari. 1991. High-albedo materials for building cooling energy use. Energy and Environment Division, Lawrence Berkeley Laboratory, September.

Thornthwaite, C. W. 1956. Modification of rural microclimates. Man's Role in Changing the Face of Earth. University of Chicago Press.

Thurow, C. 1983. Improving street climate through urban design. American Planning Associates. Chicago.

Tyson, P.D., W.J.F. du Toit, and R.F. Fuggle. 1972. Temperature structure above cities: review and preliminary findings from the Johannesburg urban heat island project. Atmospheric Environment, 6, 533-542.

U.S. Committee for the GARP. 1975. Understanding Climatic Change. National Academy of Science, Washington, D.C.

Van Loon, H., and J. Williams. 1977. The connection between trends of mean temperature and circulation at the surface. Part 4: Comparison of surface changes in the Northern Hemisphere with the upper air and the Antarctic in winter. Monthly Weather Revision 105, 636-647.

Yap, D., and T.R. Oke. 1974. Sensible heat fluxes over an urban area-Vancouver, B.C. Journal of Applied Meteorology, 13, 880-890. 
APPENDDX 


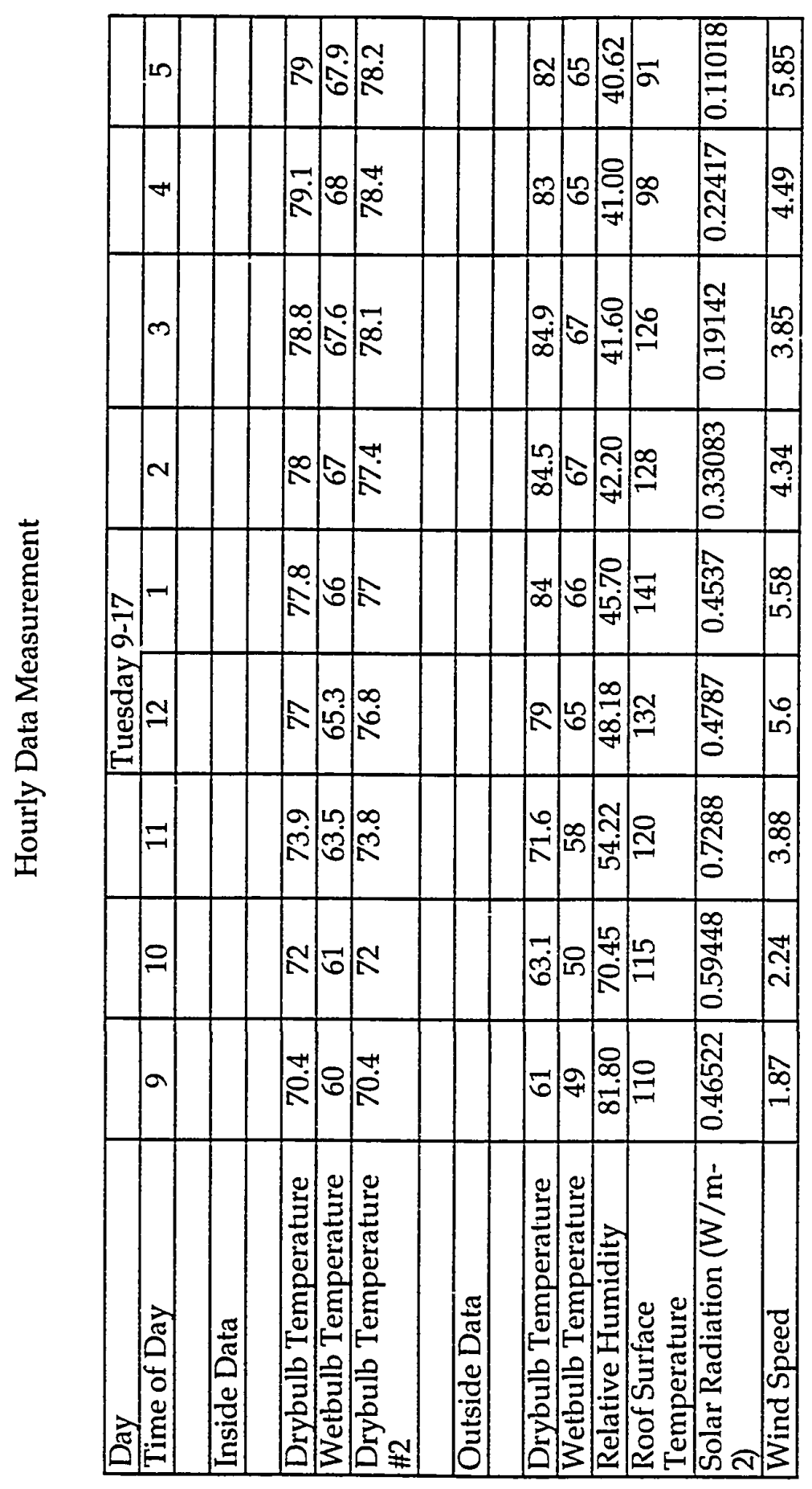




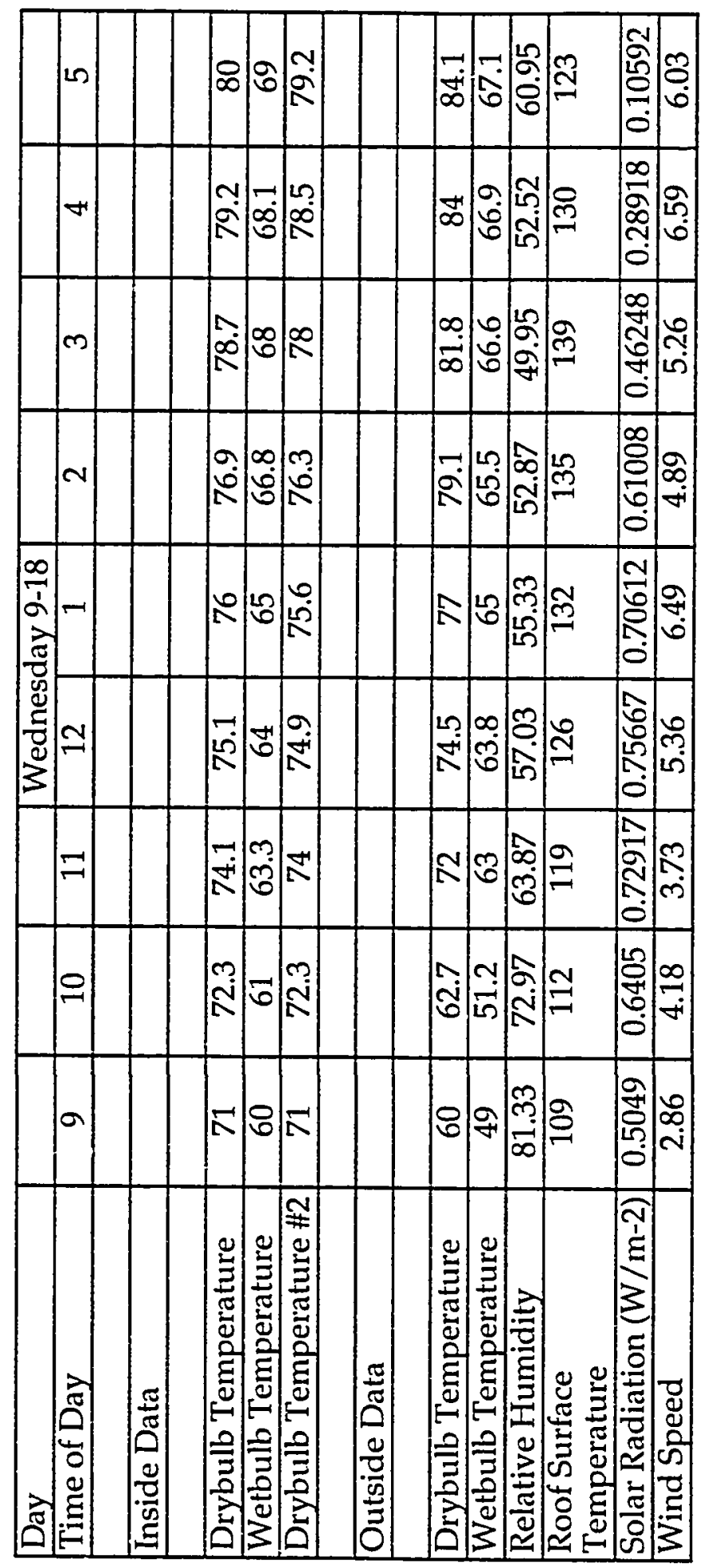




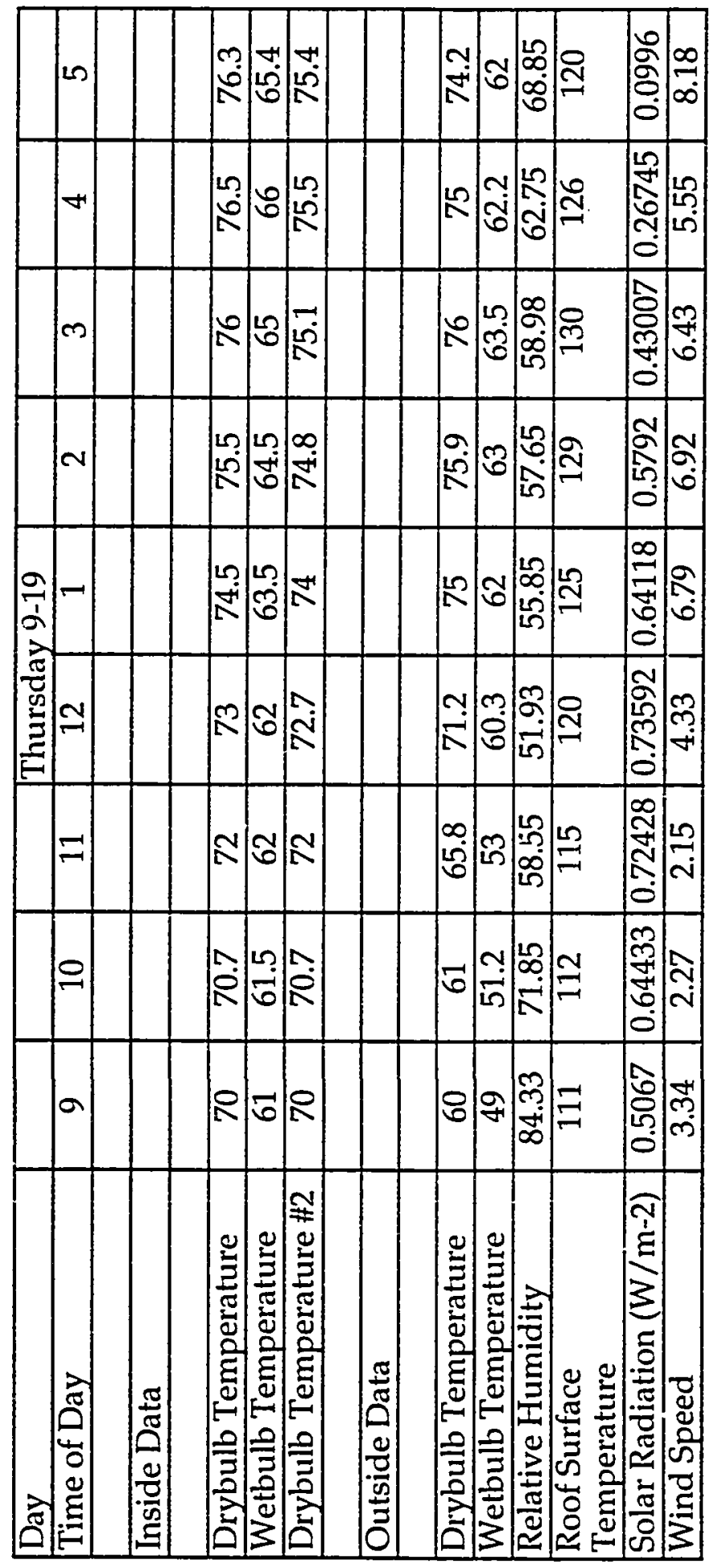




\begin{tabular}{|c|c|c|c|c|c|c|c|c|c|c|c|c|}
\hline & (1) & & $\stackrel{\infty}{\stackrel{\infty}{\aleph}}$ & $\mid$ & $\begin{array}{l}\infty \\
0 \\
0 \\
0\end{array}$ & & $\approx$ & ع & - & 8 & 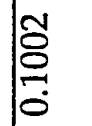 & ס̊ \\
\hline & + & & $\mathbb{\Sigma}$ & $\widehat{0}$ & $\mid \begin{array}{l}2 \\
0 \\
0\end{array}$ & & 2 & a & $\begin{array}{l}\mathbb{2} \\
8 \\
0\end{array}$ & 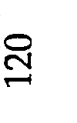 & 跑 & an \\
\hline & $m$ & & 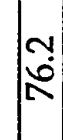 & $\left|\begin{array}{c}9 \\
10\end{array}\right|$ & $\sqrt{10}$ & & 2 & $\widehat{\delta}$ & 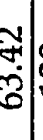 & 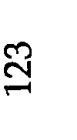 & 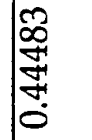 & S \\
\hline & $N$ & & $\mid \begin{array}{l}10 \\
10 \\
\mathbb{2}\end{array}$ & $\left|\begin{array}{c}n \\
18 \\
100\end{array}\right|$ & $\mid \infty$ & & $\mid$ & 6 & 今े & חֶ & 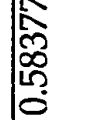 & $\left|\begin{array}{l}\infty \\
0 \\
\infty\end{array}\right|$ \\
\hline I & - & & $\vec{I}$ & (ت) & $\stackrel{N}{N}$ & & 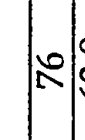 & 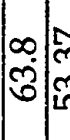 & कि & సે & 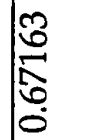 & 它 \\
\hline 일 & 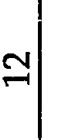 & & $\begin{array}{l}\infty \\
\infty \\
\Omega^{2}\end{array}$ & $\left|\begin{array}{c}0 \\
0 \\
0\end{array}\right|$ & $\stackrel{n}{n}$ & & ma & 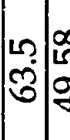 & & $\stackrel{\text { }}{\underline{N}}$ & 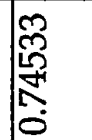 & $\mid \begin{array}{l}\infty \\
\infty \\
\sim\end{array}$ \\
\hline & 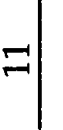 & & $\mid \begin{array}{l}n \\
\mathbb{N}\end{array}$ & $\left|\begin{array}{c}2 \\
3 \\
0\end{array}\right|$ & đa & & $\left|\begin{array}{l}\infty \\
10 \\
10\end{array}\right|$ & 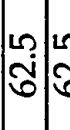 & حై & $\stackrel{0}{=}$ & 令 & $\mid \begin{array}{c}N \\
m\end{array}$ \\
\hline & $\stackrel{ }{-}$ & & 玣 & 6 & $\mid \underset{\Sigma}{\widetilde{\Sigma}}$ & & & - $6 \mid$ & 永 & $\stackrel{\overbrace{}}{\approx}$ & 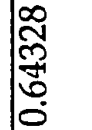 & $\left|\begin{array}{c}\infty \\
\infty \\
-1\end{array}\right|$ \\
\hline & $a$ & & $\mathbb{R}$ & 8 & $\mathbb{R}$ & & & is & & $\stackrel{\circ}{=}$ & 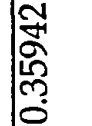 & 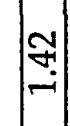 \\
\hline 帘: & 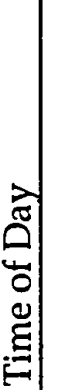 & 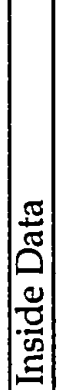 & 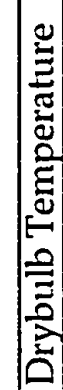 & 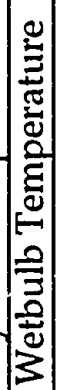 & 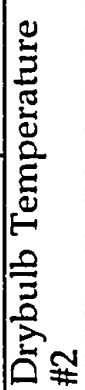 & 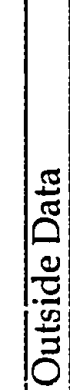 & 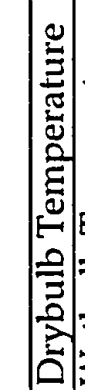 & 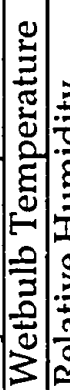 & & 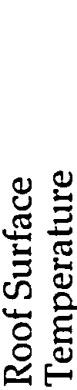 & 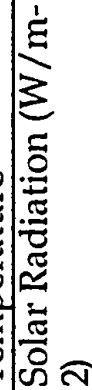 & 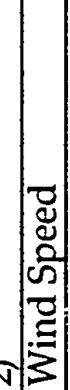 \\
\hline
\end{tabular}




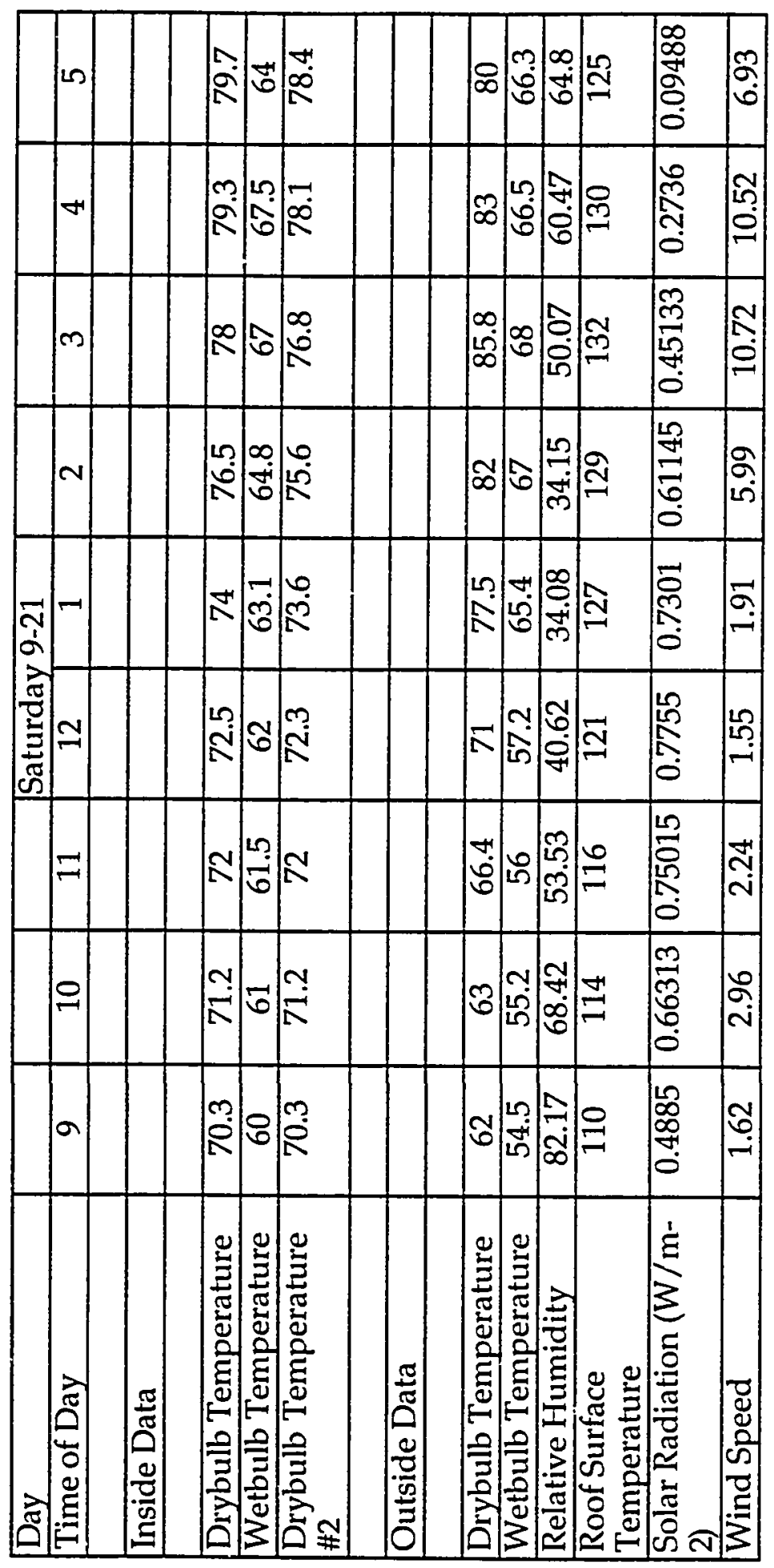




\begin{tabular}{|c|c|c|c|c|c|c|c|c|c|c|c|c|}
\hline & ת & & $\mid$ & 6 & $\mid \begin{array}{c}n \\
\end{array}$ & & $\approx$ & $=$ & 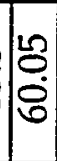 & & 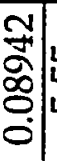 & $\begin{array}{l}\mathrm{L}^{2} \\
\mathrm{~L}\end{array}$ \\
\hline & +4 & & $\mathfrak{R}$ & $\left|\begin{array}{l}1 \\
0 \\
0 \\
0\end{array}\right|$ & 只 & & $\frac{\sim}{\infty}$ & 6 & $\begin{array}{l}10 \\
10 \\
10 \\
10\end{array}$ & 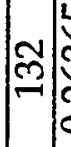 & 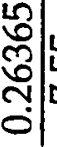 & مَّ \\
\hline & $m$ & & $\begin{array}{l}20 \\
\infty \\
0\end{array}$ & $\infty$ & مِ & & $\infty$ & 6 & $\begin{array}{l}3 \\
0 \\
\text { กิ }\end{array}$ & $\vec{m}$ & 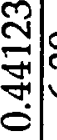 & ले \\
\hline & $v$ & & $\mathbb{\infty}$ & $\mid$ & $\stackrel{m}{N}$ & & $\infty$ & $\mid \begin{array}{l}m \\
0 \\
0\end{array}$ & 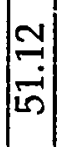 & : & 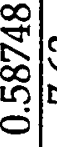 & 象 \\
\hline N & -1 & & 10 & $|\vec{b}|$ & $\left|\begin{array}{c}0 \\
10\end{array}\right|$ & & $\mathbb{R}$ & $\left|\begin{array}{c}n \\
c \\
0\end{array}\right|$ & à & & 命| & ஜூ \\
\hline 永 & & & $\mid \begin{array}{l}n \\
\tilde{n} \\
\tilde{n}\end{array}$ & 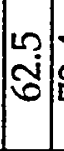 & त्: & • & 苗 & in & 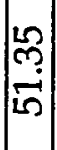 & స્| & $\frac{N}{\widetilde{N}}$ & $\mid \begin{array}{l}\infty \\
\stackrel{2}{1} \\
10\end{array}$ \\
\hline$F$ & & & $\overrightarrow{\boldsymbol{N}}$ & $\widehat{\sigma}$ & $\left|\begin{array}{l}0 \\
-1\end{array}\right|$ & & $尺$ & $\left|\begin{array}{c}\sim \\
\sim \\
\multirow{2}{*}{}\end{array}\right|$ & 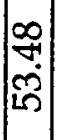 & ع & 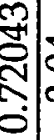 & $\begin{array}{l}\dot{0} \\
\dot{0}\end{array}$ \\
\hline 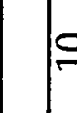 & & & 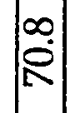 & 6 & $\mid$ & & $\mid$ & ก & $\begin{array}{c}\text { ㄱ. } \\
\text { तु } \\
\end{array}$ & 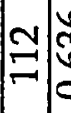 & 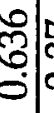 & ले \\
\hline$\sigma$ & & & $\left|\begin{array}{l}\infty \\
\hat{i}\end{array}\right|$ & 8 & $\left|\begin{array}{l}\infty \\
0 \\
0\end{array}\right|$ & & 3 & เి & $\left|\begin{array}{c}\infty \\
0 \\
0 \\
n\end{array}\right|$ & $=$ & 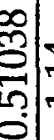 & $\underset{ت}{ت}$ \\
\hline อิ| & & 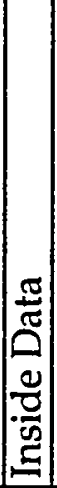 & 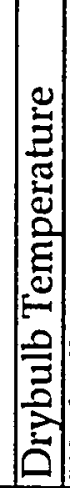 & 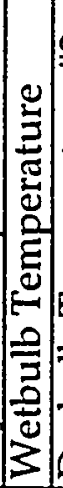 & 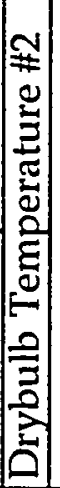 & 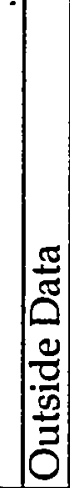 & 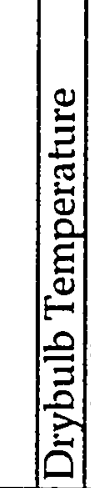 & 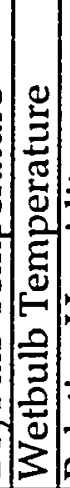 & 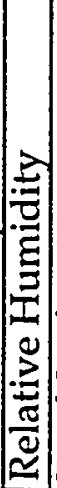 & 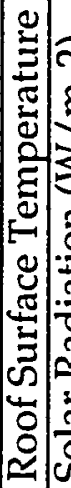 & 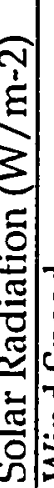 & 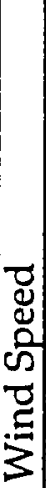 \\
\hline
\end{tabular}




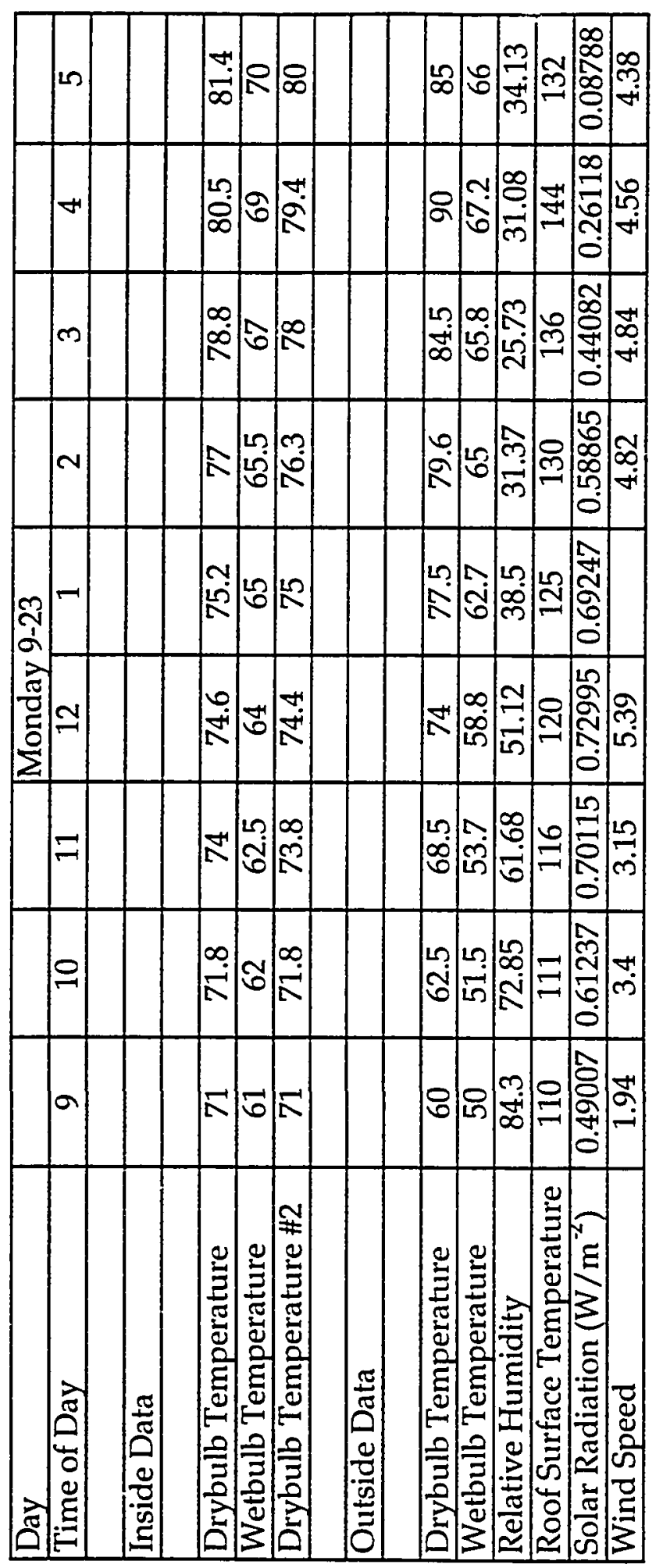




\begin{tabular}{|c|c|c|c|c|c|}
\hline 10 & & \begin{tabular}{|l|l|l|}
$\infty$ & $\infty$ & $\infty$ \\
0 & 0 & 0 \\
0
\end{tabular} & & 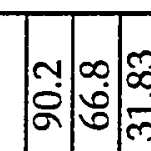 & 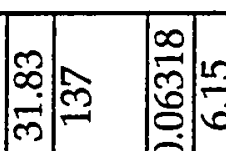 \\
\hline 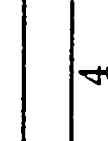 & & 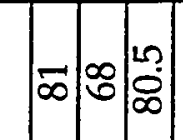 & & F & 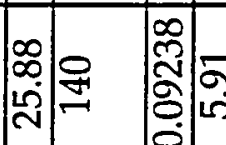 \\
\hline$m$ & & 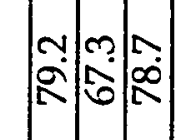 & & 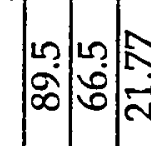 & 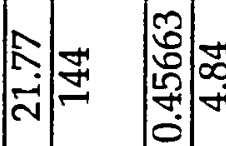 \\
\hline N & & 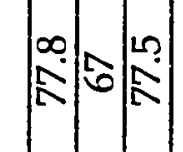 & & & 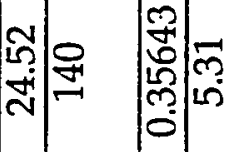 \\
\hline & & 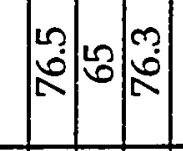 & & $\left|\begin{array}{l}1 \\
0 \\
\infty\end{array}\right|$ & נ: \\
\hline & & & & 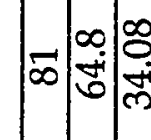 & 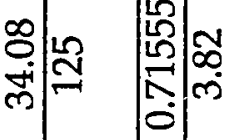 \\
\hline & & 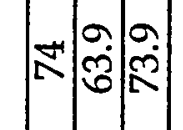 & & & 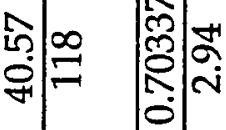 \\
\hline 우 & & 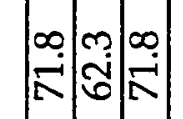 & & 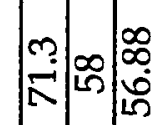 & 品 \\
\hline & & $R|E| R \mid$ & & 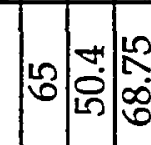 & 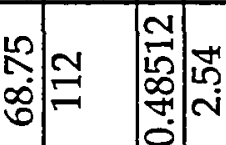 \\
\hline $\mid$ & 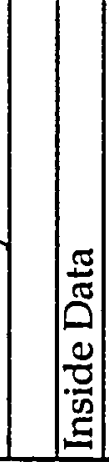 & 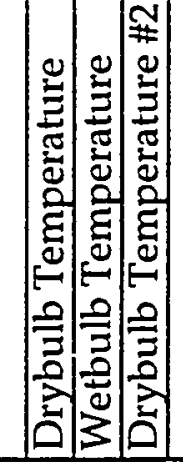 & 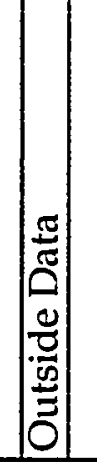 & 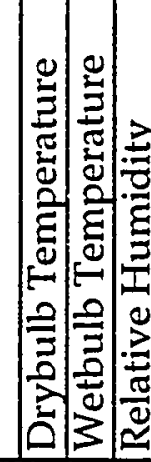 & 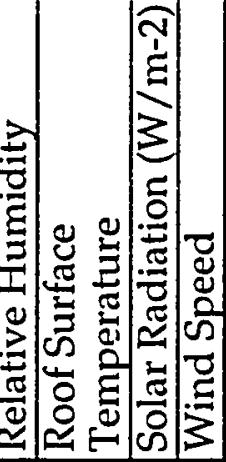 \\
\hline
\end{tabular}




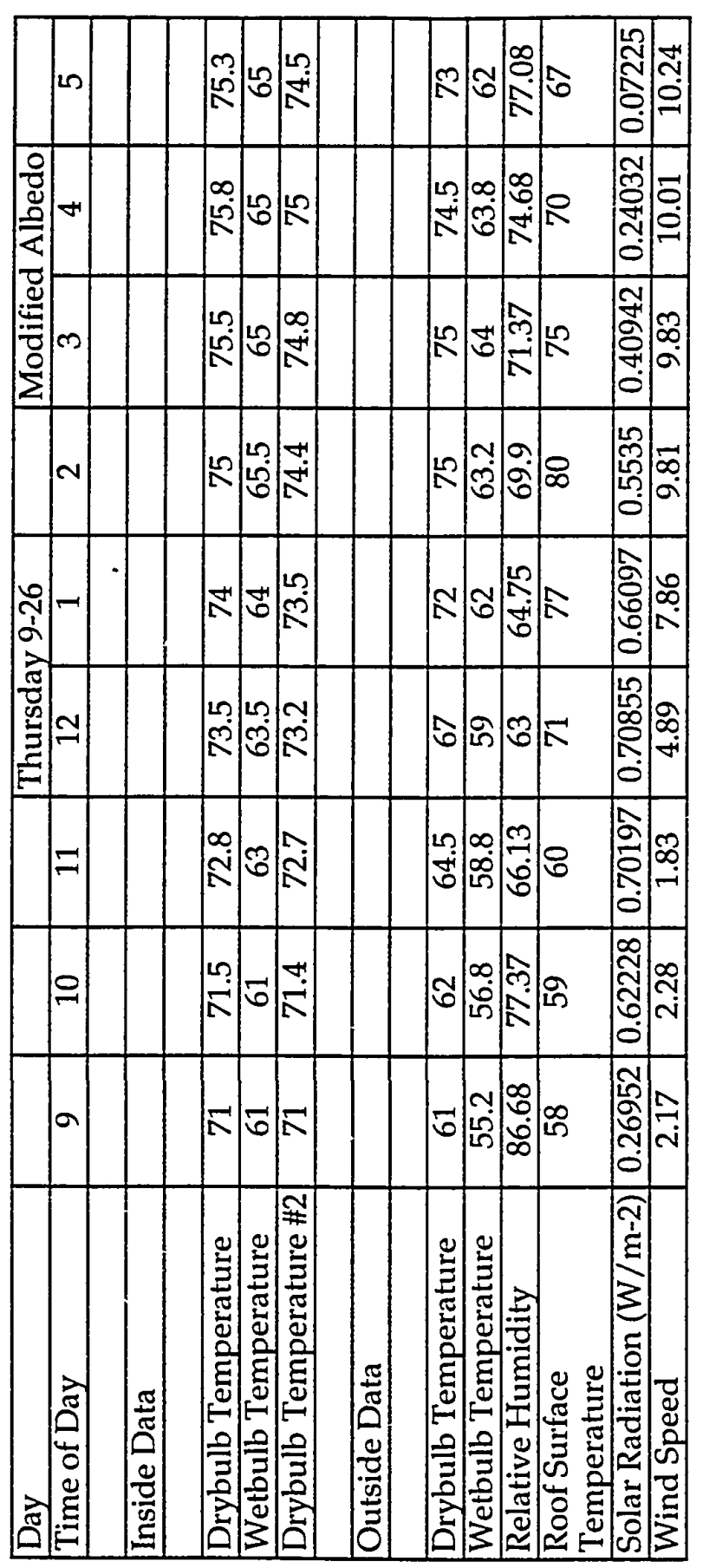




\begin{tabular}{|c|c|c|c|c|c|c|c|c|c|c|c|c|}
\hline & $|00|$ & & $\stackrel{1}{2}$ & 8 & $\mid ⿱ R ⿻) 丨$ & & $\overline{\boldsymbol{N}}$ & 祭 & $\begin{array}{l}\Omega \\
\mathbf{N}\end{array}$ & 18 & $\mid \begin{array}{l}\infty \\
\text { مू } \\
\stackrel{8}{0} \\
0 \\
0\end{array}$ & $\begin{array}{l}\infty \\
\mathbb{N} \\
\Omega\end{array}$ \\
\hline \multirow{3}{*}{ 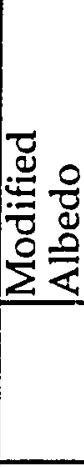 } & +4 & & $\mid \begin{array}{l}1 \\
0 \\
0 \\
1\end{array}$ & 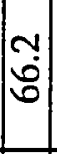 & $\mid$ & & $N$ & 18 & $\mid$ & $\mathbb{N}$ & 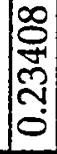 & $\underset{7}{Z}$ \\
\hline & $|\pi|$ & & 10 & 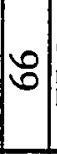 & 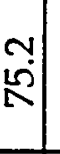 & & 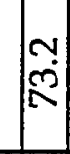 & 8 & $\left|\begin{array}{c}1 \\
2 \\
\infty \\
0\end{array}\right|$ & $\infty$ & 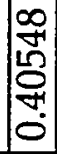 & 고 \\
\hline & $|N|$ & & $\begin{array}{l}m \\
2 \\
\end{array}$ & $\begin{array}{l}m \\
10 \\
0\end{array} \mid$ & $\begin{array}{l}\infty \\
\mathbb{R}\end{array}$ & & $\mid \begin{array}{l}0 \\
\mathbb{N}\end{array}$ & $\mid \begin{array}{l}0 \\
0 \\
0\end{array}$ & g) & $\infty$ & 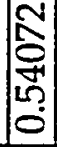 & $\stackrel{8}{0}$ \\
\hline \multirow{5}{*}{ 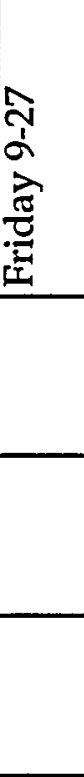 } & $-1 \mid$ & & 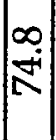 & 10 & $\begin{array}{l}N \\
\mathbb{N} \\
\mathbb{N}\end{array}$ & & $\mathbb{N}$ & $\left(\begin{array}{c}5 \\
\overline{6}\end{array}\right.$ & $\begin{array}{l}m \\
0 \\
0 \\
0\end{array}$ & $\hat{N}$ & 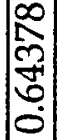 & $\begin{array}{c}\sim \\
N \\
\infty\end{array}$ \\
\hline & $\stackrel{\sim}{二}$ & & 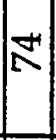 & : & \begin{tabular}{|c|}
0 \\
\end{tabular} \mid & & 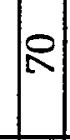 & 6 & {$\left[\begin{array}{c}N \\
\delta \\
\delta\end{array}\right.$} & $\mathbb{N}$ & $\mid \begin{array}{l}\infty \\
2 \\
2 \\
0 \\
0 \\
0\end{array}$ & $\overrightarrow{0}$ \\
\hline & $\exists$ & & 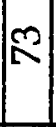 & $\mid$ & $\begin{array}{l}\infty \\
\mathbb{N}\end{array} \mid$ & & 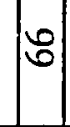 & $\mid$ & $\left|\begin{array}{l}\infty \\
0 \\
n \\
0 \\
0\end{array}\right|$ & 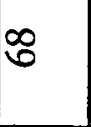 & $\begin{array}{l}\hat{1} \\
\hat{n} \\
0 \\
0 \\
0\end{array}$ & $\begin{array}{c}\infty \\
0 \\
\text { m. }\end{array}$ \\
\hline & 으 & & $\mathbb{N} \mid$ & & $\mathbb{N}$ & & $\left|\begin{array}{c}n \\
\tilde{0}\end{array}\right|$ & $\infty$ & $\mid$ & 8 & $\mid \begin{array}{c}n \\
m \\
\vdots \\
0 \\
0\end{array}$ & $\underset{ت}{\sharp}$ \\
\hline & $a \mid$ & & $\left|\begin{array}{c}2 \\
8 \\
\delta\end{array}\right|$ & 8 & תִ. & & $\mid \begin{array}{l}10 \\
0 \\
0\end{array}$ & 洪 & $\mid$ & 8 & 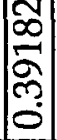 & 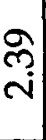 \\
\hline$\stackrel{\tilde{\sigma}}{\Theta}$ & 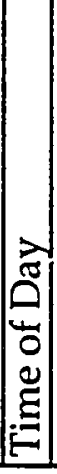 & 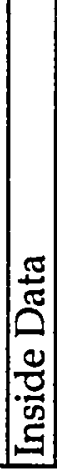 & 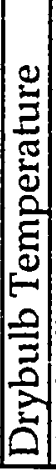 & 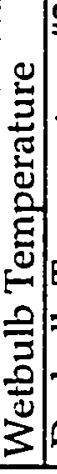 & 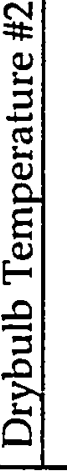 & 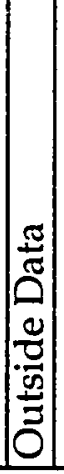 & 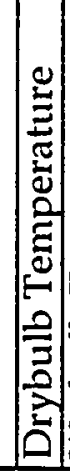 & 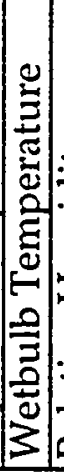 & 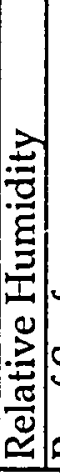 & 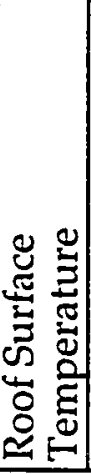 & 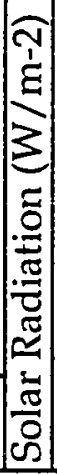 & 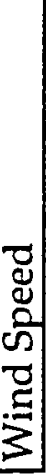 \\
\hline
\end{tabular}




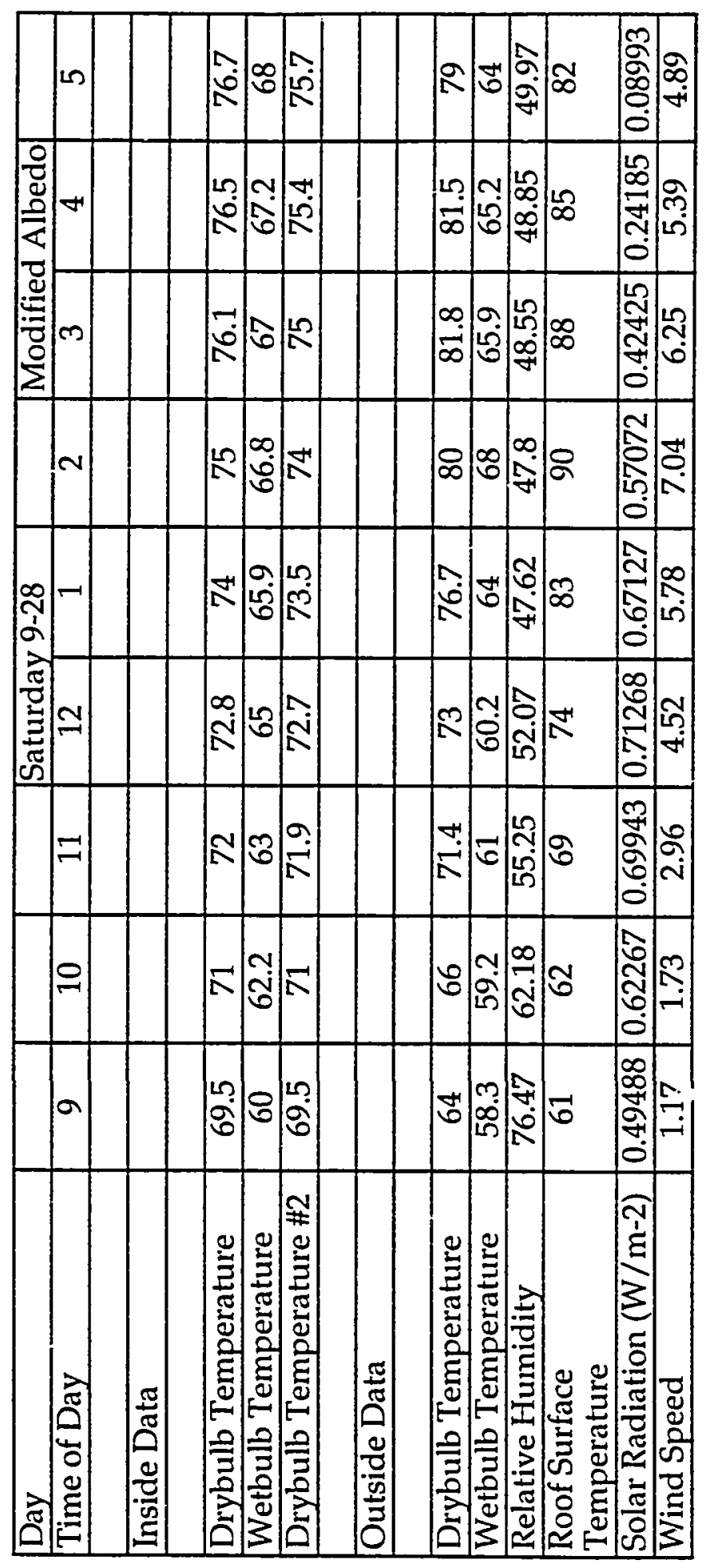




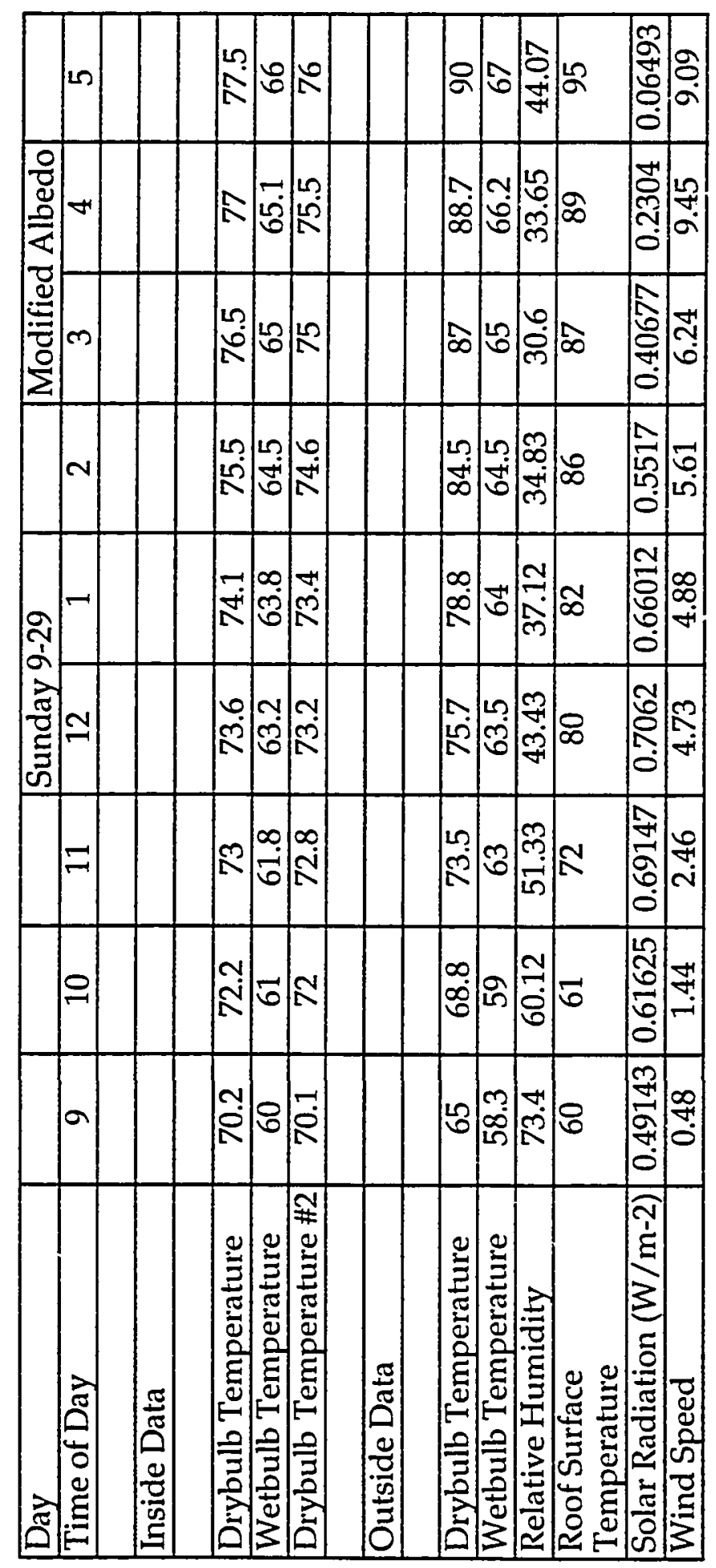




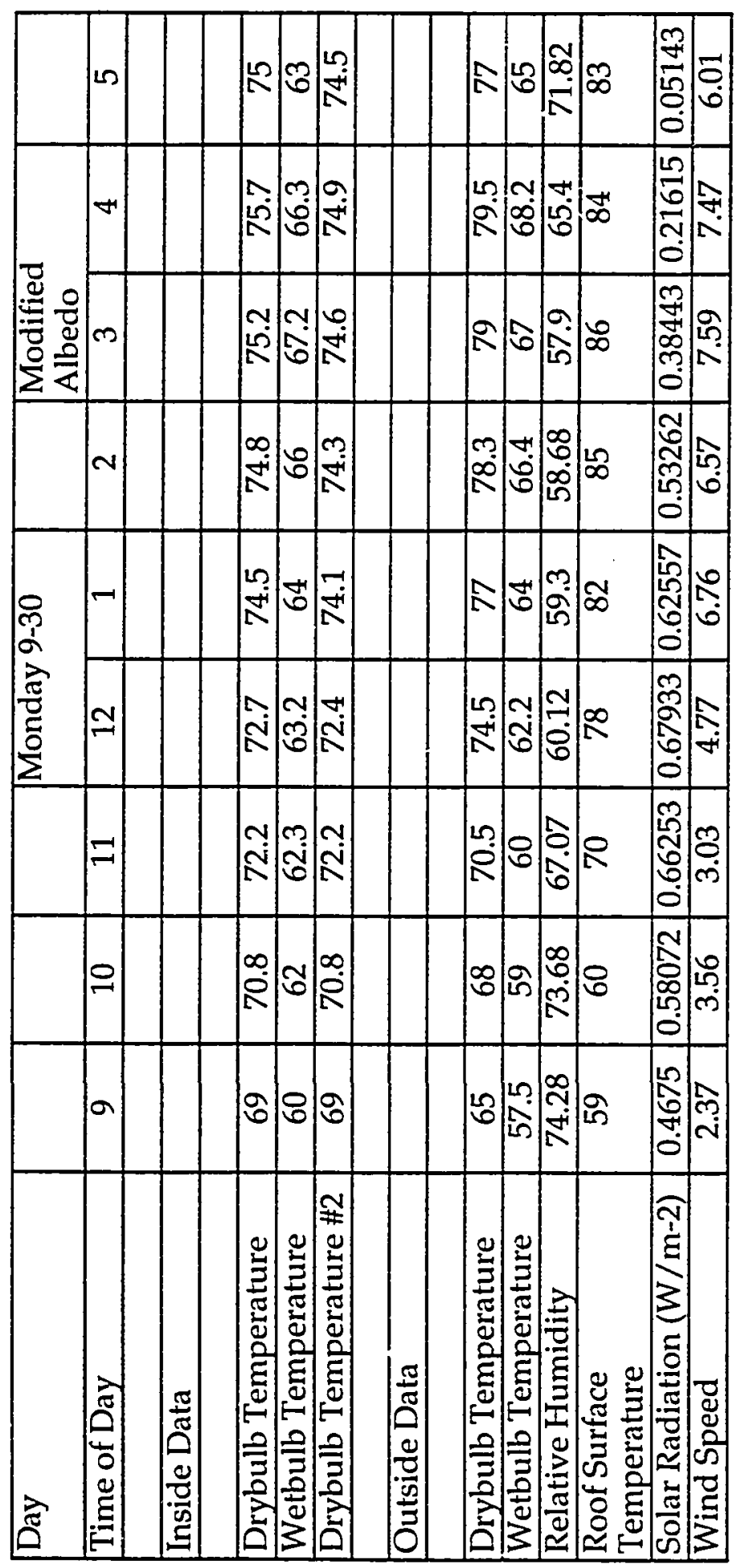




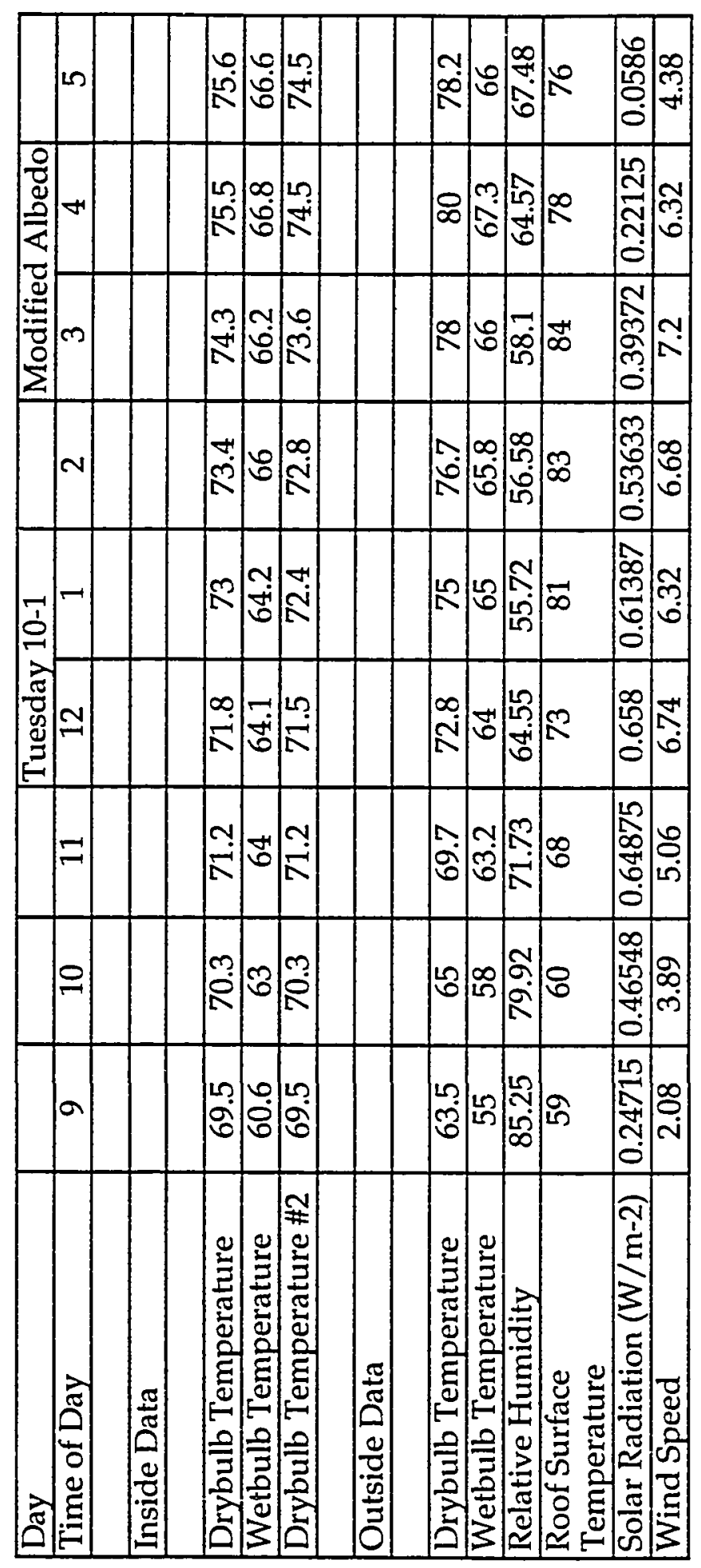




\begin{tabular}{|c|c|c|c|c|c|c|c|c|c|c|c|c|}
\hline & | 10 & & $\approx$ & 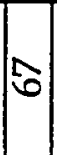 & $\mid \begin{array}{l}5 \\
100\end{array}$ & & $\not{\infty}$ & 18 & 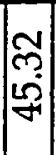 & $\infty$ & 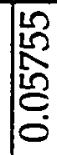 & 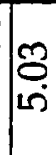 \\
\hline \multirow{3}{*}{ 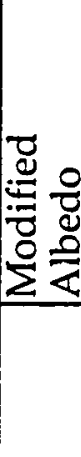 } & 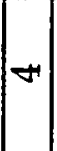 & & 10 & $\widehat{0}$ & $|\mathbb{R}|$ & & $\infty$ & 6 & $\left|\begin{array}{c}20 \\
\stackrel{2}{*} \\
f\end{array}\right|$ & $\infty$ & 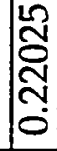 & $\infty$ \\
\hline & $m$ & & $\mid \begin{array}{l}+ \\
\mathbb{N}\end{array}$ & 18 & $\left|\begin{array}{l}N \\
\mathbb{N}\end{array}\right|$ & & $\begin{array}{l}n \\
\infty \\
\infty\end{array}$ & {$\left[\begin{array}{l}n \\
\infty \\
0\end{array}\right.$} & $\left|\begin{array}{l}2 \\
2 \\
2\end{array}\right|$ & ঞ̊ & 岕 & ชิ \\
\hline & $i v j$ & & $\underset{\mathbb{R}}{0}$ & (ே) & $\left|\begin{array}{l}L_{0} \\
\end{array}\right|$ & & $\infty$ & 0 & $\begin{array}{l}0 \\
F\end{array}$ & ळ & $\begin{array}{l}20 \\
2 \\
2 \\
10 \\
0\end{array}$ & 0 \\
\hline \multirow{5}{*}{ 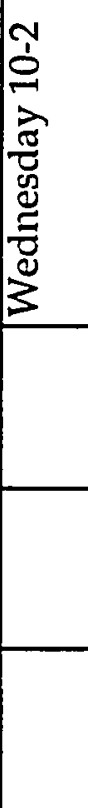 } & $|-|$ & & مُ & ( & $\left|\begin{array}{c}\infty \\
\mathbf{N} \\
\mathbf{N}\end{array}\right|$ & & 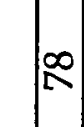 & $\left|\begin{array}{l}1 \\
10\end{array}\right|$ & $\left|\begin{array}{c}0 \\
0 \\
0\end{array}\right|$ & $\infty$ & $\begin{array}{l}\infty \\
0 \\
\text { లై } \\
0 \\
0\end{array}$ & 9 \\
\hline & $\cong$ & & $\begin{array}{l}\infty \\
\mathbb{N}\end{array}$ & $\mid$ & $\begin{array}{l}12 \\
\mathbb{N}\end{array}$ & & $\begin{array}{l}\infty \\
\infty \\
\infty\end{array}$ & $\mathbb{0}$ & {$\left[\begin{array}{c}N \\
\text { Nin } \\
1\end{array}\right.$} & $\hat{\Sigma}$ & $\mid$ & $\begin{array}{l}\infty \\
\infty \\
\infty\end{array}$ \\
\hline & $\exists$ & & $\boldsymbol{N}$ & $|\widetilde{\sigma}|$ & $\boldsymbol{\Sigma}$ & & 8 & $\begin{array}{l}\mathcal{N} \\
\mathcal{N}\end{array}$ & $\left|\begin{array}{c}N \\
\bar{\sigma} \\
\bar{\sigma}\end{array}\right|$ & 6 & 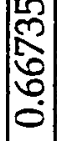 & م̂ \\
\hline & 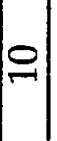 & & R & $\overline{0}$ & $\mathbb{R}$ & & 8 & 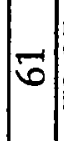 & $\begin{array}{l}2 \\
2 \\
m\end{array}$ & 8 & 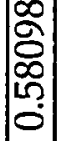 & $\begin{array}{l}g \\
\text { i } \\
\end{array}$ \\
\hline & $a$ & & $\begin{array}{l}1 \\
\infty \\
\infty\end{array}$ & & $\mid$ & & نُ & 令 & $\left|\begin{array}{c}\infty \\
0 \\
\infty \\
\infty\end{array}\right|$ & $\infty$ & 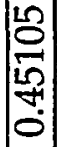 & 근 \\
\hline $\overrightarrow{\widetilde{\Omega}}$ & 表 & 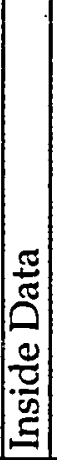 & 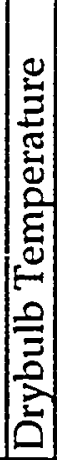 & 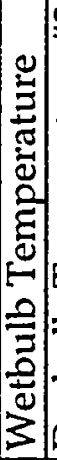 & 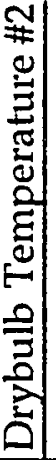 & 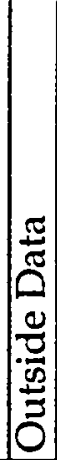 & 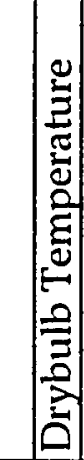 & 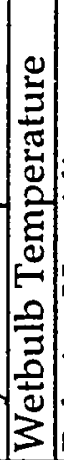 & 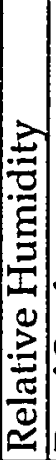 & 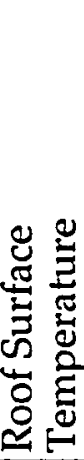 & 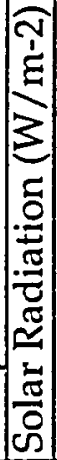 & 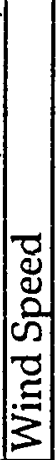 \\
\hline
\end{tabular}




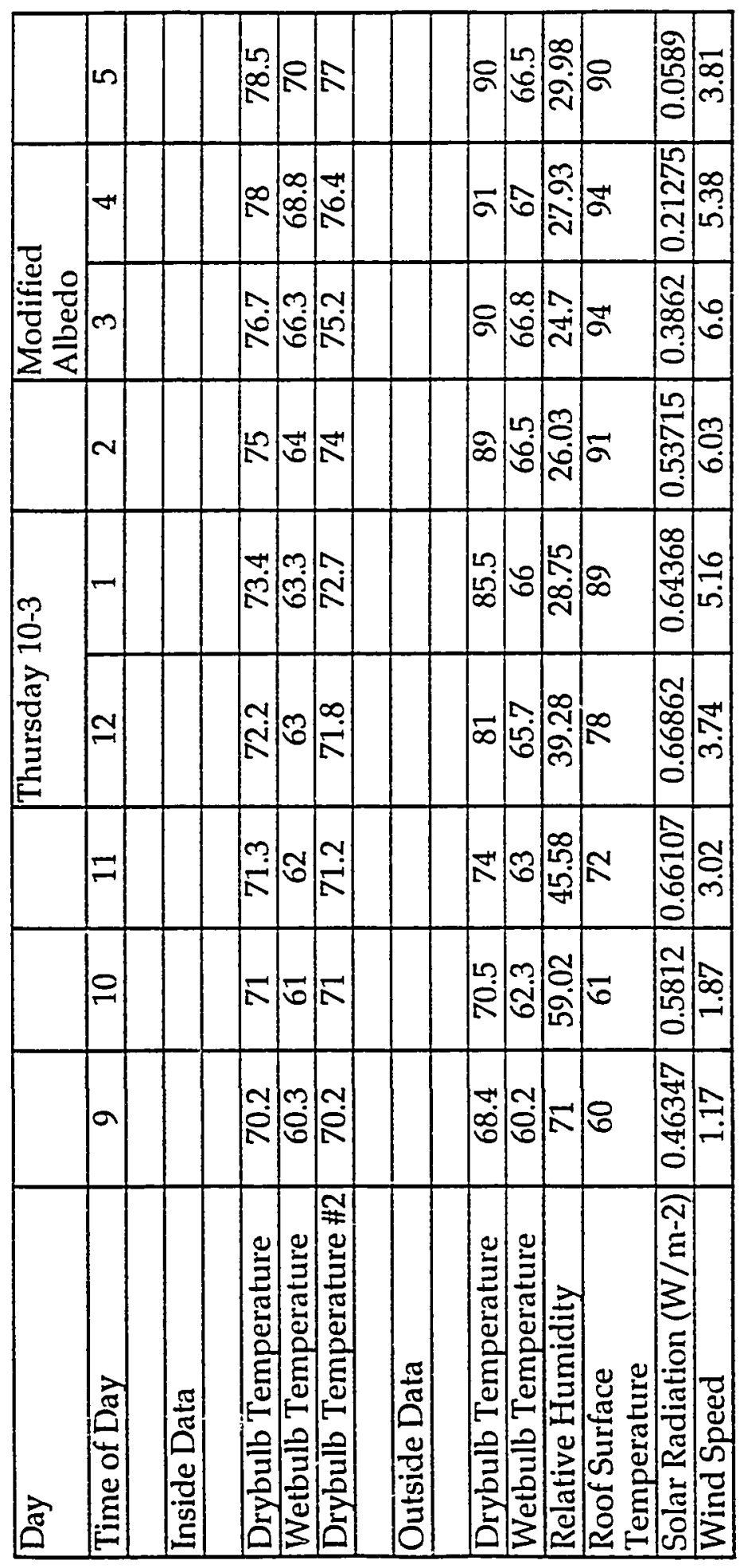

